"Posibles riesgos y consecuencias de la agricultura familiar al salir de la informalidad productiva para desarrollarse en el territorio."

Med. Vet. Lisandro E. Butler

Trabajo de Tesis para ser presentado como

Requisito parcial para optar al Título de

MAGISTER SCIENTIAE EN PROCESOS LOCALES DE INNOVACION Y DESARROLLO RURAL (PLIDER)

UNIVERSIDAD NACIONAL DE LA PLATA

FACULTAD DE CIENCIAS AGRARIAS Y FORESTALES

DEPARTAMENTO DE DESARROLLO RURAL

CARRERA DE MAESTRIA

La Plata, Argentina

Abril 2020 
Magister Scientiae en Procesos Locales de Innovación y Desarrollo Rura

\title{
"Posibles riesgos y consecuencias de la agricultura familiar al salir de la informalidad productiva para desarrollarse en el territorio."
}

\author{
Ing. Agr. Guillermo Hang \\ Director de tesis \\ Mg. Sc. Ing. Agr. Gustavo Fabián Larrañaga \\ Co-director de tesis
}

Med.Vet. Sergio Dumrauf

Tutor 
"Posibles riesgos y consecuencias de la agricultura familiar al salir de la informalidad productiva para desarrollarse en el territorio."

Lisandro Eduardo Butler

Evaluada por:

Ing. Agr. Dr. Pedro Carricart

Evaluador

Lic. Dra. María Amalia Lorda

Evaluadora

Lic. Msc. Guillermo Neiman

Evaluador 


\section{Dedicatoria}

A mi compañera de vida y a mis hijos, que supieron acompañar y contener el proceso de esta tesis con gran esfuerzo, comprendiendo y brindando su continuo apoyo y acompañamiento.

También quiero dedicar esta tesis a las trabajadoras y los trabajadores, a las productoras y los

productores, así como a todas y todos los que día a día se levantan con el compromiso de hacer una Argentina más justa. 


\section{Agradecimientos}

A mi director Guillermo Hang, a mi codirector Gustavo Larrañaga y a mi tutor Sergio Dumrauf por su dedicación, acompañamiento y los innumerables aportes.

A mis compañeros "pliderianos" que acompañaron la ardua tarea de dar forma y estructura a las ideas y pensamientos con jugosos debates e intercambios, así como supimos compartir hermosos momentos de distención y alegría.

Al INTA por darme la posibilidad de crecer y formarme a través de su sistema de becas.

A los productores tamberos-maseros por darme la posibilidad de conocerlos, relacionarnos, trabajar y construir juntos un camino lleno de desafíos.

A los docentes y no docentes de PLIDER, por su dedicación y predisposición.

A mis compañeros de trabajo por acompañar y apoyarme continuamente.

A Calvet por incentivarme para hacer la maestría, estar siempre, aportando ideas, prestando oídos y apoyándome incondicionalmente.

A Danton por incentivarme y orientarme en los primeros pasos como Maestrando.

A Mariucha por el aliento, los aprendizajes y el camino recorrido.

A mi familia, quienes han padecido las largas horas de lectura, cursada y emociones.

A los que desinteresadamente me brindaron su tiempo para realizar las entrevistas. 


\section{Contenido}

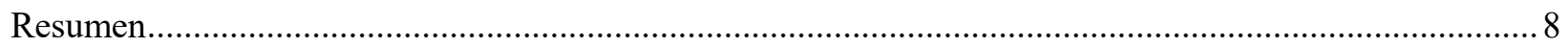

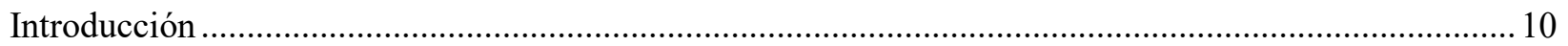

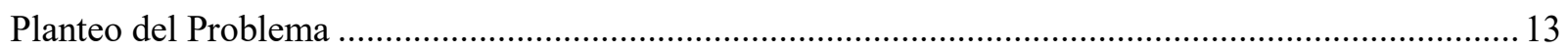

Antecedentes generales sobre el complejo lácteo nacional y su reflejo provincial............................ 13

La actividad láctea en argentina y su representación en la Provincia de Buenos Aires durante los últimos 30 años: décadas del 1980, 1990, 2000 y 2010.............................................................. 14

La emergencia de un nuevo eslabón en la producción láctea, el tambo-fabrica.................................. 19

Producción láctea - masera en la Cuenca de Abasto Sur ...........................................................................2 21

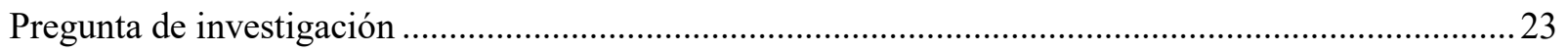

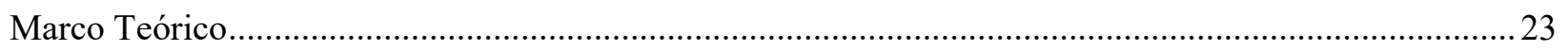

Desarrollo, desarrollo territorial local y la importancia de la producción familiar en la configuración

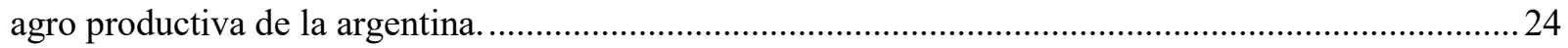

Desarrollo en las primeras décadas de la Argentina democrática .........................................................28

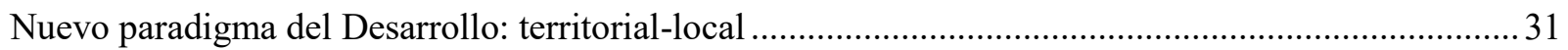

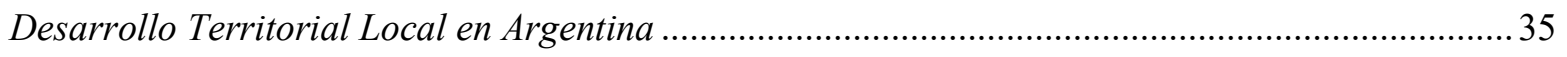

Agricultura familiar y la informalidad como contexto en la producción primaria. ...............................46

Políticas públicas expresadas en marcos normativos - legislativos.................................................53

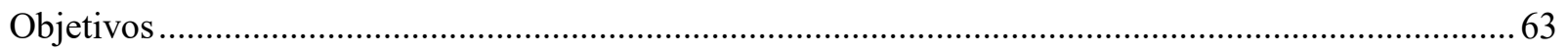

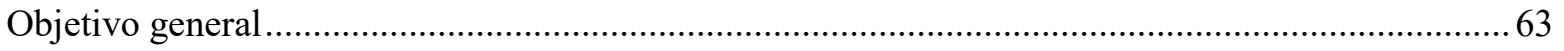

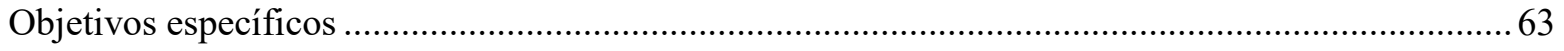

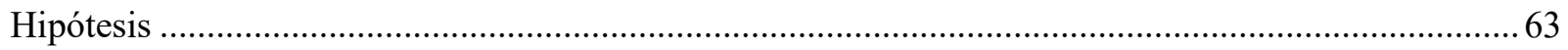

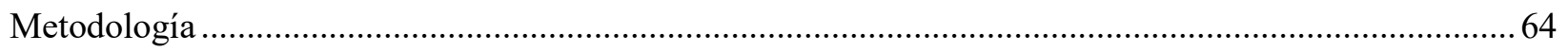

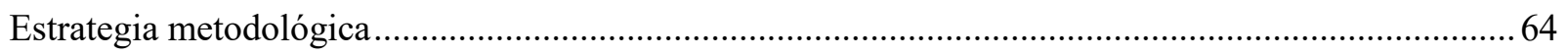

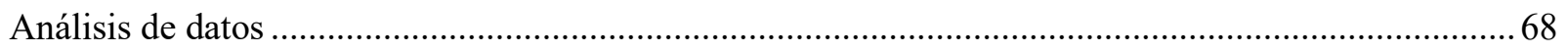

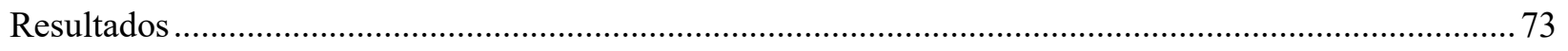

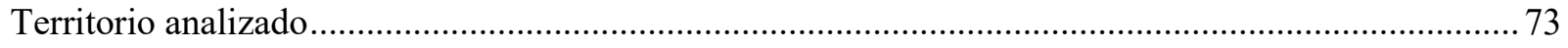

Transformaciones de la actividad lechera en la cuenca del Abasto Sur...............................................76

Aspectos Institucionales, el Estado y su papel normativo en la elaboración de masa para mozzarella.. 79

El Estado Provincial y su papel en la regulación de la actividad tambera-masera. ..............................89

Ley $N^{\circ} 11.089$, origen, implementación e inconvenientes para su cumplimiento. ........................... 99

Caracterización de la cadena láctea del queso mozzarella en los estratos de la pequeña producción. . 107 
Caracterización del tambo - fábrica en la Cuenca del Abasto Sur ............................................... 107

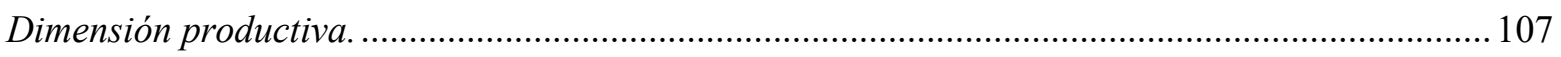

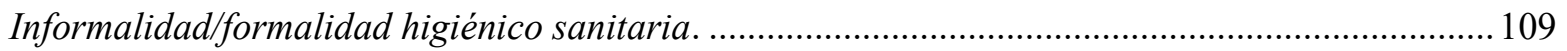

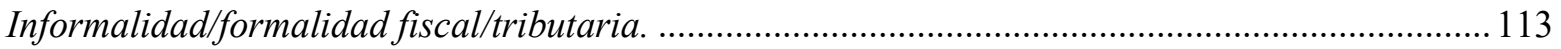

Estructura de los mercados, eslabón comercial, agroindustria. ......................................................... 119

El estado, las Instituciones no gubernamentales inherentes y sus concepciones sobre la

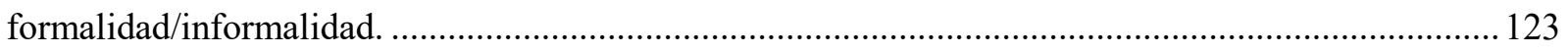

Evolución y estado actual de la producción masera en la cuenca de Abasto Sur. ............................... 129

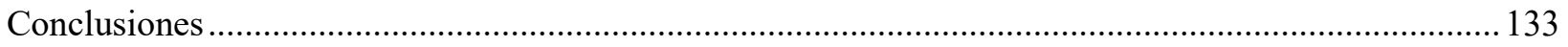

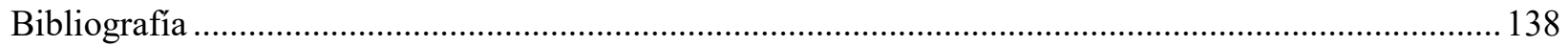

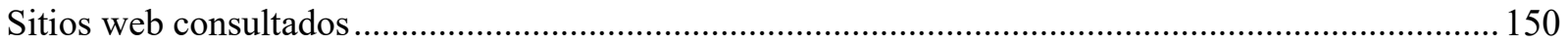

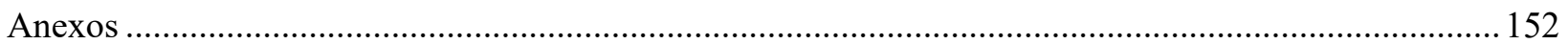

\section{Índice de figuras}

Figura 1: ejes del marco teórico y sus inter-relaciones....................................................................24

Figura 2: esferas de lo formal y lo informal, sus relatividades y sus márgenes de operación compartida. 60

Tabla 3: productores y familias productoras entrevistadas. .................................................................. 70

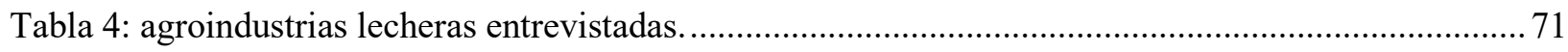

Figura 5: registros fotográficos instancias de trabajo en terreno, entrevistas en profundidad,

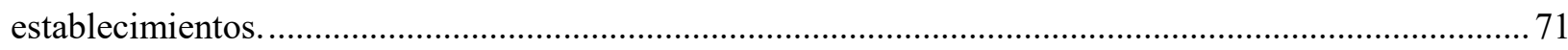

Tabla 6: funcionarios públicos Nacionales, Provinciales y Municipales, y docentes universitarios

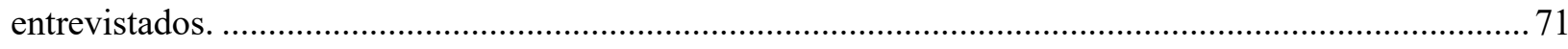

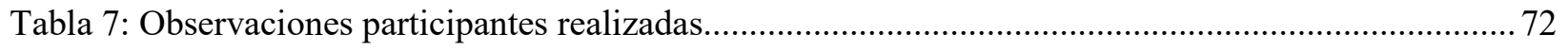

Figura 8: registros fotográficos instancias de trabajo en terreno, observación participante. ...................... 72

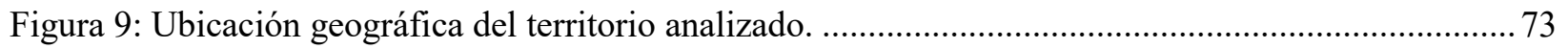

Figura 10: Ubicación de A.M.B.A. en Prov. de Buenos Aires, sus coronas urbanas y red vial .................75

Figura 11: Evolución de los sistemas de producción láctea en Argentina. .............................................78

Tabla 12: Requisitos higiénico/sanitarios Nacionales-Provinciales-Municipales. ................................... 93

Tabla 13: Requisitos en los diferentes sistemas Nacionales. ................................................................. 94

Tabla 14: Esquema de obligaciones a cumplir en lo tributario y fiscal Nacional y Provincial.................. 95

Figura 15: Unidad productiva familiar habilitada y sus consecuentes impactos. ................................... 106

Figura 16: Dimensiones a abordar en un proceso de formalización. ....................................................... 119

Figura 17: variables y condicionamientos de la informalidad. ............................................................. 123 
Figura 18: Variabilidad de la informalidad en relación a la regulación estatal...................................... 126 


\section{Resumen}

La presente Tesis aborda los marcos legales establecidos para la producción y manufacturación lechera con la mirada puesta en las pequeñas producciones familiares, a partir de un recorrido teórico por el desarrollo y las posibilidades del sector agropecuario argentino, estableciendo múltiples relaciones entre la trayectoria que ha experimentado este sector y las principales transformaciones políticas, económicas y sociales de la Argentina en las últimas décadas. Se propone investigar en particular, las normas impuestas así como los modos que asume la agricultura familiar para salir de la informalidad productiva y los vínculos de este proceso con la planificación e implementación de políticas públicas. A continuación, pretendemos desarrollar las principales características del contexto histórico, desde la visualización y posterior surgimiento de un modo productivo, su transformación en la implementación del neoliberalismo durante los años noventa, hasta el cambio de contexto para el sector entre los años 2003-2015, atendiendo especialmente a las modificaciones que se sucedieron en el sector agropecuario de la economía y a los cambios en la estructura del Estado; para luego adentrarnos en las preguntas e hipótesis propias de esta investigación.

Este trabajo aspira a generar conocimientos sobre los procesos económicos, culturales y políticoinstitucionales, ligados a la formalización ${ }^{1}$ de las pequeñas producciones de masa para mozzarella, estando en íntima relación con el desarrollo de tramas productivas y comerciales en

\footnotetext{
${ }^{1}$ La formalización es el proceso que llevan a cabo las empresas para incorporarse a la economía formal. Presenta diversas dimensiones:

- Registro y concesión de licencias por parte de las autoridades nacionales, provinciales y municipales;

- Acceso a la seguridad social para el propietario de la empresa y sus empleados;

- Cumplimiento del ordenamiento jurídico vigente, entre otras cosas en materia de impuestos, cotizaciones a la seguridad social y legislación laboral.

La formalización es un proceso gradual. (OIT 2014).
} 
conjunto con la valorización de sus productos, analizando las limitaciones, los efectos e impactos de esta acción sobre los territorios. Para esta tarea se trabajó sobre la Cuenca del Abasto Sur, por coexistir en este territorio un gran número de pequeños tambos familiares dedicados a la producción de leche y la elaboración de subproductos lácteos.

Desde las instituciones estatales se promociona la incorporación a la cadena formal de toda producción de alimentos de origen animal, por estar comprendida dentro de la salud pública. En este sentido, el Estado tiene que dar las garantías de inocuidad, teniendo la capacidad de fiscalizar el proceso desde la obtención de la materia prima hasta su transformación en alimento. En esta obligación de incorporación, el Estado desconoce los posibles riesgos que correrían estas pequeñas unidades productivas, con el agravante que se encuentran gestionadas en su mayoría por productores familiares con bajos niveles de capitalización; pudiendo ser propietarios, arrendatarios y en algunos casos empleados o medieros rurales, que se encuentran relegados por su baja escala productiva, bajos procesos de adopción de tecnologías, dificultades en la organización y fundamentalmente con informalidad en la producción por la imposibilidad de adaptar su sistema productivo a las exigencias tecnológicas de las agroindustrias, contempladas en las normativas vigentes, el contexto económico sectorial desfavorable -precios y valor de los insumos entre otros- y el alto endeudamiento. Éstos, se encuentran comprendidos en una estandarización productiva empresarial, teniendo que lidiar en un mercado de alta competitividad, no apto para este tipo de producciones familiares. 


\section{Introducción}

Los cambios en la actividad láctea producidos durante las décadas de 1980 y 1990 en las distintas cuencas lecheras del país, posibilitaron la incorporación a las unidades productivas de distintos tipos de tecnologías capital intensivas, con una consecuente intensificación de la producción, permitiendo aumentar la productividad y su volumen final.

De esta manera, se produjo una significativa diferenciación entre los establecimientos que se encontraron altamente tecnificados, con gran capacidad productiva, respecto de los tambos más pequeños, cuya adopción tecnológica fue baja o nula, obligándolos a desempeñar su producción en los márgenes de la informalidad ${ }^{2}$. Las características del contexto en estas dos décadas, daban un escenario por demás complicado para las producciones pequeñas, ya que muchas de ellas no tenían acceso a financiamiento, no contaban con capital para inversión y la oferta de capacitaciones era escasa para adaptarse a las nuevas tecnologías, tornándose extremadamente difícil la supervivencia. Estas condiciones llevaron a un fuerte proceso de concentración de la producción, a costa del pasaje a la informalidad y hasta la desaparición de producciones tamberas pequeñas, por no encontrarse dentro de los llamados tambos eficientes, debido a que habían quedado relegados por su baja productividad y calidad de producto.

Tal situación de "atraso tecnológico" actuó como limitante a la hora de colocar el producto en el mercado, que exigía mayores niveles de calidad, así como mayores volúmenes que permitiesen

${ }^{2}$ La OIT define a la economía informal como: “el conjunto de actividades económicas desarrolladas por los trabajadores y las unidades económicas que, tanto en la legislación como en la práctica, están insuficientemente contempladas por sistemas formales o no lo están en absoluto. Las actividades de esas personas y empresas no están recogidas por la ley, lo que significa que se desempeñan al margen de ella; o no están contempladas en la práctica, es decir que, si bien estas personas operan dentro del ámbito de la ley, ésta no se aplica o no se cumple; o la propia ley no fomenta su cumplimiento por ser inadecuada, engorrosa o imponer costos excesivos."(90 Conferencia Internacional del Trabajo de 2002, Ginebra, OIT). 
aumentar la eficiencia en la logística empleada. Estos tambos con defíciencia tecnológica (que no pudieron adaptarse a los cambios tecnológicos y de mercado) fueron los que tuvieron que encontrar canales de comercialización alternativos a las grandes usinas lácteas, comercializando en pequeñas usinas con bajas exigencias en cuanto a calidad de leche. O, alternativamente, convertirse en elaboradores de masa para mozzarella ${ }^{3}$, un subproducto lácteo, con bajas exigencias en cuanto a calidad, logística de entrega, e instalaciones para su elaboración. Incursionando en una nueva dimensión manufacturera láctea, agregando valor a su producto, dando cuenta de la adaptabilidad y flexibilidad de las pequeñas producciones al contexto (Nogueira, 2008).

Ante esta problemática los organismos estatales abordan sin grandes éxitos, acciones de fomento a la formalización productiva y comercial, englobando producciones con un amplio abanico de actividades y ocupaciones informales que se caracterizan por el reducido tamaño, los bajos niveles de productividad y el escaso capital para operar, tratándose de un sector que se desarrolla al margen de las reglas de juego establecidas por el Estado, esto es, al margen de las normativas vigentes. Esta acción nos permite vislumbrar que para los pequeños emprendimientos, potenciales generadores de agregado de valor local, es necesario acciones previas para su regularización.

Pretendemos situarnos en la discusión sobre la dimensión de los cambios económicos y culturales que pueden sufrir las producciones familiares al entrar en el circuito formal. En este sentido, se tornan imperantes los análisis y las reflexiones sobre las potenciales tensiones que puedan surgir en base a la acción, donde el propio Estado sea parte del eje de investigación para

\footnotetext{
${ }^{3}$ masa acidificada (producto intermedio obtenido por coagulación de la leche por medio de cuajo y/u otras enzimas coagulantes apropiadas), complementada o no por la acción de bacterias lácticas específicas.(Código Alimentario Argentino. Capitulo VIII Artículo 618 - (Resolución Conjunta SPRyRS y SAGPyA Nº 33/2006 y º 563/2006).
} 
detectar las posibles modificaciones a las que fuera sometido para dar una contención real, con normativas diferenciadas que cobijen al pequeño productor para su posterior desarrollo sin inconvenientes ni riesgos. Esto, formulando y ejecutando políticas públicas para poder garantizar la permanencia del productor en este nuevo escenario, tornándolo necesario para no incurrir en promocionar un eslogan, sin tener un conocimiento cierto sobre cómo afectará a la familia productora el ser visibilizada y posteriormente estandarizada bajo determinadas normas productivas cuando ésta ingrese al sistema de producción y comercialización dominantes.

\section{Planteo del Problema}

\section{Antecedentes generales sobre el complejo lácteo nacional y su reflejo provincial.}

La evolución de la producción lechera nacional en las últimas décadas, se ve reflejada de manera similar en las principales cuencas lecheras de nuestro territorio Nacional, incluyendo la Provincia de Buenos Aires, afectando particularmente a los productores agropecuarios. Para estos, la desregulación que se llevó a cabo, junto con los cambios que se dieron en el complejo agroindustrial, han reducido su capacidad de decisión sobre la producción y los insumos utilizados, así como el poder de negociación del precio de venta (Teubal y Rodríguez, 2001). Impactando en la cadena láctea conformada por la trama productiva (a la que ellos pertenecen) y comercial; englobando los procesos productivos, logísticos, de distribución, comerciales, y los servicios e infraestructura de apoyo, públicos y privados que enmarcan las actividades que participan en la elaboración de leche, quesos y otros productos lácteos (Bisang et al., 2003).

Esto se empieza a manifestar a través de la incorporación paulatina de elementos tecnológicos internacionales (Gutman y Gatto, 1990) los cuales traerán modificaciones sustantivas en el uso de la tecnología, en las formas de organización, en la reconfiguración de agentes económicos, en 
los sistemas de relaciones e incluso, en los marcos institucionales (CEPAL, 2005). Es en este período que se empieza a evidenciar el resultado futuro de este proceso por la falta de adecuación de la estructura productiva, su posterior fragmentación y el escaso o nulo vínculo con el sistema innovativo local, generando una distorsión de los precios relativos, con sus efectos diversos en materia de asignación de recursos y distribución de ingresos; imposibilitando la generación y apropiación de ganancias y rentas, de posibilidades de desarrollo y expansión.

Esta dinámica sustentada por una alta demanda internacional -modelada ahora bajo nuevas formas organizacionales- encuentra su contrapartida en los cambios estructurales generados en lo productivo, en lo tecnológico y su oferta local (Bisang et al., 2008), produciendo la eliminación de muchos pequeños productores que no pudieron acompañar esta transformación tecnológica en el marco de las condiciones vigentes. (Gutman y Gatto, 1990).

Lo dicho trae interés de revisar el rol de los diferentes sectores económicos participantes y de la acción que le cabe al Estado en los aspectos normativos y regulatorios de corto plazo y en la estrategia política, requiriendo la revisión conceptual del sector público con respecto a las actividades de la cadena láctea Argentina (Teubal y Rodríguez, 2001).

\section{La actividad láctea en argentina y su representación en la Provincia de Buenos Aires durante los últimos 30 años: décadas del 1980, 1990, 2000 y 2010.}

En la década de 1980, los productos lácteos elaborados estuvieron bajo una dinámica productiva motorizada por y orientada hacia el mercado interno (Gutman, 2000), donde los excedentes no encontraban oportunidades en el mercado externo. Esto generó una fuerte crisis en el sector provocada en cierta medida por los vaivenes económicos y políticos que se fueron dando en el país durante dicha década. Por estos tiempos el modelo de producción lechera era pastoril, operando con una dotación inicial de capital fijo y escaso capital variable, con mano de obra no 
calificada, funcionando con una mínima sanidad y escasa alimentación adicional, haciendo uso de los ciclos naturales de pastos y partos (producción estacional), obteniendo menor productividad a bajo costo y de calidad media, constituyendo un sistema productivo sustentable (Bisang et al., 2003). Este modo productivo se mantuvo hasta finales de la década en donde comienzan las transformaciones productivas, tecnológicas y organizativas en la producción primaria, impulsado y estimulado por las grandes empresas lácteas a través de sus servicios de extensión (Gutman, 2000)

Posteriormente en la década del 1990, la creación del MERCOSUR y la desregulación económica produjo un sin fin de contradicciones en la cadena. La transformación tecnológica que había comenzado en la década anterior se ve estimulada por la apertura de los mercados internacionales permitiendo la tecnificación tanto a nivel primario como industrial, pasando de 6 mil millones de litros en 1990 a más de 9 mil millones de litros en el año 1997. Este aumento de la producción de leche se dio en un contexto caracterizado por la concentración de la propiedad, una sustantiva mejora tecnológica y la reducción del número de tambos que no pudieron afrontar el "salto" tecnológico, debido a que este esquema de funcionamiento impulsaba a la producción primaria hacia un modelo tecnológico de mayor requerimiento de capitales (fijos y circulantes). Modelo que Bisang et al. (2008) lo contextualizan como la generalización de un modelo de relación en el que se inducía a la actividad primaria hacia una expansión en la producción, con mayores exigencias de calidad, trasladando procesos hacia el productor primario y mejorando la estructura de costo de las industrias.

Aquí podemos encontrar dos actores fundamentales para llevar a cabo la tecnificación, los proveedores de insumos, por un lado, y las usinas lácteas demandando calidad y volumen (vía pagos diferenciales) por otro, incidiendo sobre el comportamiento del productor primario quien 
respondió, a la medida de su capacidad, incorporando masivamente tecnologías disponibles como genética, sanidad animal, sistemas de alimentación, maquinarias (ordeñe, enfriado de leche y sistemas de limpieza de los tambos) y técnicas de manejo del rodeo. De muchas de estas tecnologías se valió la industria para trasladar etapas que se realizaban en ella, a la producción primaria, siendo la principal el enfriado y refrigerado de la leche.

Se considera importante aclarar que las tecnologías demandadas nacían de una industria que ya se perfilaba a definirse como un mercado de tipo oligopólico concentrado y diferenciado, integrado por las tres mayores Usinas Lácteas categorizadas por su valor de producción Cooperativas Unidas Limitada Sancor, Mastellone S.A. y Nestlé S.A., generando el 57\% del valor de producción y el 51\% del valor agregado. Porcentaje destacable que en algunos casos (como el servicio de extensión de La Serenísima) les otorgó la posibilidad de convertirse en motores de la difusión de criterios y normas de calidad y de innovaciones tecnológicas asociadas a los nuevos estándares, mediante acuerdos formales o informales con los tambos. Para ello, fue apoyándose en su propio servicio de extensión, ocupando el intersticio desatendido por el Estado debido a su escasa participación en el sistema de asistencia, regulación y control de los diferentes sectores; limitándose a aspectos normativos relacionados con la sanidad, la higiene, inocuidad y calidad de los productos (Bisang e al. 2003). Esto posiciona, fortalece y empodera el oligopolio y consolida su transformación en los núcleos centrales de la trama láctea, responsable ahora de la regulación intersectorial y reforzando la brecha tecnológica entre los tambos (Gutman y Gatto, 1990). Esta presión dirigida desde la agroindustria hacia los productores primarios se suscita no solo a partir de los acontecimientos antes mencionados, sino que también se debe a la presión de las grandes empresas en cadena de la distribución minorista (GD), que tenían la posibilidad vía importaciones de hacerse de productos de calidad superior jugando un 
rol central en la fijación de estándares de calidad de las materias primas y productos lácteos nacionales. (Bisang et al., 2003).

Aproximadamente a partir de 1998 hasta el año 2002 la lechería entra en un proceso de crisis, resultado de los cambios sufridos durante toda la década, experimentando un fuerte declive de la producción, una reducción en el número de tambos con la consecuente concentración de la actividad en establecimientos de mayor tamaño, capaces de afrontar en mayor o menor medida, a través de préstamos (endeudamiento), los costos de las tecnologías importadas (un claro ejemplo de este proceso fue el carácter obligatorio de la incorporación de máquinas de enfriado de la leche por parte de la industria) desafiando la sostenibilidad de la unidad productiva por peligrar el cumplimiento de los pagos por los precios bajos de la leche. Precios que habían cambiado hacia una relación privada ya que se acordaban entre el tambo y la industria, sin distinción entre precio base y precio excedente (Bisang et al., 2003) y con inestabilidad de los plazos de pago, dificultando las perspectivas de supervivencia de las explotaciones tamberas.

Se modificaron así las variables que atribuían la sostenibilidad de las explotaciones tamberas hacia un aumento de la productividad (y de facturación), de la eficiencia y de la diversificación productiva (soja). El sector primario se encontró frente al cierre de muchos tambos y la disminución del rodeo lechero. Diversas estimaciones indican el cierre de alrededor de 3.500 unidades productivas, de un total estimado de 15.500 explotaciones comerciales. (Bisang et al., 2008). Esto, en gran parte, se les puede atribuir a los sectores industriales más concentrados, que mejoraron su posición relativa transfiriendo a los productores primarios parte de los costos de la crisis a través de un menor dinamismo de precios pagados por la materia prima (Bisang et al., 2003). A su vez, respaldando a la mejora de posición por parte de la industria, se puede agregar la ampliación de oferta de leche fluida por fuera de las Cuencas cercanas a los grandes centros de 
consumo, por entrar en escena el transporte de productos lácteos en camiones con equipos de frio, ampliando la posibilidad de acopiar leche de tambos ubicados a grandes distancias, contribuyendo a producir cambios significativos en el escenario de la trama lechera nacional (Vertiz, 2017). Este hecho, con el propósito de potenciar áreas con mejores condiciones agroecológicas para la producción de leche como las Cuencas Mar y Sierras o la Cuenca del oeste, dio la posibilidad de remisión de su producción a las grandes usinas del gran Buenos Aires en detrimento del abastecimiento a las usinas locales (Gutman y Rebella, 1990).

Siguiendo los vaivenes de le economía nacional, la producción se reactiva después de la devaluación del 2002, no alcanzando sin embargo los valores del año 1999. Los cambios estructurales registrados tanto en la producción primaria como industrial durante los '90, traducidos en una mayor eficiencia, con fuertes aumentos de productividad, permiten hablar hoy de un complejo lácteo más eficiente y moderno, pero también saca a la luz la gran diversidad de formas que existen en la trama productiva láctea del país (Mateos, 2006).

Este reflejo de la situación Nacional se advierte del mismo modo en las Cuencas Lecheras de la Provincia de Buenos Aires, donde su participación a nivel nacional ha oscilado entre el 20\% y el $23 \%$, acompañando su comportamiento a la tendencia nacional; pero en el contexto mencionado anteriormente, la respuesta de la provincia, por las características de sus unidades productivas lecheras, es relativamente más rápida, registrando una caída del número de tambos existentes y un aumento de la producción media de alrededor del 74\% aproximadamente. En tal sentido, podemos nombrar como causal de esta baja del número de unidades productivas, el dominio de la comercialización de la leche fundamentalmente por firmas de gran escala $(80 \%)$, estando ausente en este eslabón empresas cooperativas, reforzando el dominio oligopólico de procesamiento y/o comercialización de la leche, observando una mayor incidencia de la venta 
directa al circuito minorista por parte de los tambos que quedaron en el camino del "salto tecnológico" (Castellano et al., 2009).

\section{La emergencia de un nuevo eslabón en la producción láctea, el tambo-fábrica.}

En este escenario de profundos cambios en la trama láctea del país y su reflejo en la Provincia de Buenos Aires en cuanto a las formas de articulación con la producción primaria, es necesario hacer referencia sobre el condicionamiento para el desenvolvimiento de la actividad producto de la insuficiente infraestructura rural. Los caminos rurales toman relevancia por incidir directamente sobre el desarrollo de las actividades productivas, de comercialización, así como también y no menos importante, en la mejora de la calidad de vida de la población rural (Salomon, 2017). Es esta infraestructura rural la que tuvo un papel crucial para la emergencia de este nuevo eslabón de la producción primaria del que nos ocuparemos en este punto. Pero antes, reforzando la importancia de los caminos, y retomando a Salomon (2017) se hace necesario reconstruir una política pública sobre los caminos, en este sentido el vicepresidente segundo de la Asociación Argentina de Carreteras, el Lic. Miguel Ángel Salvia, sentencia que los caminos rurales "son accesos a los establecimientos agropecuarios y son los que permiten la salida de la producción hacia los puntos de acopio. Resaltando que la mejora de los caminos rurales trae distintos tipos de beneficios: económicos (altas tasas internas de retorno, mejora en la productividad global, mejora en la rentabilidad del productor); sociales (mejora en la calidad de vida) y fiscales (valorización de predios y mayor percepción por mejora en actividad) ('Revista Vial files”, 2018). Abonando a esta mirada, Escobal y Ponce (2002) resaltan la necesidad de inversión en materia de infraestructura rural mediante políticas públicas sostenidas y concertadas entre lo público y lo privado, que permita reducir los costos de producción y los costos de transacción, promoviendo el comercio y facilitando la división del trabajo. 
Fue en este espacio rural de mala infraestructura pública, especialmente de los caminos, que se conjugaron junto con la presión de tecnificación para dar origen a una estratificación de producciones, las altamente eficientes y las desplazadas o marginalizadas predominantes en las cuencas lecheras Bonaerenses (Bisang et al., 2003). Se origina así, la emergencia de esta nueva figura que nos aboca en el presente trabajo, "la producción de masa para mozzarella".

Corría la década de 1980 y como ya se mencionó comenzaban a irrumpir los primeros avances tecnológicos y normativos en la actividad láctea. Durante 1985 y 1986 se registraron en la cuenca Oeste de la Provincia de Buenos Aires graves inundaciones que imposibilitaron, por la mala situación vial (caminos rurales), la entrega de leche fluida por parte de los tambos. Ante esta restricción, se permitió desde el Gobierno Provincial la elaboración en la unidad productiva primaria de una manufactura que permitiese almacenarla por un lapso mayor de tiempo sin que se deteriore. En este contexto de búsqueda de soluciones a la falta de infraestructura y al impedimento del despliegue de la logística para la comercialización de leche fluida surge como opción la elaboración de masa para mozzarella como producto final remitida a la agroindustria para elaborar mozzarella. Este permiso por parte del Ejecutivo Provincial se complejizó y en los años posteriores a esta primera autorización de elaboración confeccionó un marco normativo que encuadro los requisitos edilicios e higiénico-sanitarios. Como resultado, en 1991 se creó la figura de "tambo - fábrica", bajo la ley provincial $N^{\circ} 11.089$ con su respectivo decreto reglamentario $\mathrm{N}^{\circ}$ 83, designando como autoridad de aplicación al hoy Ministerio de Desarrollo Agrario de la Provincia de Buenos Aires. Es importante resaltar que los tambos elaboradores de masa para mozzarella siguen bajo la figura de productores primarios, y no industriales, ya que ésta se considera como un producto intermedio. 
A partir de este hito, del contexto requisitorio de elaboración y de los bajos precios relativos, es que en la marginalidad y fuera de los canales legales sociales e impositivos, como proveedores de PyMEs industriales (Gutman, 2006), asi como los productores adoptan según Bassi et al. (como se citó en Biolatto et al., 2003) un conjunto de estrategias como la mano de obra familiar para el logro de supervivencia, y la manufactura, para no solo conseguir una diferencia en el valor de comercialización sino también una elaboración y almacenamiento mediante procesos muy simples y de bajo costo con respecto a la leche fluida. Dichas estrategias fueron claves para la persistencia, e hicieron posible la permanencia de las pequeñas producciones en un contexto marcado por la economía de mercado y que, desde los discursos oficiales pronosticaban su desaparición (Biolatto et. al., 2003). Esto podría corroborarse a través del informe de Comerón et al. (2000), donde manifiesta que la escala productiva es fundamental para el mantenimiento de la unidad productiva del sector, por lo que generalmente aquellos establecimientos con menos de 1000 litros diarios de producción encuentran muy comprometida su sostenibilidad.

\section{Producción láctea - masera en la Cuenca de Abasto Sur}

La Cuenca del Abasto Sur se encuentra en la Provincia de Buenos Aires, comprendida por doce partidos de gran importancia en la participación de la producción lechera nacional, contribuyendo aproximadamente con el $28 \%$ de la producción total del país (M.A.A., 2010). Su localización es en cercanía con el mayor centro de consumo del país, la Ciudad Autónoma de Buenos Aires y su área Metropolitana, en un radio de 100 a 150 kilómetros; de aquí su nombre como abastecedor de leche a este gran núcleo urbano. Está conformada por las unidades productivas tamberas presentes en esta área rural, las cuales estructuran el espacio y constituyen el eslabón principal de producción (Barros, 1999). 
Esta cuenca es especialmente sensible a condiciones adversas de mercado, ya que en ella prevalecen sistemas de producción intensivos y altamente especializados si la comparamos con otras cuencas lecheras, lo que dificulta una vez establecido, un cambio de actividad. También esta región tiende a tener costos de producción promedio superiores a los de otras cuencas (Moreira et al., 2004), por no poseer las mejores aptitudes agroecológicas para la producción lechera. Los sistemas productivos utilizan una mayor proporción y cantidad de suministro de concentrados para la alimentación vacuna (Bisang, 2008), característica dada por la menor capacidad del recurso suelo (Arzubi y Schilder, 2006), aumentando la dependencia de insumos externos y con ello los costos de producción (Moreira et al., 2004).

Caracterizada por estar conformada por un gran número de tambos relativamente pequeños y de menor eficiencia productiva respecto a otras cuencas provinciales, alberga una importante cantidad de plantas de procesamiento que reciben y transforman leche de otras cuencas. Produce aproximadamente el $17 \%$ del total de la leche, con un volumen de producción entre 970.000 litros diarios y 29.000.000 de litros mensuales. Esto indica un relativo menor tamaño/ eficiencia, de los mismos respecto a otras regiones de producción. (M.A.A., 2010), contando con 585 tambos, representando el $22 \%$ de la provincia (M.A.A., 2010), con una producción media de leche, por unidad, de 1.440 litros. De éste, el 84,3\% se vende a las industrias como leche fresca, y el 10,9\% se entrega como masa para elaboración de mozzarella en los establecimientos más pequeños (Arzubi y Berbel, 2003) representando el $32 \%$ y, microtambos que representan el 50$55 \%$ del total provincial y que se encuentran en la cuenca bajo estudio (Marino et al., 2011). La industria, a la que se le remite la leche fluida, es la que asumió un rol destacado en el cambio de contexto de la Cuenca del Abasto, tomando como punto de partida, la ventaja de la relevancia industrial en el año 1961, donde la capital federal prohíbe la venta de leche sin pasteurizar, hito 
que impulsó la expansión de una de las más grandes industrias lecheras, "La Serenísima" (Mastellone Hnos. S.A.) ubicada justamente en la Cuenca del Abasto, consolidando e implantando la intervención de la industria en los medios técnicos de la producción primaria para generar y difundir patrones tecnológicos de adopción obligatoria (Posada, 1995).

\section{Pregunta de investigación}

En base a lo expuesto resulta interesante indagar en el recorrido de la trama láctea argentina y su reflejo en la Cuenca del Abasto Sur, para entender los procesos que tienen que transitar los pequeños productores lecheros que agregan valor a su producción (mediante la elaboración de masa para mozzarella), para adecuarse a las exigencias del Estado, para así intentar esbozar los orígenes de los fenómenos de la informalidad productiva, que permitan identificar con mayor precisión los factores que inciden en ésta, buscando así, generar aportes para el diseño y promoción de políticas factibles de implementación y cumplimiento, a través de una explicación teórica sólida y empíricamente comprobable por medio de la cual se podría acercar respuestas apropiadas al interrogante formulado en este trabajo.

De tal manera, se llega a la formulación de la pregunta de investigación:

\section{¿Corre riesgo la permanencia de las pequeñas producciones familiares lecheras-maseras de la cuenca del Abasto Sur al salir de la informalidad productiva?}

\section{Marco Teórico}

El Marco Teórico propuesto aborda tres ejes fundamentales: a) el Desarrollo territorial local como concepto de creación de sujetos y eje de construcción del entramado rural, incluyendo sus particularidades y potencialidades, buscando una integralidad de las relaciones socioeconómicas, 
para incorporar este concepto como uno de los niveles claves para el diseño de políticas económicas, sociales y productivas. b) La informalidad productiva como gran condicionante para esa tarea y c) el análisis de las Políticas Públicas como potencial instrumento para la contención y el fortalecimiento de la agricultura familiar y consecuente impacto en el desarrollo rural. Cabe destacar que, lo que respecta a informalidad productiva, la bibliografía encontrada fue muy escasa (casi nula), teniendo que extrapolar conceptos de informalidad urbana (microempresas, trabajo, entre otros) hacia lo rural.

Figura 1: ejes del marco teórico y sus inter-relaciones.

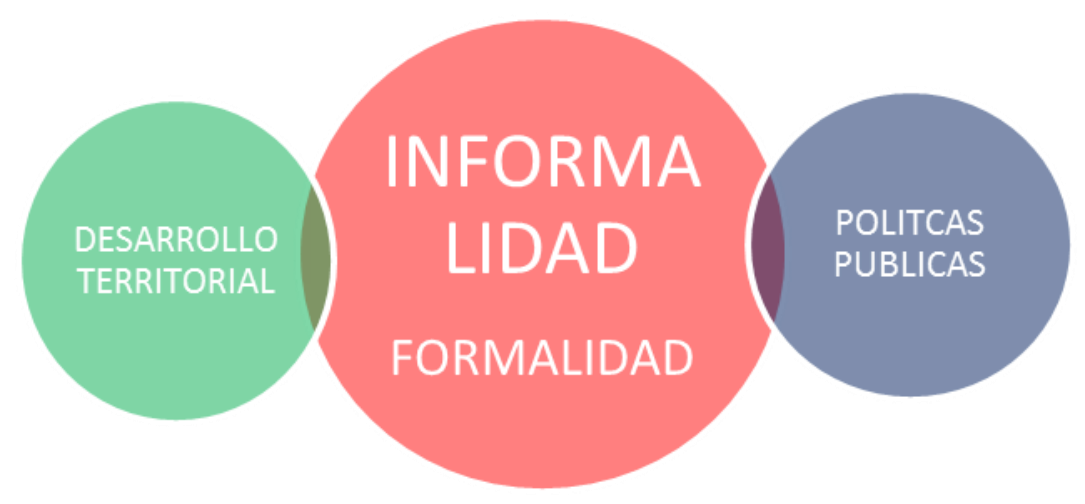

Fuente: Butler, L. Elaboración propia.

\section{Desarrollo, desarrollo territorial local y la importancia de la producción familiar en la configuración agro productiva de la argentina.}

Resulta necesario para el trabajo de investigación, realizar el recorrido por el término "desarrollo", y el lugar en la agenda por éste ocupada, en los últimos 30 años de la política argentina, para obtener una noción de su complejo y condicionado significado, por ser éste, el resultado de una construcción social e histórica. De tal manera, se irá analizando si este concepto 
es tan global como para dar forma a un nuevo entramado productivo que involucre a todos los actores rurales, o contrariamente el avance de éste, provocará un aumento de la marginalidad de ciertos sectores rurales.

La Argentina, caracterizada por ser desde sus inicios un país agro-ganadero, comienza a sufrir un proceso de mutaciones, que puede remontarse al proyecto político-económico de la última dictadura militar (1976-1983) y que se radicaliza en la década del noventa con la plena implementación del modelo neoliberal, dando como resultado una transformación estructural en el seno de la actividad agraria. En dicho marco, mediante políticas públicas de desregulación del estado y liberalización comercial (apertura de los mercados agrarios entre otros), se potenció el desarrollo de los agro negocios, conformados por grandes empresas, semilleras y pools de siembra que juntamente con un reducido número de exportadoras y con un componente financiero importante, inciden fuertemente en la dinámica del sector agropecuario argentino (Giarracca et al., 2008), favoreciendo la concentración de tierras, el arrendamiento por parte de pools de siembra y la consecuente disminución de las pequeñas producciones, arrojando Teubal (como se citó en Castro et al., 2009) que entre los censos de 1988 y 2002 la desaparición del 25\% de las explotaciones agropecuarias existentes en el país, o sea, 87 mil explotaciones de las cuales el $86 \%$ tenían menos de 200 has y $9 \%$ entre 200 a 500 has.

Se instaura entonces un modelo neoliberal basado en el financiamiento - endeudamiento, desindustrialización del modelo de acumulación y la reducción del gasto público como los principios rectores del nuevo enfoque implementado, coincidente con las propuestas de los organismos internacionales de financiamiento, que fueron aceptadas sin miramientos por las autoridades locales. 
Consolidado en la escena político-institucional, el mencionado modelo de desarrollo, inicia una progresiva retirada del Estado, dejando en manos de organizaciones no gubernamentales la responsabilidad de actuar en el ámbito rural y cumplir las funciones que tradicionalmente han estado reservadas al sector público, privatizando de este modo la función social del Estado, con una evidente falta de coordinación política y estratégica (Manzanal, 1990).

Sumada a la apertura y desregulación del mercado, se tendió a un aumento de la escala de las explotaciones viables y una consecuente concentración del poder económico en el medio rural, profundizando los problemas de equidad. En ese contexto, la eficiencia microeconómica, la escala de producción, el nivel tecnológico, la mayor productividad del trabajo, la opción por modelos intensivos, la integración agroindustrial y la capacitación empresarial, eran considerados factores determinantes para la supervivencia de las explotaciones agrarias (Lattuada y Estrada, 2001). Así se fue orientando y definiendo los rumbos de las políticas de desarrollo, mientras el Estado, minimizado y muchas veces pasivo, no solo sancionó leyes y formuló políticas que beneficiaron mucho más los intereses de las empresas de capital nacional y transnacional, sino que les cedió la toma de decisiones. Ellas mismas han actuado como formuladoras de proyectos y leyes, asegurando su ejecución por medio de apoyo político y económico del estado; generando e intensificando las desigualdades sociales, mediante la exclusión, la precarización laboral con desempleo estructural, el control social de la mayor parte de la población rural y la destrucción de territorios campesinos e indígenas (Fernandez, s/f).

Arturo Escobar (2007) destaca como discurso histórico, que el concepto de desarrollo, aparece a principios del periodo posterior a la Segunda Guerra Mundial (1945 en adelante y con el surgimiento de la Economía del Desarrollo), si bien sus raíces yacen en procesos históricos más 
profundos de la modernidad y el capitalismo. Este hecho se dio, operando a través de dos mecanismos principales: el primero, la profesionalización ${ }^{4}$ de los problemas de desarrollo, lo cual ha incluido el surgimiento de conocimientos especializados así como campos para enfrentar y pugnar con todos los aspectos negativos del subdesarrollo, como los conceptos capitalistas sobre la tierra, la agricultura y la crianza de animales. El segundo, es la institucionalización del desarrollo, mediante la vinculación sistemática de conocimiento y práctica por medio de proyectos e intervenciones particulares. Desde esta perspectiva, las estrategias como "el desarrollo rural", podrían verse como un mecanismo sistemático para vincular conocimientos expertos sobre agricultura, alimentos, etc. con intervenciones particulares (extensión agrícola, crédito, infraestructura, etc.) de manera que aun cuando aparentan ser "la forma natural de hacer las cosas", resultaron en una transformación profunda del campo y de las sociedades campesinas de muchas partes del tercer mundo, de acuerdo a los lineamientos de los conceptos capitalistas sobre la tierra, la agricultura, la crianza de animales, etc. (Escobar, 2007). En este contexto una sociedad tradicional, para reconvertirse en una sociedad moderna, debe incluir normas institucionalizadas, de alfabetización, de consolidación de organizaciones burocráticas especializadas (públicas y privadas) y de sistemas de participación político-democráticas (Alburquerque, 2003).

Este aparato de intervención y transferencia de paquetes tecnológicos para el desarrollo rural, se hizo posible por la implementación de programas y proyectos a través de las instituciones

\footnotetext{
${ }^{4}$ El concepto de profesionalización se refiere básicamente al proceso mediante el cual el Tercer Mundo es incorporado a la política del conocimiento especializado y de la ciencia occidental en general. Esto se logra mediante un conjunto de técnicas, estrategias y prácticas disciplinarias que organiza la generación, validación y difusión del conocimiento sobre el desarrollo, incluyendo a las disciplinas académicas, a los métodos de enseñanza e investigación, a los criterios de autoridad y a otras diversas prácticas profesionales. En otras palabras, los mecanismos a través de los cuales se crea y mantiene una política de la verdad y que permiten que ciertas formas de conocimiento reciban el estatus de verdad (Arturo Escobar, 2007, p. 86).
} 
creadas en lo que fueron los acuerdos de Bretton Woods, como el Banco Mundial y el Fondo Monetario Internacional, que desplegaron por el mundo el discurso "desarrollista" (Escobar, 2005), imponiendo sus enfoques e ideas a los programas y proyectos por ellos financiados en las diferentes etapas históricas, haciendo predominar sus propuestas, conceptos, instrumentos y expresiones comunes, diseñando y construyendo la intervención de las políticas públicas (Feito, 2008).

En este sentido, se actuó homologando el concepto de subsistencia con el de pobreza, así como se arraigan los conceptos económicos occidentales como equilibrio, costo-beneficio, eficiencia, etc., llevando el concepto de desarrollo como progreso, como un "continuo perfeccionamiento de la cultura" (Eschenhagen, 2001), imponiendo al mundo a través de las instituciones internacionales, la modernización y el desarrollo económico bajo un modelo productivo europeooccidental, basado en una identidad etnosistémica, inequitativa y antiecológica, generando concentración, centralización e interdependencia (Sevilla Guzmán, 2004). Con la intensión de modernizar la tecnología utilizada, impulsar la agricultura comercial y promover una rápida industrialización y urbanización en reemplazo de un sector tradicional asentado en la agricultura de subsistencia, de baja productividad y con escasas articulaciones con el mercado comercial (Lattuada et al., 2015). El acercamiento entre los países del mundo desarrollado permitió perfeccionar el control ejercido sobre las economías de los países subdesarrollados, ya que el dominio de un desarrollo tecnológico permanentemente innovativo permite una captación más eficiente del mercado de productos agropecuarios y manufacturados (Manzanal, 1990).

\section{Desarrollo en las primeras décadas de la Argentina democrática}

Una vez recuperada la democracia en la Argentina y a finales de la década de 1980 aparece esta visión de desarrollo en los primeros programas de intervención rural, focalizados por audiencia, 
originando en las instituciones gubernamentales la incorporación de áreas específicas para el caso, con el objetivo de promover la adopción de tecnologías apropiadas y la conformación de organizaciones locales, buscando mejorar la competitividad productiva y promover la diversificación y la integración a procesos agroindustriales para acceder a diferentes mercados con mayor probabilidad de éxito (Lattuada et al., 2015). De esta manera, el Estado buscaría la promoción de las exportaciones para obtener divisas para el pago de la deuda externa, asociada a la escasez de recursos y capitales, relegando para mejores épocas la promoción del mercado interno, del cual dependen los pobres rurales para trabajar, producir y consumir (Manzanal, 1990). Esto conllevaba a que los productores, a través de su interacción y del asesoramiento técnico con el respaldo de múltiples instituciones, buscaban el camino que consideraban más adecuado para su caso. Es así que el productor entraba en procesos simples como el reordenamiento de su actividad productiva, o más complejos como mejorar las condiciones de seguridad alimentaria, organizar su unidad productiva o intensificar la producción; como así también para otros, las transformaciones requeridas podían ser más profundas (Lattuada et al., 2015).

En continuidad, entre 1990 y 2002 con la llegada del neoliberalismo a las políticas gubernamentales y por ser de interés la persistencia -o no- de los pequeños y medianos productores en las condiciones que establece en sus distintas etapas el modo de producción capitalista, se pusieron en marcha los primeros programas de asistencia y de desarrollo para pequeños y medianos productores agropecuarios a través del financiamiento internacional, llevados adelante por diferentes agencias gubernamentales. Es un contexto donde se minimiza el rol del Estado en la sociedad y que toma como eje conductor al mercado, considerando innecesarias y contraproducentes las políticas sectoriales y proponiendo programas asistenciales 
y compensatorios para quienes se encuentren fatalmente condenados a la exclusión en el nuevo contexto de acumulación e integración a la economía mundial (globalización). Esto, según Lattuada et al. (2015), no debe interpretarse como la imposición de una receta para que se replique automáticamente en todos los programas, sino como el predominio de una serie de ideas, conceptos, instrumentos y expresiones comunes que en determinados contextos históricos se encuentran presentes como sustratos transversales en el diseño y en las estrategias de intervención, tomándola como una acción colectiva de los estados nacionales y de los estados provinciales y municipales. Por otra parte, abonando la idea de imposición, podemos asumir el gran condicionamiento a través del Consenso de Washington de los abordajes implementados, imponiendo un ajuste estructural, privatización y apertura indiscriminada de los mercados, con disciplina fiscal, unificando los tipos de cambio, con liberalización comercial y financiera y eliminando las barreras a la inversión extranjera. En esta línea se puede puntualizar que entre 1983 y 2002 la relación entre los organismos internacionales de financiamiento y el estado argentino estuvo caracterizada por una gran inestabilidad política con grandes cambios de autoridades, una gran desarticulación entre el estado nacional y los estados provinciales y por ultimo un gran descalabro económico del país. Este escenario operó, tal como lo caracteriza Manzanal (2006), a favor del capital más concentrado que avanzó con tecnologías que ahorraban mano de obra, con el uso de transgénicos y de insumos importados, consolidando un sistema agroalimentario mundial a medida de las grandes corporaciones transnacionales, desprotegiendo, marginalizando y excluyendo a los sectores productivos de menores recursos. En donde los diferentes programas de intervención fueron insuficientes para contrarrestar las políticas macroeconómicas (Lattuada et al., 2015), desapareciendo el $25 \%$ de los establecimientos 
agropecuarios, siendo en su mayoría pequeños y medianos productores (Teubal y Rodríguez, 2001).

\section{Nuevo paradigma del Desarrollo: territorial-local}

En este escenario neoliberal, donde en la Argentina de los años 90' se plasmaban los primeros programas de intervención, en América Latina ya se comenzaban a discutir nuevos enfoques de desarrollo, analizando lo "local-rural", como nuevo espacio de estudio, en donde los potenciales recursos son otorgados por actores fundamentales, los locales. Esta nueva atmósfera a la que Arturo Escobar (2005) denominó posestructuralismo, re significó el concepto "desarrollo", otorgando la conducción y la organización de la vida social al sujeto (Eschenhagen, 2001) como agente de desarrollo con sus prácticas del saber, del hacer y de la economía política de la verdad (rasgo característico del desarrollo), a través de la generación masiva de conocimientos, adaptando los avances tecnológicos y creando versiones locales de intervención (Escobar, 2005). Se plantea entonces, que el camino para lograrlo es en base a la re construcción de la cultura, las normas y las reglas que rigen una sociedad por medio de la organización institucionalizada, que regularán los comportamientos y las relaciones humanas a partir de las instituciones, entendidas como las normas y las reglas restrictivas formales (leyes, reglamentos, programas) así como también las informales (ideas, creencias, valores). Estas instituciones que afectan a través de sus incentivos, sus oportunidades y sus restricciones, las acciones de los agentes y, a largo plazo, el desarrollo de los territorios y de los países (Paz, 1999). En torno a esto Schneider (2004), define Desarrollo Rural como un proceso de acciones articuladas y orientadas a inducir cambios socioeconómicos y ambientales en el ámbito del espacio rural, para mejorar la renta, la calidad de vida y el bienestar de las poblaciones rurales que, dadas las especificidades y particularidades del espacio en que se desarrolla, es un proceso evolutivo, interactivo y jerárquico. En este 
marco, la visión de lo rural se perfecciona al abandonar la intervención netamente productiva (agricultura y ganadería) para valorizar la cuestión territorial, en donde las áreas rurales vuelven a aparecer como nuevos espacios estratégicos para el desarrollo económico y para la creación de procesos de desarrollo más diversificados y sustentables, permitiendo resolver los problemas de congestión urbana y superar los crecientes niveles de desigualdad (Sili, 2010). En este mismo sentido Schneider; Peyré (2006), no consideran al desarrollo rural en forma aislada sino que sostienen que su discusión se conecta al debate más general sobre el cambio social y que se debería orientar a mejorar la calidad de vida, a ampliar la justicia social y las libertades individuales y a la emancipación política.

La identidad del desarrollo rural que aplica el desarrollo agropecuario, pondera además de este, los vínculos urbano-rurales y las dinámicas de los mercados locales, exigiendo reformas institucionales, descentralización y fortalecimiento de los gobiernos locales, concertación social, intersectorial y público-privada, entre otros. Por ello, según Schejtman y Berdegue (2004), se requiere una compleja arquitectura institucional, para mediar entre el Estado, el Mercado y la Sociedad conteniendo cinco elementos: 1.- las atribuciones y capacidades de los gobiernos locales en sus dimensiones técnicas, administrativas y políticas; 2.- la coordinación y la existencia de controles y equilibrios entre los niveles nacional, provincial y local de gobierno; 3.las redes y otras formas de asociación entre los gobiernos locales, para generar organizaciones de alcance regional capaces de emprender las tareas de la transformación productiva; 4.- las organizaciones económicas y de representación de la sociedad civil; y 5.- los espacios y mecanismos para la concertación público-privada en las escalas y ámbitos que sean pertinentes para el Desarrollo Territorial Local (DTR). Para Vadell, et. al., (2012), en el desarrollo rural, percibido como un proceso de cambio estructural hacia la redistribución del bienestar en todas 
sus dimensiones, las políticas deben considerar que los espacios rurales trascienden a la cuestión agropecuaria y sectorial, enmarcando la dimensión sectorial del mundo rural en un universo más heterogéneo de relaciones sociales y de producciones no agropecuarias. Concibiendo lo rural en un sentido amplio, comprendiendo lo económico, lo político, lo social y lo cultural. Aportando sobre esto Soler (2008) destaca que el Desarrollo Rural debe basarse en los principios de justicia social, de mejoramiento de la calidad de vida y de la plena vigencia de los derechos. Otorgándole al Estado un rol central, como responsable y como garante y destaca la necesidad de protagonismo y de participación de la población y de sus organizaciones en la construcción de un nuevo proyecto social, económico y político, debiendo generar espacios y herramientas para que la población se pueda integrar, opinar y decidir sobre sus políticas (Vadell et. al., 2012).

La generación masiva de producción de conocimientos es promovida basándose en la transformación de objetos de desarrollo a sujetos y agentes, naciendo de la capacidad de revalorización de lo local, adaptando los avances tecnológicos y creando versiones locales de intervención, empoderando a movimientos sociales en proyectos de desarrollo (Escobar, 2005). Según Albadalejo y Bustos Cara (2004), se crean múltiples alternativas siempre en base a prácticas democráticas sostenidas, reivindicando el derecho a la diferencia, centralizando el papel de la comunidad y de sus actores en la toma de decisiones y en la construcción de su destino. En el mismo sentido Bustos Cara (2002c) define al territorio como un espacio con sentido y establece la centralidad de la subjetividad en la interpretación de los procesos territoriales, orientando la construcción del futuro en su inmaterialidad y en su materialidad. Desde esta perspectiva, cada sistema territorial toma sentido a partir de una cosmovisión que enmarca una ideología o un sistema de ideologías, basándose en estructuras complejas de imaginarios que dan el sentido a las representaciones y percepciones que orientan la acción. El 
hombre es acción y reflexión, es sensible, modificable y auto-modificable, recrea representaciones, imaginarios, ideologías y cosmovisiones, transformado su identidad y cultura (Bustos Cara, 2002a). El mismo autor amplia la mirada diciendo que el sentido está dado por las “ideologías dominantes en una etapa histórica determinada, en relación a un proyecto compartido colectivamente o no, pero hegemónico". Para el autor, "la identificación territorio - sentido, que puede darse de modo consciente o inconsciente, tiene una base explicativa económica ligada al sistema de producción y acumulación y a las formas de apropiación vigentes y tiene, también, una expresión política”. La complejidad de la construcción “está dada por la co-habitación de proyectos alternativos o contradictorios, aquellos que provienen de otros pasados o que se orientan hacia otros futuros" (Bustos Cara, 2002b).

Si a estos abordajes los combinamos con las políticas de valor agregado en origen promovidas durante el periodo 2010-2015, se obtendría un potencial vehículo para la transformación del territorio, expresando su capacidad como punto de demanda de mano de obra y como ámbito para la creación de procesos de desarrollo más diversificados y sustentables (Sili, 2010). Que acompañado de una continua discusión en cuanto a la aplicación de políticas públicas que moldeen el empoderamiento de las explotaciones, respetando su tipo de producción, con sus prácticas, sus técnicas, sus ritmos y sus costumbres, con la capacidad de manufacturar sus materias primas para sostenerse, reestructurarse y fortalecerse, alcanzando un afianzamiento por medio de un tejido productivo integrado cooperando y compensando las asimetrías.

Gordillo (como se citó en Schejtman y Berdegue, 2004) a principios del nuevo milenio destacaba como un fenómeno importante del desarrollo rural contemporáneo el papel de la movilización social de diversos sectores de pequeños y medianos productores, asalariados rurales y pobladores sin tierra entre otros, como catalizador de transformaciones y reformas institucionales, 
concibiéndolos como recursos de transformación social y profundización democrática. Ya que se encuentran inmersos en un territorio, planteado por Linck (2006) como objeto de la acción colectiva, de relaciones de competencia y cooperación, de conflictos que se pueden resolver y superar mediante la construcción de solidaridad y/o jerarquía, territorio que Mancano (2006) lo asume como un espacio social, que incluye las dimensiones de lo social, político, cultural y económico, es decir, que considera a las relaciones sociales en su complejidad, espacial y temporal. Sin límites físicos, sino por la manera en que se produce el relacionamiento y la interacción social entre los diferentes actores (Abramavoy, 2006).

\section{Desarrollo Territorial Local en Argentina}

Como fruto de estas nuevas líneas de abordaje teórico planteadas en los años 90', recién en la Argentina se comienza a hablar del Desarrollo Territorial Rural ${ }^{5}$ en la segunda mitad de la década del 2000, viéndose plasmada a través de programas de intervención política, en aras de profundizar las reformas que posibiliten una consolidación de las instituciones y organizaciones de la sociedad civil de orden local o territorial en los procesos de desarrollo rural. Esta posición se gesta en un contexto ideológico, político y económico diferente al de la década previa, favoreciendo el diálogo de políticas para avanzar en nuevos proyectos de desarrollo e inversión en el sector rural (Lattuada et al., 2015). Apareciendo el Estado no solo como formulador y

\footnotetext{
${ }^{5}$ Definimos el DTR como un proceso de transformación productiva e institucional de un espacio rural determinado, cuyo fin es reducir la pobreza rural.

El DTR descansa sobre dos pilares estrechamente relacionados, la transformación productiva y el desarrollo institucional cuyo contenido es necesario precisar:

La transformación productiva tiene el propósito de articular competitiva y sustentablemente a la economía del territorio con mercados dinámicos, lo que supone cambios en los patrones de empleo y producción de un espacio rural determinado.

EI desarrollo institucional tiene como objetivo estimular la concertación de los actores locales entre sí y entre ellos y los agentes externos relevantes, así como modificar las reglas formales e informales que reproducen la exclusión de los pobres en los procesos y los beneficios de la transformación productiva.(Schejtman et al, 2004)
} 
ejecutor de políticas descendentes que bajan estructuradas hacia la población, sino como la guía para la elaboración de políticas adecuadas, contemplando las diferencias y particularidades locales y culturales, para construir una política "desde abajo", de forma ascendente, como estrategia para atender a los excluidos rurales, formando parte de una política territorial, para el desarrollo local (Manzanal, 2006).

Desde esta perspectiva se abre un camino para nuevas intervenciones que terminen por borrar las secuelas de las políticas públicas del estado argentino durante las décadas neoliberales. En este enfoque predomina la política por sobre la economía y el Estado sobre el mercado, con fuerte apoyo al pequeño productor rural y a la inclusión de los sectores más vulnerables de la estructura social (Feito, 2008). Aspirando a la contención de la población rural, para el sostenimiento y la configuración del entramado social, por ser necesario el "mantenimiento de la estructura territorial y de la permanencia de la gente en el medio rural" (Sili, 2010, p 20). Por lo tanto, si se sigue el mismo camino, sin una real contención, promoción y seguridad, se seguirá fomentando la disolución de lo rural, la concentración de tierras, los monocultivos, las grandes cadenas industriales, el hacinamiento y la híper población en las grandes ciudades. En el mismo sentido Manzanal (1990) advierte que es importante recordar que enfrentar a la pobreza rural es un modo indirecto de solucionar simultáneamente algunos aspectos de la pobreza urbana, ya que menos pobres rurales migrarán hacia las ciudades a engrosar la masa de los marginales urbanos, o como afirma Soverna (2004), las políticas de desarrollo rural iniciadas a fines de los años '80 tenían como objetivo principal frenar la migración, en una etapa donde crece el índice de desocupación urbana y aumenta el costo económico de atender la población que se asienta en los márgenes, no sólo de las grandes ciudades, sino de las medianas y chicas. 
Sobre la misma línea Arturo Escobar plantea que el Estado necesita de la articulación y enriquecimiento por parte de la sociedad para ser transformado a través de un nuevo contrato social (Escobar, 2005). De esta manera se va democratizando la elaboración de políticas públicas, a través de las instituciones y organizaciones con las que dialogan y gestionan. (Lattuada et al., 2015), estimulando la confianza, la reciprocidad y la cooperación para una concertación público - privada a través de la promoción de las relaciones (Manzanal, 2006).

En lo sustancial, para el sector agropecuario, el Estado nacional crea y pone en marcha los Programas de Desarrollo Rural de la Secretaria de Agricultura, Ganadería, Pesca y Alimentación (SAGPyA), que significó un paso importante hacia políticas estatales focalizadas en pequeños productores, avanzando hacia su visibilización y terminando con el supuesto de una relativa homogeneidad de los productores en el sector agropecuario, los cuales demandan una atención especial con distintas y múltiples herramientas.

Para esto se concretaron incorporaciones estratégicas en organismos de ciencia y técnica para encabezar la dinamización de las producciones. Tal es el caso del Instituto Nacional de Tecnología Agropecuaria (INTA) que en su Plan Estratégico Institucional 2005-2015 incorpora en su misión, ampliar el sujeto de acción al conjunto del sistema agropecuario, agroalimentario y agroindustrial, estableciendo como ámbito de intervención las cadenas de valor, los sistemas productivos/agroecosistemas predominantes y los territorios, así como la generación de tecnologías para economías emergentes (Soverna, 2015). En consecuencia se crea en el año 2005 el Centro de Investigación para la Agricultura Familiar (CIPAF) con el objetivo de generar, adaptar y validar tecnologías apropiadas para el desarrollo sostenible de la agricultura familiar, con llegada a todos los territorios del país por medio de sus dependencias, los Institutos para la 
Investigación y Desarrollo Tecnológico de la Agricultura Familiar (IPAF), generando misiones y funciones específicas dentro del organismo, para lo que definen como

Un tipo de producción donde la unidad doméstica y la unidad productiva están físicamente integradas, la agricultura es un recurso significativo en la estrategia de vida familiar, la cual aporta la fracción predominante de la fuerza de trabajo utilizada en la explotación, y la producción se dirige tanto al autoconsumo como al mercado (INTA PEI, 2005, p. 5).

Este camino hacia la institucionalización fue posible debido a que el país se suma a la Red Especializada de la Agricultura Familiar del Mercosur ${ }^{6}$ (REAF), dando comienzo a una serie de cambios en los que se mostrará la importancia asumida por el Estado hacia este sector, comenzando por la generalización y unificación del término agricultor familiar para referirse a un conjunto heterogéneo de hogares de campesinos, trabajadores rurales, pequeños y medianos productores, implicando no sólo un cambio de nomenclatura, sino también la ampliación de la base social a quien se dirigirían las políticas de Desarrollo Rural (Soverna, 2015).

La Provincia de Buenos Aires se suma a esta nueva etapa y crea la Dirección de Desarrollo Rural dentro de su Ministerio de Asuntos Agrarios, que junto con la Dirección de Transferencia de Tecnología y Experimentación, dota 32 agentes en el territorio y 10 chacras experimentales que le permiten proyectar el trabajo en terreno. Pero al carecer de una caracterización global y comprensiva de la población objetivo: volumen, características, tipos y subtipos de pequeños productores se definieron como compartimientos estancos sin comunicación fluida con las

${ }^{6}$ http://www.reafmercosul.org/ 
dependencias, secretarias y direcciones las cuales le otorgarían un mayor peso específico para la acción concreta (Soverna, 2004).

En paralelo y continuando la búsqueda de institucionalización de la agricultura familiar en el año 2005 se crea el Foro Nacional de la Agricultura Familiar (FoNAF), con la intención de generar un espacio de interlocución entre el Estado y las 900 organizaciones de la agricultura familiar (Soverna, 2015), bajo una dinámica de planificación participativa. De allí, se deriva la formulación un "documento base de conformación" (Documento de Mendoza) en donde se represente e incluya a todos los sujetos, definiendo a la agricultura familiar como:

Una forma de vida y una cuestión cultural, que tiene como principal objetivo la reproducción de la familia en condiciones dignas, donde la gestión de la unidad productiva y las inversiones en ella realizadas es hecha por individuos que mantienen entre sí lazos de familia, la mayor parte del trabajo es aportado por los miembros de la familia, la propiedad de los medios de producción (aunque no siempre de la tierra) pertenece a la familia, y es en su interior que se realiza la transmisión de valores, prácticas y experiencias (FoNAF, 2006, p. 4).

Si comparamos ambas definiciones (INTA-FONAF), en esta última se hace mención a la cuestión cultural, no menos importante para el desempeño de la producción y sostenimiento de las unidades productivas. En este documento (Foro de Políticas Públicas Rurales, 2006) se destaca la necesidad de un Estado nacional que planifique y oriente las políticas de desarrollo rural, con participación activa y compromiso de los Gobiernos provinciales, la imprescindible participación organizada de la sociedad rural en la definición de las políticas a ellos destinadas, y la importancia de la implementación de políticas activas focalizadas a favor de una agricultura 
familiar que trascienda lo estrictamente agropecuario y priorice la inclusión económica y social (Narodowski, 2013). El Foro es resultado de que ya en el segundo semestre de 2004 empieza a sesionar la $\mathrm{REAF}^{7}$ del Mercosur, que tuvo decisivo impacto en el diseño y la construcción de políticas públicas diferenciadas para el sector, proponiendo un plan de trabajo en conjunto entre las instituciones gubernamentales (SAGPyA e INTA) y organizaciones de productores representativas de la agricultura familiar, plasmada en una agenda regional. De estas acciones y a través del intercambio, la articulación y el dialogo político, se sentaron las bases para la creación del Foro Nacional de la Agricultura Familiar, inaugurado en diciembre de 2005 y formalizado en marzo de 2006 por Resolución - SAGPyA N 132. (Lattuada et al., 2015). Estas acciones fueron algunas de las muchas tomadas por el Estado Nacional tendientes a formar una red de técnicos distribuidos en todas las regiones del país, con instrumentos para comprender la realidad campesina y herramientas para realizar diagnósticos participativos, interactuar y hacer propuestas (Soverna, 2004).

La Argentina transitó cuatro años de acciones territoriales focalizadas y segmentadas hacia el sector de la agricultura familiar, hasta que un hito histórico nos sitúa en lo que se podría llamar una segunda etapa de profundización, dada a partir del año 2008, en donde el conflicto del Gobierno con el sector agroexportador pampeano, tiene como resultado la creación a finales del 2009 del Ministerio de Agricultura Ganadería y Pesca de la Nación. En esta instancia, se integró a su estructura a la Secretaria de Agricultura Familiar y Desarrollo Territorial y se promueve la creación de la Unidad para el Cambio Rural (UCAR). De tal manera, se buscó centralizar la

\footnotetext{
${ }^{7}$ La Reunión Especializada de Agricultura Familiar del MERCOSUR (REAF) es un espacio de encuentro entre productores familiares, organizaciones e instituciones rurales de la región, funciona desde 2004 con el objetivo de generar un marco de políticas públicas regionales para la agricultura familiar.
} 
planificación, la ejecución, la evaluación y el seguimiento de todos los programas de desarrollo con financiamiento externo, facilitando y potenciando las condiciones para mejorar el diálogo y la coordinación de políticas Nación-Provincias sobre el desarrollo rural (Lattuada et. al., 2015). Con intención de ir forjando mejores condiciones institucionales que den como resultado la generación de capacidades políticas, convocando a la participación de todo el espectro de actores sociales, económicos y políticos, abordando participativamente los distintos niveles de competencia territorial (Lattuada y Nogueira, 2013).

Esta acción nos orienta en la transformación que comienza a transitar el Estado para fortalecer sus instituciones y organizaciones, dotándolas de capacidad para recabar información compleja, procesarla y posteriormente formular e implementar políticas públicas, construyendo un Estado con mayores capacidades internas, siendo las instituciones su columna vertebral (Mendiaz, 2004).

Las mencionadas políticas públicas se logran consolidar por la creciente visibilización de las pequeñas producciones a partir de la creación del Registro Nacional de la Agricultura Familiar ${ }^{8}$ (ReNAF) y el Monotributo Social Agropecuario, señalados por Craviotti (2013) como los dos hitos producto de este proceso de institucionalización de la problemática de la agricultura familiar en el aparato estatal. Ello permitió al Estado construir otros indicadores de interés para el sector como los socioeconómicos, ambientales, de sustentabilidad de la producción agropecuaria familiar y de los recursos naturales, los cuales brindaron una identificación genuina

\footnotetext{
${ }^{8}$ Este registro tiene como objetivo conocer cuántos son los agricultores familiares, cómo se distribuyen en el territorio, qué, cómo y cuánto producen, en qué situación están sus viviendas, de qué forma acceden a servicios de salud y educación, etc., permitiendo una mayor visualización territorial para implementar líneas de acción que apunten a resolver las necesidades reales de los productores familiares, con el objetivo de contar en forma oportuna y permanente con información fehaciente, confiable y actualizada, con datos cuantitativos y cualitativos sobre la estructura del sector de la agricultura familiar
} 
como tales, facilitando el acceso a las políticas que se implementen. Este avance en la consideración dentro de las políticas públicas del gobierno fue producto de la movilización a lo largo de los años a través de las diferentes agrupaciones y movimientos representativos de la agricultura familiar y del campesinado, dando consecuentemente una mayor institucionalidad y por ende una mayor fuerza de negociación para la implementación de políticas públicas (programas proyectos, instrumentos) destinadas al sector.

Por último, se podría mencionar a la Ley de reparación histórica de la agricultura familiar para la construcción de una nueva ruralidad en la argentina ${ }^{9}$ promovida desde la Secretaria de Agricultura Familiar y el Movimiento Campesino de Santiago del Estero (MOCASE), como una tercera etapa de profundización de políticas. Pero por ser sancionada pero no implementada, la nombraremos como un hito histórico concordando con lo expresado por Craviotti (2013), reconociéndole así a la agricultura familiar su condición de partícipe central de la estructura agropecuaria nacional, habitante y actor productivo del territorio rural, principal generador de empleo agropecuario, dinamizador de las economías locales, integrante de comunidades y tramas socio territoriales, y constituyente insoslayable del paisaje cultural de las regiones del país. Entendiendo que las diferencias y los desequilibrios territoriales en nuestro país y en la provincia no son producto de circunstancias espontáneas y neutras, sino que responden a una conformación históricamente construida, resulta indispensable abordar la Agricultura Familiar con un diseño socioeconómico y territorial equilibrado con el mundo urbano y generando condiciones más

${ }^{9} \mathrm{~N}^{\mathrm{o}}$ de Expediente 2840-D-2014. Trámite Parlamentario 032 (24/04/2014). Sumario: REPARACION HISTORICA DE LA AGRICULTURA FAMILIAR. REGIMEN. Firmantes: GIACCONE, CLAUDIA ALEJANDRA RAIMUNDI, CARLOS - GERVASONI, LAUTARO - MARCOPULOS, JUAN FERNANDO - CANELA, SUSANA MERCEDES - PASTORIZA, MIRTA AMELIANA - CARMONA, GUILLERMO RAMON - RUBIN, CARLOS GUSTAVO. Giro a Comisiones AGRICULTURA Y GANADERIA; FAMILIA, MUJER, NIÑEZ Y ADOLESCENCIA; PRESUPUESTO Y HACIENDA 
justas de desarrollo. Es indudable el rol que cumple este sector en nuestras provincias, el país y en la economía del MERCOSUR (Proyecto de Ley, Honorable Cámara de Diputados de la Nación).

Este último hito, cierra una década de reestructuración del estado, mediante políticas públicas para el abordaje de desarrollo territorial local, con vistas al empoderamiento de los sujetos de la agricultura familiar, mediante el acceso y la disponibilidad de información, recursos productivos y poder de negociación. Exponiendo la complejidad del concepto, construido a partir de significados relativos e históricos, pudiendo ser interpretados como un modelo, una política, un proceso o una meta de transformación de un país, un territorio o un grupo social específico. Esta complejidad pudo haber sido la que obstaculizó el alcance de los resultados esperados a través de la implementación de las políticas de desarrollo, no logrando generar un impacto sobre la disminución de la pobreza rural y el desarrollo de los territorios. Posiblemente por no contar con un alto grado de articulación interinstitucional, predeterminado por una política de desarrollo rural explicita y una coordinación de actores e instituciones gubernamentales y no gubernamentales, que no fue capaz de generar participación en los espacios de poder para la definición y la ejecución de políticas públicas y de las estructuras creadas para tal fin (Lattuada et al, 2015). Esto, Craviotti (2013) lo define como el "complejo interjuego de las instituciones, las estructuras y los actores sociales" (p. 8), y abordado desde Mançano Fernández (s/f, p 6) nos da la posibilidad de considerar su origen en "la disputa de los territorios", indicando que la convergencia de los distintos modelos de producción genera una competencia y tensión.

Lattauda et al. (2015) hace referencia a dos visiones o enfoques en cuanto a la política de desarrollo territorial local y a sus estrategias de intervención en la Argentina. Por un lado ubica a los programas de intervención con financiamiento internacional focalizados en los aspectos 
económicos productivos, contemplando que mediante una mejora de estos, los sujetos se fortalecen y se posicionan en el mercado y en la cadena de valor, y que posteriormente a este fortalecimiento se avanza en la esfera organizacional. Y por otra parte ubica a las organizaciones no gubernamentales de productores enfocadas centralmente en lo organizacional social y político. Para este autor, luego se pueden integrar las dos visiones, sin la ponderación de alguna, diciendo que los programas tienen que abordar con una mirada de desarrollo territorial y coordinación nacional, que posibilite el acceso y control de los recursos productivos, la generación de ingresos a partir del desarrollo productivo y el agregado de valor local, a la vez que el fortalecimiento de las organizaciones y redes posibiliten el acceso y la permanencia en mercados y cadenas de valor. Esta integración se plasma en el trabajo de Manzanal (2006) en donde plantea que una política de desarrollo rural-local se logra a partir de una democracia local participativa y organizada para la construcción de una nueva hegemonía para la equidad social y la redistribución del ingreso con sustentabilidad ambiental. Tal propuesta se lograría a través de una descentralización de funciones, decisiones, y recursos a los actores locales, un exhaustivo seguimiento y control del accionar publico acompañándolo de una aumento en la gestión y la autogestión por parte de las organizaciones locales en paralelo de una ampliación y una multiplicación de las articulaciones entre estas a nivel local y regional (Manzanal, 2006).

A lo largo de este capítulo se han recorrido tres décadas de transformaciones profundas en la estructura del estado para avanzar en políticas públicas para el desarrollo de las producciones familiares. Este progreso es el resultado de la movilización por parte de las organizaciones de productores para la visibilización de este sector y la ocupación de la agenda Estatal para el abordaje de sus problemáticas. Se generaron capacidades humanas y organizativas, tanto gubernamentales como no gubernamentales para que a partir de las experiencias acumuladas 
(García et al, 2008), se pudiesen plantear planes estratégicos profundizando los abordajes territoriales, como así también, los necesarios cambios técnicos-normativos y fiscales. Partiendo de la creencia que más allá de que el desarrollo rural en el país nace desde la necesidad de contrarrestar las externalidades del proyecto neoliberal, sin contar con una política y un plan estratégicos, nos encontramos ante la necesidad de atender los aspectos legislativos, normativos e impositivos para el abordaje de la compleja estructura burocrática estatal, poniendo especial atención a las consecuentes informalidades productivas causadas por esta, y considerándola como la probable principal causa de la exclusión de las pequeñas producciones de la esfera formal de producción. En este sentido Lattuada et al. (2015) describen que a pesar de contar con las estructuras, los contenidos y los procesos han sido poco fructíferos en general y que sus resultados son más débiles en la medida en que se accede a mayores niveles de responsabilidad política. Resulta interesante en esta línea, el aporte que realiza Manzanal (2006) al señalar que el modelo de la política democrática clientelística, promueve la participación de la población a través de proyectos diseñados en "forma participativa", que no hace más que condicionar a los destinatarios a pedir participativamente lo que el estado, y los programas, están dispuestos a otorgar, resultando las demandas de los beneficiarios, con escasas o nulas construcciones participativas genuinas. Esto nos lleva al análisis de distintos autores como Lattuada, Castignani y Manzanal que las políticas de los programas de desarrollo apuntan a una estandarización productiva empresarial como única salida de la agricultura familiar para su fortalecimiento y sostenibilidad, aplicados bajo los términos de eficiencia, mercado libre, competitividad y rentabilidad, construyendo un marco de relaciones de desigualdad y poder, y conllevando impactos sociales, culturales, ambientales y económicos. De tal manera, se estima trascendente y necesario reflexionar para que el rediseño institucional tenga como propósito fundamental la 
seguridad y soberanía alimentarias, con base en pequeños productores, en términos de equidad y sostenibilidad (Fletes Ocon et al., 2016), ya que mediante el modelo convencional se sigue expulsando población del aparato productivo, polarizando a la sociedad y aumentando la masa de marginados (Manzanal, 2006).

\section{Agricultura familiar y la informalidad como contexto en la producción primaria.}

El impacto de las políticas públicas de los noventa y la consecuente crisis que generó en los primeros años del siglo XXI, produjeron cambios importantes en las formas de organización de la economía, en el funcionamiento de los mercados laborales y en la reestructuración de la producción alimentaria (Craviotti, 2008). Este hecho da como resultado un incremento de la informalidad $^{10}$ en el empleo, en la producción y en la actividad económica (Carpio, 2007).

La agricultura familiar, no queda exenta del mercado ni de las normas de funcionamiento estatal, su grado de dependencia sobre el mercado de bienes y servicios es directamente proporcional a su condición de oferente de productos. Esta articulación, asimétrica, conduce a transferencias del sector de la agricultura familiar al resto de la economía, por ser subordinada no solo por la agricultura capitalista, sino también y no menos importante por el complejo industrial, entrando en juego su viabilidad (Fernández Equiza, s/f). Este intercambio de compra de bienes y servicios finales y venta de sus productos, en término de sus precios relativos, es sistemáticamente desfavorable (CEPAL, 1980). La exclusión atañe a personas que están fuera de una sociedad de la que, al mismo tiempo, forman necesariamente parte: intentan vivir o por lo menos sobrevivir en las condiciones de esa sociedad, movilizar recursos existentes y desarrollar estrategias

\footnotetext{
${ }^{10}$ Apoyándonos en el significado del concepto de producción informal de Carpio como aquella que realizan los que no se encuentran registrados y por ende, las actividades que llevan a cabo no se rigen por las leyes, reglamentos y normativas vigentes, siendo su forma de producción y comercialización por fuera de los circuitos formales. (Carpio, 2007).
} 
diversas. Estrictamente hablando están, no fuera de la sociedad, sino fuera de ciertos circuitos y prácticas y ya no son de la incumbencia de ciertas instituciones por lo mismo que incumben a otras (Granda Aguilar, 2008), requiriendo esto una valoración completamente diferente, por parte del estado y la sociedad, por su importancia en la configuración de los territorios y su fuerza de trabajo empleada (CEPAL, 1980). Es aquí donde podemos hacer una primera diferenciación entre lo formal y lo informal de los mecanismos que estructuran y limitan el comportamiento de la sociedad. Quedando representado lo formal en leyes y reglamentos, mientras que la representación de lo informal estaría basado en las costumbres, convenciones, y patrones de conducta autoimpuestos. Estos contratos entre los individuos institucionalizados están orientados a enfrentar las fallas del mercado, buscando una mayor simetría en el poder de negociación, el acceso a la información y la distribución de los riesgos.

Los recursos que poseen las familias dependen de las oportunidades provistas por el Estado, el mercado y la sociedad (Craviotti, 2008). Es entonces, más que esperable, que sin estas, y con mayor peso específico, la del Estado, la penetración del capital en sus distintas formas (complejo agroindustriales, concentración de la propiedad, megaempresas, desarrollo de innovaciones tecnológicas y de infraestructura básica, entre otros) genere una instancia de destrucción y por ende de desaparición de las explotaciones de menor escala y por consiguiente la del sector campesino (Paz y Gonzales, 2010). Esta función que debería tener el Estado para los pequeños productores tendría como fin generar mejores condiciones para el acceso a los mercados, promoviendo el protagonismo en las instituciones públicas y privadas para abordar los mercados informales y las cadenas de valor (Muñoz y Viaña, 2012). Sin esta injerencia los pequeños productores se vieron y se ven obligados a buscar alternativas institucionales, políticas y económicas en los intersticios del propio Estado, obteniendo como resultado no solo sustento 
de sus unidades productivas, sino que su desarrollo y fortalecimiento, estableciendo cierta autonomía y hegemonías basadas en redes sociales y de parentesco, sustituyendo en gran medida el rol Estatal (Tassi, 2012). Se origina así, una economía oculta dentro de la economía oficial, coexistiendo mercados formales e informales asociados y no reconocidos.

En este contexto no se conciben términos absolutos, sino que se admite el uso de términos relativos, asumiendo que toda actividad formal posee una cuota de informalidad y toda actividad informal posee un cierto margen de operación en la formalidad (Tokman, 2001). Inmersos en estas relatividades los pequeños productores van buscando su protección y mejoría, entrando y saliendo ante los posibles escenarios favorables y desfavorables, permitiendo cambiar rápidamente las estrategias de producción y comercialización (Tassi, 2012) que, inmersos en este modelo agroalimentario sostenido por empresas trasnacionales, no solo buscan mejorar su economía, sino el respeto y consolidación de pautas culturales, familiares, sociales, ecológicas y de arraigo (Pengue, 2005).

La acción o inacción por parte del Estado, De Soto (1987) la analiza bajo una mirada neoliberal, la que reinara en la década de los $90^{\prime}$, sosteniendo que el problema no es la economía informal, sino el Estado, por ser esta una respuesta popular espontánea y creativa ante la incapacidad de este para satisfacer las aspiraciones más elementales. En su trabajo, destaca que:

Existe una importante probabilidad de que, desde el punto de vista económico, en estas actividades la gente directamente involucrada así como la sociedad en general esté mejor si la ley nominalmente aplicable es violada que si es cumplida. En tal sentido podríamos decir que la informalidad se produce cuando el Derecho impone reglas que exceden el marco normativo socialmente aceptado, no ampara las expectativas, elecciones y 
preferencias de quien no puede cumplir tales reglas y el Estado no tiene la capacidad coercitiva suficiente (p. 12).

Este liberalismo expresado en De Soto plantea que la informalidad es de carácter netamente superestructural ya que los países de América Latina están en la etapa mercantilista, definida por un Estado que oprime a la iniciativa privada, la desalienta, la enfrenta abiertamente con el complejo sistema de normas y regulaciones que limitan o les impiden desplegar su capacidad y los obligan a operar ilegalmente violando las normativas existentes (De Soto, 1987). En la misma línea, pero tomando al mercado también como condicionante, podemos representar la informalidad como un intento de crear y fomentar circuitos económicos paralelos a los reconocidos por el Estado, regidos por códigos, prácticas y valores que no condicen con los intereses del estado y del mercado empresarial (Tassi, 2012).

Estos inadecuados marcos regulatorios originan y restringen la expansión productiva de las actividades informales, es una herencia colonial que implica altos costos por la estructura burocrática, transformándose en obstáculos para el desarrollo, desincentivando la inclusión a la producción formal (Tokman, 2011). Sobre este aspecto y con enfoque en los sistemas agroalimentarios, es relevante la creciente importancia en el sector rural de las normas y estándares privados que hoy regulan de manera determinante el funcionamiento de estos sistemas. Dichas pautas no solo inciden a nivel nacional sino que son impuestas a escala global por enormes empresas transnacionales. Imponiéndose las formulaciones y aplicaciones de los estándares privados de las empresas, de manera unilateral a los gobiernos nacionales, teniendo hoy mucha más importancia en estructurar las decisiones de los principales agentes económicos de la región, que casi cualquier norma pública dictada de conformidad con las leyes de cada país. Esto trae aparejado la ausencia de un sistema legal no discriminatorio; y la presencia de 
mecanismos de arbitrajes confiables y accesibles (Schetjam et al., 2004). Por ello, se requiere la adecuación del sistema normativo existente para que contemple las necesidades reales de los que no están en condiciones de cumplir, asumiendo que la factibilidad de la formalización depende en parte de la capacidad de crecimiento de la unidad productiva, y en mayor medida de la adecuación a los sistemas regulatorios (Tokman, 2011). Generaría esto, el incumplimiento de estas dinámicas económicas, de inserciones y retiros sucesivos de los mercados o de la pluriactividad. Este movimiento en la frontera de lo informal y lo formal les otorga un cierto margen de maniobra ante el intento de subordinación del mercado, a la vez que forma parte de las estrategias de subsistencia (Muñoz y Viaña, 2012).

Por otra parte, Carpio define y caracteriza las unidades de producción informales por la escasez de los recursos con que operan, que determina los bajos niveles tecnológicos y de productividad con que actúan (Carpio, 2007). El autor define por oposición a las actividades formales, resultando en la exclusión al acceso de los mercados y recursos productivos (Tokman, 2011). Carpio (2007) sostiene que:

Generalmente el tamaño y la escasez de recursos explican la mayoría de las limitaciones productivas de la empresa, los bajos ingresos que reciben y las deficientes condiciones de trabajo con que desarrollan sus actividades operando al margen de las normas legales existentes. Por una parte el escaso tamaño y la escasez de recursos determinan ciclos productivos orientados por las necesidades de subsistencia que muchas veces les impiden aprovechar las oportunidades del mercado para mejorar el ciclo productivo de su unidad productiva. Esa misma escasez determina la utilización de tecnologías productivas sencillas u obsoletas, con bienes de capital generalmente de segunda mano, con vida útil 
sostenida por reparaciones y ajustes que generan mayores costos de mantenimientos y menores rendimientos (p.14).

Es en este sentido que el autor se apoya en torno a la Teoría de la Dependencia para expresar que este condicionamiento en cuanto a tamaño y escases de recursos es el que limita las producciones de la "empresa", denominándola y centrándola como la corriente estructuralista de inspiración Marxista, la cual adjudica los problemas del subdesarrollo y la pobreza a las relaciones de subordinación y dependencia de las economías Latinoamericanas a las principales economías del sistema capitalista obradoras del "desarrollo capitalista" en la región. Afirma también, que la condición de informal remite a una combinación de factores entre la composición técnica del capital $^{11}$ y las relaciones de producción ${ }^{12}$ que determinan los niveles de productividad. Esos niveles fijan los límites entre la actividad económica formal y la informal a partir de la brecha de productividad que los separa. (Carpio, 2007). Admitiendo así, diferencias con la mirada neoliberal, pero tomándola en este trabajo también como factor determinante, adjudicándosele a la intervención del Estado, la responsabilidad de la existencia de actividades informales, como principal paralizador del libre desenvolvimiento para el crecimiento y el desarrollo de las unidades productivas. En el mismo sentido Soverna (2004) relaciona la dificultad de producir a los problemas estructurales de las pequeñas producciones, como la falta de tierra o de titulación, de capital, de escala (que traen aparejados los de organización), pero también problemas

\footnotetext{
${ }^{11}$ Según K. Marx, los capitales empleados en el proceso productivo podían dividirse en medios de producción empleados y en fuerza de trabajo necesaria para su empleo, recibiendo el nombre de composición orgánica la primera y composición técnica la segunda. Marx afirma que el proceso de acumulación del capital conduce a un incremento de la composición orgánica en detrimento de la técnica, lo que lleva consigo un aumento en la productividad del trabajo.

${ }^{12}$ Según K. Marx, es el conjunto de relaciones que se establecen entre los hombres como consecuencia de la producción o trabajo. En las relaciones de producción el marxismo distingue entre: Relaciones técnicas: entre el agente y el medio de producción y las Relaciones sociales: entre los agentes mismos.
} 
tecnológicos, de capital de explotación para adquirir insumos, de comercialización y de las condiciones de infraestructura.

Esta misma teoría marxista clásica es la que propone que la producción familiar, y en particular la de carácter mercantil simple, en lo que respecta a la utilización del trabajo y fuerza de trabajo (Murmis, 1991), entraría en un proceso de descomposición al avanzar el capitalismo. Sin embargo, coincidiendo con Nogueira (2013) podemos plantear que, la existencia actual de este tipo de producción, es una realidad propia del capitalismo hoy globalizado, al menos en algunos países.

Ante este escenario de potenciar lo rural, surge la necesidad de plantear un nuevo enfoque para el abordaje de las principales problemáticas de la agricultura familiar para la inclusión social. Entrando así en escena, la problemática de la informalidad productiva en las pequeñas producciones; ya que tienen un elevado grado de vulnerabilidad por su incapacidad de inserción en el mercado y la escasa dotación de recursos, agregando la vulnerabilidad social del productor y su familia por las condiciones de pobreza y los déficits de coberturas en salud, seguridad social y mucho menos en seguros contra accidentes o riesgos laborales (Carpio, 2007) los cuales implicarían gran parte de la sustentabilidad familiar (Tomassino, 2001).

Reconociendo que en el universo de la informalidad encontramos una población que maniobra dentro de ésta como estrategia de supervivencia sin posibilidad de integración a los circuitos de producción y comercialización hegemónicos, también es oportuno y recalcable que dentro de este universo se encuentran unidades productivas cuya posibilidad de crecimiento y desarrollo se encuentran ligadas a la incorporación a los circuitos formales (Tokman, 2001), por ser identificadas situaciones de pobreza que se superponen o convergen en tres ámbitos: la 
limitación de los recursos productivos, una inserción laboral precaria y el aislamiento geográfico en áreas marginales (Manzanal et al., 2010).

Del recorrido por estos autores se puede destacar una vez más, la necesidad de la intervención del Estado como garante del sostenimiento y desarrollo de las pequeñas unidades productivas en este nuevo escenario.

\section{Políticas públicas expresadas en marcos normativos - legislativos}

Este apartado tiene la intención de describir la importancia de la política pública en la construcción de un contexto propicio para promover la contención y el desarrollo de las unidades productivas familiares en el ámbito de lo local-territorial. Para ello se tomará como base el planteo de Martínez Nogueira (1995), al abordar el análisis de las políticas públicas por medio de la indagación de acciones y decisiones estatales, así como de los procesos en torno a ellas desencadenados y por ellas producidos, ya que las políticas públicas son "una noción que remite al estado, a sus articulaciones con la sociedad, a la administración pública y a sus actividades concretas, siendo comprensiones sociales relativamente compartidas" (p. 3). A la vez es importante considerar que la acción o la inacción por parte del Estado también se incluye en el concepto de la política pública (Zeller, 2007), en torno a lo que Oszlak y O’Donnell (como se citó en Zeller, 2007) denominan la "cuestión"13. De tal manera, se percibe en su implementación la generación de acciones y reacciones y por ende, impactos en el seno de la sociedad, en un momento histórico y situadas en un contexto determinado (Zeller, 2007). Por ello, aparece como indispensable la realización de un análisis de la política pública que resulte capaz de dilucidar las

\footnotetext{
${ }^{13}$ La cuestión es el tema en que la política pública busca incidir. Las condiciones del surgimiento de la cuestión y de las posturas adoptadas por los actores privados ante ella, conforman un complejo proceso social que da lugar a su surgimiento, tratamiento y posible resolución. El estudio de ese problema constituye un primer nivel de análisis de la política pública. (Oszlak y O’Donnell, 1984 en Zeller, 2007, p. 3).
} 
posibles consecuencias para los pequeños productores ante su formalización. Se intenta así, superar las tres acciones estatales tradicionalmente implícitas en su rol: ignorar, perseguir o blanquear, dando paso a una cuarta acción, la facilitación del pasaje de la informalidad a la formalidad (Tokman, 2001), para su contención y adecuación de las normativas que cobijarán al productor para el acceso a la formalidad y su posterior permanencia en ella, sin inconvenientes ni riesgos. Se entiende de esta manera que el Estado es quien debe poseer esta capacidad analítica contextual (Nogueira, 1995) para no incurrir en promocionar un eslogan, sin tener un conocimiento cierto sobre cómo afectará a la familia productora, ser visibilizada y posteriormente estandarizada bajo determinadas normas productivas. Por lo general, en las producciones familiares no se establecen relaciones laborales, y por su carácter de sobrevivencia, operan con niveles de productividad e ingresos bajos, quedando imposibilitados de hacer frente a obligaciones administrativas y tributarias (Tokman, 2001).

La capacidad Estatal se ve en las políticas públicas promocionadas, y es en este aspecto en donde se puede ver reflejada la facultad y suficiencia del Estado para articular con la sociedad, con sus instituciones y organizaciones (Mendiaz, 2004), llevando a cabo reformulaciones y reinterpretaciones dinámicas, y así llegar a la construcción de políticas públicas derivadas de profundos procesos de interacción (Martínez Nogueira, 1995). Es coincidente con lo planteado por Rofman (2005), en la necesidad de edificar una política económico-social que posea como principal factor mejorar los ingresos de las familias, su poder de negociación y la riqueza productiva de dichos actores sociales, pregonando desterrar la pobreza y la exclusión social que afectan a gran parte de este sector del campo argentino.

Esta necesidad deviene de lo que Cuadrado Roura (2006) califica como cambios institucionales, capaces de lograr objetivos que con la actual estructura estatal no sería factible. Podemos tomar 
que en nuestro país esto se inicia a partir del año 2003 que luego de la crisis política, económica y social vivida en el país en el año 2001, produciéndose una profunda transformación en la concepción del Estado, promoviendo su participación e intervención, dando comienzo a una concepción de la política pública bajo un "Nuevo Modelo en construcción, productivo/inclusivo, orientado principalmente a la economía real y al empleo, promoviendo la recuperación de los márgenes de autonomía del Estado con relación al mercado y a los organismos internacionales, diversificando y complementando la matriz productiva nacional” (García Delgado, 2010, p. 24). Acompañando estas concepciones las diferentes organizaciones sociales, campesinas, ambientalistas, partidos políticos y grupos de investigadores se pronuncian en contra del modelo productivo extractivo, visualizándose la convivencia de al menos dos modelos de gestión y producción agrícola, el modelo del agronegocio, basado en las exportaciones con visión empresarial capitalista a escala global, y el modelo de la agricultura familiar, emprendimientos que resisten o subyacen al margen del sistema (García et al., 2008). En el escenario descripto, se plantea además, la modificación de la concepción del desarrollo a través del cambio en la relación entre el estado y la sociedad (Feito, 2008), observándose a partir del 2003 y tomando mayor fuerza luego del año 2008, con la creación del Ministerio de Agricultura Ganadería y Pesca de la Nación, en donde se introducen nuevas capacidades administrativas y políticas acordes al cambio del paradigma político y del discurso oficial, que junto a la habilidad de generar la recepción de las demandas de la sociedad, lo dotan de fortaleza (Lattuada, 2011). Estas transformaciones de la concepción y del rol del Estado tienen su fundamento en un enfoque heterodoxo y neoinstitucionalista, donde el poder del Estado depende, no del grado de imposición de sus decisiones, sino fundamentalmente de sus características internas (Mendiaz, 
2004), de la fortaleza de sus instituciones, de su capacidad para recibir demandas de la sociedad y generar políticas públicas.

Esta nueva estructura alcanzada en el ámbito público, jerarquiza el desarrollo rural, logrando así una construcción institucional para articular horizontal y verticalmente la intervención -las capacidades políticas- que el nuevo Estado requiere en relación con los estados provinciales y municipales así como también con las organizaciones de la sociedad civil (Lattuada, 2011). Este nuevo espacio estratégico para el desarrollo, tiene como articulador entre el Estado nacional, en su rol de promotor del desarrollo, al Estado municipal como ejecutor. El mismo, que fuera impulsado con una lógica empresarial en la década neo-liberal, desconcentrando las responsabilidades desde el gobierno nacional hacia las administraciones sub nacionales, asumiendo un rol principal en la ejecución de políticas públicas, dada su capacidad de gerenciador local, actuando en la difusión y promoción de actividades agroindustriales en pos de una mayor transformación de materias primas en el ámbito territorial local, logrando instalar el concepto de Agregado de Valor, el cual recorrió una larga trayectoria hasta convertirse en una política estratégica para el Estado nacional ligada al crecimiento y desarrollo económico. Castellano (2014) amplia y complejiza este concepto abogando por la inclusión de la heterogeneidad de actores y sujetos que dan forma y sustancia al Sistema Agroalimentario Argentino, ponderando a quienes llevan adelante la producción. En tal sentido, aquellos sobre los cuales dicha iniciativa recae son los productores primarios y agroindustrias (micro, pequeñas y medianas, y con diferentes lógicas de organización social de la producción), por constituir la interface sobre la que se asienta la posibilidad de un mayor agregado de valor y su captación local en el territorio, favoreciendo así una redistribución de la renta generada en las tramas de las que participan y que usualmente son gobernadas por un núcleo reducido de empresas que 
imponen dinámicas propias de acumulación. Concibiendo lo que Strom Thaker (como se citó en Zeller, 2007) denomina "vulnerabilidad del estado"14, en donde la influencia del sector privado con grandes capacidades de inversión y lobby condicionan la formulación e implementación de determinadas políticas públicas. Este sector se configura en torno a organizaciones privadas del mundo rural, siendo muy heterogéneas en cuanto a su poder de incidencia en la política y a sus formas de acción, las que vinculadas a las actividades más dinámicas ejercen un mayor poder de negociación frente al Estado y en muchos casos ejercen un liderazgo que trasciende su ámbito sectorial. A pesar de sus limitaciones, si se crean los incentivos adecuados, estas organizaciones podrían jugar -y en algunos casos lo han hecho- un papel importante en la articulación de acuerdos funcionales al desarrollo territorial rural. Por su parte, las organizaciones que agrupan a micro y pequeños productores agropecuarios y rurales, han tenido una evolución positiva desde la época en que su papel se limitaba a la reivindicación ante el Estado.

Nuevamente apoyándonos en Zeller (2007) se asume como problema, para el estudio de las políticas públicas, los constantes cambios entre el ámbito público y privado, las modificaciones y estructuraciones entre las distintas áreas estatales competentes y las políticas implementadas, así como la intervención de los distintos niveles jurisdiccionales (nación, provincias, municipios). Si tomamos estas complejidades y realidades, fue imprescindible que la Agricultura Familiar logre su denominación como sujeto, el cual le permitiese participar en la "arena política"15, revistiendo

\footnotetext{
${ }^{14}$ Las Vulnerabilidades del Estado. Estructuralmente, la vulnerabilidad del Estado a la influencia del sector privado, está ligada a la dependencia del Estado a las inversiones de este sector. A menores niveles de crecimiento, se espera que el Estado sea más dependiente del nivel de las nuevas inversiones. Cuando el Estado tiene un amplio acceso a fuentes alternativas de capital que puede usar para fomentar el empleo y el crecimiento económico, las presiones del sector de negocios surten menor efecto, debido a que el Estado puede buscar apoyo en otra parte. (Strom Thaker, 1997 en Zeller, 2007, p.4).

${ }^{15} \mathrm{Si}$ entendemos al Estado como una relación social, el mismo constituye un escenario de negociación de compromisos en el que intervienen diversas fuerzas políticas o grupos sociales capaces de negociar en el ámbito
} 
un carácter esencial, pues es a partir del mismo, o más bien de las variables que intervienen en su consideración como tal que se constituye como un sujeto de política pública en un contexto. Esto significa, en algún punto, una novedad en la construcción de las políticas orientadas al medio rural en Argentina, ocupando un lugar en la "agenda"16 pública (Nogueira, 1995). Interesa reflexionar entonces sobre aquellas variables que definen al productor familiar ${ }^{17}$ hoy como un sujeto de políticas públicas $\mathrm{y}$, asimismo, las discusiones que aparecen en torno a las mismas que suponen una heterogeneidad vinculada a cuestiones territoriales, culturales y laborales, las cuales quedaron visibilizadas por los programas de intervención desde los años 1990 (Gras, 2006). Para alcanzar esta denominación de sujeto, previamente tiene que haber una identificación y una visibilización, que fue producto en la Argentina de la movilización a lo largo de los años de las diferentes agrupaciones y movimientos representativos de productores, especialmente la FoNAF $^{18}$ (Nogueira, 2013), con lógicas de acción diferenciadas de aquellas que tradicionalmente han representado a los sectores rurales. Además, tales organizaciones se encuentran en rigor, mucho más vinculadas a las economías regionales que a la región pampeana.

político y en el que cada sector social intenta imponer sus intereses. Este ámbito de negociación es denominado por diversos autores "arena política".(Zeller, 2007).

16 "Agenda" se refiere a aquellas cuestiones que demandan la atención de la ciudadanía y que se debaten en la esfera pública, contrastando interés, aspiraciones, percepciones y evaluaciones, y generando demandas sobre la acción estatal.

${ }^{17}$ Según Grass la categoría "productor familiar" refiere a un heterogéneo conjunto de productores que reconocen algunas características comunes: poseen cierta capacidad de acumulación, son propietarios de un capital productivo (tierra y/o capital fijo o circulante), en cuya reproducción adquiere importancia el trabajo del productor y /o de sus familiares. Es decir, titulares de explotaciones que se caracterizan por la interconexión entre la acumulación de capital y la reproducción y el bienestar de la unidad doméstica. (Gras 2006).

${ }_{18}$ Confluencia de más de 900 organizaciones que asocian a unas 180 mil familias de productores en todo el país, reunidos para consensuar y proponer alternativas de desarrollo rural con equidad e inclusión.

Organizaciones con historia de lucha en defensa de los intereses nacionales que al fin somos escuchados.

Un espacio formal de concertación legitimado por la SAGPyA (resolución 132/06) donde las organizaciones interactuamos con los funcionarios de las áreas competentes. Las organizaciones del Foro funcionamos con una Mesa Nacional ( 2 delegados por provincia y 2 de Pueblos Originarios), una Mesa Ejecutiva (2 delegados por región y 1 de Pueblos Originarios). http://www.fonaf.org.ar/index.php/78-destacadas/74-que-es-la-fonaf-2 
En ese marco de construcción inclusiva y productiva, la discusión se encuentra dominada por las nuevas formas de articulación entre el Estado y la sociedad civil, nutriéndose de la visión del problema según quienes los padecen (Neiman, 2010), y con visión de generar una plataforma en donde se pueda ejercer influencia sobre las normas establecidas, para así poder superar las limitaciones de la formalidad, teniendo voz y voto en cuanto a las fuerzas que condicionan y afectan las producciones formales e informales (Vorley et al., 2013).

Ante este cambio de visión, Sili (2010) proyecta esta nueva valorización e importancia de lo rural como eje de construcción y co-construcción con y entre sus actores diciendo que:

Más allá de la fuerte tradición político cultural argentina que históricamente miró al mundo rural como un espacio en donde obtener recursos para financiar a otros sectores sociales o productivos, es claro que también emerge en los últimos años un discurso nuevo por parte de sectores políticos, sindicales y de la población en general que considera a lo rural como un factor de equilibrio territorial y social para los países, como un factor de desarrollo y un espacio capaz de generar innovaciones. Las discusiones de las políticas agropecuarias giran en muchos países cada vez más en torno al mantenimiento de la estructura territorial y de la permanencia de la gente en el medio rural. Paralelamente, en el ámbito científico, social y político el discurso centrado en la productividad agropecuaria y los mercados, ha dejado espacios para la construcción de un nuevo discurso ruralista, preocupado por la valorización integral del patrimonio territorial rural, por el mantenimiento del tejido social, el medio ambiente, la calidad de los servicios y la diversificación productiva. Esto queda manifiesto a través de la puesta en marcha de programas de investigación y desarrollo con enfoques mucho más integrales. (p. 15). 
Es sobre este estado de situación que nos proponemos plantear el interrogante de cómo el Estado interviniendo en el cumplimento sobre las normativas de los sistemas de producción de los pequeños productores, garantizará competitividad por fuera de los mercados formales de esa persona, para permanecer en el tiempo y fortalecerse, porque desde ya que ningún individuo es informal, sino que sus actividades y acciones los son, y retomando la relatividad de los conceptos, es imposible realizar una división tácita entre lo formal y lo informal, dado el alto grado de dinamismo en las acciones. Este interrogante es abordado por De Soto (1987), en donde se pregunta, qué costo hay que asumir para gozar de la protección del derecho y como esto afecta el acceso o la permanencia en las diferentes actividades económicas.

Figura 2: esferas de lo formal y lo informal, sus relatividades y sus márgenes de operación compartida.

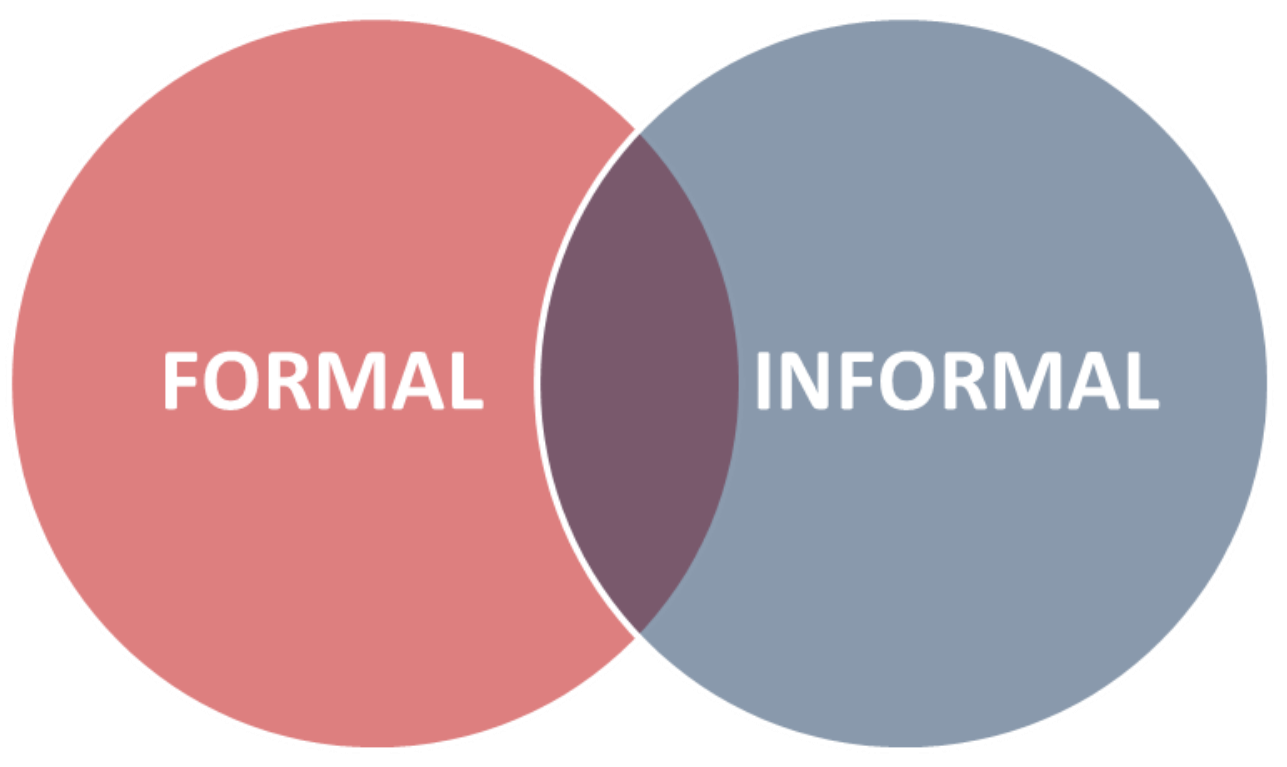

Fuente: Butler, L. Elaboración propia.

Son las políticas públicas las que marcan las dinámicas planteadas, abordadas para su análisis a partir de modelos y metodologías de análisis, asumiendo que la descripción de la política posee una importancia relevante, siendo necesario para ello realizar un análisis retrospectivo de las 
condiciones que le dieron origen, bajo un modelo de racionalidad plena, que con una información completa, capacidad de cómputo y poder suficiente para controlar los comportamientos y evitar los desvíos busque la optimización de la política (Nogueira, 1995). Y si a su vez, nos centramos en el análisis de los procesos para intentar comprender la arena política, mediante el juego de actores con sus diferentes intereses y poderes, nos podemos inclinar hacia el análisis a través del modelo institucional, en donde rigen para todos los actores determinadas reglas, normas y expectativas que estructuran los procesos de decisión y por consiguiente los resultados de la política pública, integrado en una matriz de gestión estatal que cuenta con sus diferentes estamentos, Nación, Provincia y Gobiernos locales, con sus respectivas competencias, en los escenarios del proceso y en las concepciones del juego, imponiendo valores en los contenidos tratados, movilizando recursos de poder, alianzas y modalidades operativas. (Nogueira, 1995). Inquietud generada debido a que la mayoría de las leyes y políticas tienen consecuencias importantes en la determinación del entorno competitivo de las pequeñas producciones (Vorley et al., 2013).

La definición o estructuración del problema es el punto de partida para la formulación de la política pública, por eso pasa a ser importante estudiar la definición del problema en determinado contexto histórico y su impacto en los procesos y consecuencias de los marcos normativos legales en nuestro tema específico, que es la producción en los establecimientos lecheros, indagando la informalidad como factor limitante a la hora de crear un proceso de manufactura, por ser condicionante en la inclusión o en la generación de una cadena de comercialización acorde a su producción (Castellano, 2014). Pasa a ser importante así tener en cuenta que su impacto social y espacial, su especificidad, su dimensión temporal y la relación entre el problema y otros, van a repercutir según el contexto social y político, siendo consecuente con el 
diagnóstico de la situación creada. Es central la identificación de las posiciones de los actores y participantes con respecto al proceso de formalización (la cuestión), determinando las particularidades, la evaluación del problema así como los recursos movilizados, sin perder de vista la percepción entre estos y las alternativas de resolución, que incidirán siempre sobre los resultados obtenidos. Reforzando lo antedicho, la disponibilidad y la utilización del conocimiento en su fase de formulación y de implementación resultan cruciales para el éxito o mínimamente para ofrecer viabilidad social, considerando una aceptación por parte de los posibles beneficiarios o destinatarios. De no ser así, la implementación será altamente compleja, los funcionarios reinterpretarán la directiva, adaptarán respuestas, generarían nuevos procedimientos que podrían suplantar los vacíos de la política. De esta manera, se otorgaría flexibilidad y adaptaciones de la norma según diferentes realidades (Nogueira, 1995), originando de acuerdo a los contextos políticos y sociales, voluntarismos en pro o en contra de la política.

Por último, en el ciclo de la política, resulta de sumo interés la evaluación de la misma, abriendo juicios sobre sus productos, resultados e impactos, que son analizados a través del logro de las metas (objetivación de la gestión ${ }^{19}$ ), la “transparencia y control social ${ }^{20}$ " y la continua revisión para su fortalecimiento y desarrollo (perfeccionamiento constante ${ }^{21}$ ).

\footnotetext{
${ }^{19}$ Objetivación de la gestión: permite determinar el logro de las metas, requiere la cuantificación de los productos y resultados y posibilita la medición de la eficiencia, eficacia y efectividad (Nogueira, 1995).

${ }^{20}$ Transparencia y control social: a la vez requisitos y condiciones de viabilidad del sistema democrático, éstos principios suponen la recuperación de la noción de lo "público" como la esfera de interés común, la posibilidad de afirmar un marco normativo para la convivencia y una subordinación de la acción del estado a la sociedad en su carácter de mandatario y gestión del bien común (Nogueira, 1995).

${ }^{21}$ Perfeccionamiento constante: la evaluación como esfuerzo sistemático debe brindar elementos para la revisión de las políticas y para encarar acciones de fortalecimiento y desarrollo de la gestión pública (Nogueira, 1995).
} 


\section{Objetivos}

\section{Objetivo general}

Contribuir al conocimiento de los modos y las características que asume el pasaje de la informalidad a la formalidad productiva en pequeñas producciones familiares tamberas maseras, atendiendo especialmente a las consecuencias y posibles riesgos que implica para su permanencia en dicha condición.

\section{Objetivos específicos}

- Identificar las normativas vigentes para la habilitación de establecimientos tamberos

- Identificar las normativas vigentes para la habilitación de establecimientos elaboradores de masa para mozzarella en la Provincia de Buenos Aires.

- Identificar y analizar el proceso de formalización.

- Identificar las principales dificultades y los posibles riesgos y de las pequeñas producciones familiares al entrar en el proceso de formalización.

- Identificar las principales dificultades y los posibles riesgos de las pequeñas producciones familiares al entrar en un circuito formal de producción.

- Analizar si la formalidad posibilita cierta sostenibilidad de las producciones familiares.

- Caracterizar la visión del pequeño productor frente a la formalidad productiva.

\section{Hipótesis}

Las pequeñas producciones familiares tamberas-maseras ponen en riesgo su permanencia al salir de la informalidad productiva debido a los altos costos que esta conlleva, a la dificultad para 
alcanzar y mantenerse bajo el cumplimiento de los requisitos higiénicos - sanitarios así como también de las cargas tributarias e impositivas.

\section{Metodología}

\section{Estrategia metodológica}

En este trabajo se planteó una metodología de investigación bajo la corriente cualitativa de investigación social, otorgándonos en palabras de Sampieri et al. (2006) profundidad en los datos, dispersión, riqueza interpretativa, contextualización del ambiente/entorno, detalles y experiencias únicas, posibilitándonos estudiar la expresión real de las dimensiones analizadas, aportándonos un punto de vista natural ${ }^{22}$ y holístico. Generando según Mason (como se citó en Vasilachis de Gialdino, 2006) datos flexibles y sensibles al contexto social, otorgando según Marshall y Rossman (como se citó en Vasilachis de Gialdino, 2006) un pragmatismo e interpretación basados en experiencias de los actores involucrados.

Es importante aclarar que el trabajo metodológico se realizó en un ambiente/entorno en donde el autor desenvuelve su labor diaria, de acompañamiento técnico y organizativo. Generando la posibilidad de inmersión en la vida cotidiana de los productores, a la valoración y descubrimiento de perspectivas sobre sus propios mundos, y potenciando la interacción con los participantes, tres bases fundamentales para llevar a cabo un proceso de investigación cualitativa. Siempre buscando no incidir en el control de los actores, ni influir sobre ellos, ni alterar, ni

\footnotetext{
${ }^{22}$ A lo que ese vocablo alude es a la circunstancia de que la investigadora y el investigador cualitativos se aproximan a situaciones, a acciones, a procesos, a acontecimientos reales, concretos, a interacciones espontáneas que, o bien son preexistentes, o bien, en parte tuvieron lugar, o bien se desarrollan durante su presencia en el campo y pueden continuar en su ausencia (Vasilachis de Gialdino, 2006).
} 
modificar el significado que le otorgan en sus vidas a sucesos, a procesos y a estructuras (Vasilachis de Gialdino, 2006).

Con la intención de contribuir al conocimiento de los modos y las características que asume el pasaje de la informalidad a la formalidad productiva en pequeñas producciones familiares tamberas maseras, atendiendo especialmente a las consecuencias y riesgos que implica dicho pasaje, Morse (como se citó en Vasilachis de Gialdino, 2006) nos arroja claridad al momento de describir que los resultados de la investigación cualitativa inspiran y guían a la práctica, pero a la vez dictan intervenciones y producen políticas sociales, a partir de la evaluación y posterior documentación de las transformaciones estructurales en la sociedad; transformaciones que se fueron conociendo en el transcurso del trabajo, con el deseo de entender los fenómenos sociales complejos (Yin, 2009). En este caso, han sido, los fenómenos ocasionados por la política pública para con las producciones tamberas.

El trabajo se realizó en base al estudio de casos múltiples (Yin, 2009), constituidos por un proceso social, una situación y un escenario específico, construido a partir de un recorte empírico y conceptual de la realidad de los pequeños productores tamberos en cuanto a su situación productiva en relación al control del Estado conformado como una problema de investigación, buscando la comprensión de las causalidades locales y su generalización analítica en términos conceptuales y empíricos (Neiman y Quaranta, 2006), dando la posibilidad de examinar, en la Cuenca del Abasto Sur, los efectos contemporáneos de la construcción y ejecución de las políticas públicas.

En la presente tesis se utilizó como técnica las entrevistas semiestructuradas y en profundidad, a la vez que se realizaron observaciones participantes de los eventos de estudio (Yin, 2009) para poder entender el fenómeno en la vida real en profundidad, dando compresión en las condiciones 
del contexto tal cual lo plantean Yin y Davis (como se citó en Yin, 2009). Esto fue facilitado por la íntima relación del tesista con los actores involucrados en el fenómeno bajo estudio, condición otorgada, como se mencionó anteriormente, por su relación laboral, lo que generó una menor reactividad $^{23}$ de estos en relación a otras técnicas de recolección. Tomando a la observación participante como la estrategia de presenciar de manera directa el fenómeno estudiado en su ambiente natural sin manipularlo (Marradi et al., 2007), se valora esta instancia a partir de que Kawulich (como se citó en Marradi et al., 2007) afirma que la realización de ésta conlleva el involucramiento del investigador a una variedad de actividades por un periodo prolongado de tiempo, facilitando una mejor comprensión del fenómeno. De tal manera, según Singleton se dota de profundidad y sentido a los resultados (como se citó en Marradi et al., 2007), a la vez que tomado como método directo de investigación según Valles (como se citó en Marradi et al., 2007), se posibilita acceder a las situaciones investigadas en toda su complejidad y en el momento en el que los acontecimientos ocurren, sin artificios ni simplificaciones.

El terreno, la Cuenca Lechera del Abasto Sur, fue abordado mediante una metodología que combinó una variedad de técnicas y fuentes que fueran capaces de reducir la complejidad del abordaje de la temática y de la región. Se analizaron datos cuantitativos aportados por organismos oficiales sobre la producción láctea Nacional, Provincial y por Cuenca, con recopilación de datos en censos nacionales agropecuarios, registros del SENASA, registros del Ministerio de Desarrollo Agrario así como de Gobiernos Locales, obteniendo información sobre su evolución y sus principales transformaciones. Dicha información, sin tener como objetivo su análisis exhaustivo, sino un análisis enfocado en la construcción de requisitos como política

\footnotetext{
${ }^{23}$ Tendencia de los actores a modificar sus comportamientos habituales como consecuencia de saberse observados (Marradi et al. 2007, p. 199)
} 
pública para la producción, proporcionó la posibilidad de hallar tambos-fabrica que se encuentren funcionando con habilitación, estabilizados y operando bajo las normativas vigentes en el circuito formal de producción y comercialización. Pero a la vez, se necesitó establecer contacto con familias que sean poseedoras de producciones no registradas, y esto fue posible gracias a la presencia en el territorio durante todo el periodo de realización del presente trabajo, que no solo proporcionó una óptica de análisis muy cercana a la realidad, sino que permitió la obtención de un panorama integral a través de las visiones y perspectivas sobre las relativas situaciones de "formalidad" e "informalidad" que confiere el estado, permitiendo conocer las representaciones sobre la actividad y las condiciones materiales en las que se desenvuelven.

Se realizaron técnicas de entrevistas semiestructuradas y en profundidad a productores tamberosmaseros, seleccionando aquellos que se encontraran produciendo de manera informal y tamberos-maseros que lo hacían dentro de la formalidad. El propósito fue obtener información de ambos, a efectos de construir un perfil del tipo de producción y las decisiones estratégicas de éstos para lograr su permanencia en la actividad. Las mismas se realizaron mediante el método de campo o estudio de campo por adoptar la participación y la observación, llevándose a cabo visitas a las familias productoras en sus establecimientos para la entrevista en profundidad.

Un desarrollo previo de proposiciones teóricas guió la recolección de información (Yin, 2009) bajo la misma técnica, de entrevistas en profundidad y semiestructuradas, a informantes claves y funcionarios de Organismos e Instituciones públicas Municipales, Provinciales y Nacionales, así como a proveedores de insumos e industriales, con la intención de asegurar cierta libertad para introducir preguntas adicionales, buscando precisar conceptos y obtener la mayor información sobre los temas deseados (Sampieri et al., 2006). Estos encuentros, así como los diálogos, estuvieron centrados en la práctica real, situados y bajo un proceso interactivo (Vasilachis de 
Gialdino, 2006) permitiendo entrevistar e interpelar ampliamente a funcionarios de las Direcciones de Producción locales, del Ministerio de Agroindustria de la Provincia de Buenos Aires con sus respectivas direcciones y al Ministerio de Agricultura, Ganadería y Pesca con sus entes descentralizados de control/fiscalización y ciencia/tecnología.

A su vez, se llevaron a cabo mediante la observación participante, registros de asambleas regionales de los partidos de Magdalena y Punta Indio en el año 2017, talleres Interinstitucionales sobre requisitos y normativas para la habilitación de tambo-fábrica durante los años 2015, 2016, 2017 y 2018 en los partidos de Brandsen, San Vicente, Cañuelas, La Plata, Magdalena, Punta Indio; y charlas técnicas en Exposiciones específicas de queso Mozzarella (Fiesta Provincial de la Mozzarella).

Complementando lo anteriormente señalado, se utilizaron materiales gráficos como revistas y noticias surgidas en los principales periódicos nacionales y portales de Internet sobre el sector lácteo y sobre la producción de masas pre maduradas de manera específica, así como documentos técnicos de referencia.

\section{Análisis de datos}

La metodología de investigación, se basó en el estudio de casos múltiples (Yin, 2009), con datos obtenidos de entrevistas semiestructuradas y en profundidad a:

- Productores tamberos-maseros: se seleccionaron aquellos que se encontraban produciendo de manera informal y tamberos-maseros que se encontraban funcionando dentro de la formalidad, obteniendo información de ambos, permitiendo construir un perfil de tipo de producción y conocer las decisiones estratégicas de éstos para la permanencia. 
- Sector privado: industrias, proveedores de insumos, médicos veterinarios e ingenieros agrónomos ligados a la actividad.

- Informantes Calificados: funcionarios, investigadores y técnicos, de nivel nacional, provincial y municipal.

Debido a que pusimos en juego diferentes actores del ámbito público, con capacidades de relatos y descripciones diferenciadas, en cuanto a lecturas, trayectorias y experiencias, los ejes de análisis con sus respectivas preguntas abarcaron a todos los entrevistados, con preguntas adaptadas y orientadas a cada caso. Teniendo en cuenta al entrevistado, se profundizó en el eje donde su aporte podía ser mayor. Es importante aclarar que en el eje donde se trabajó la trayectoria de las políticas públicas, los funcionarios políticos, o técnicos, aportaron una lectura y un análisis a partir de otro marco contextual e histórico.

A partir del material recolectado en las entrevistas, así como en las observaciones participantes, se procedió a desgrabar las primeras, siendo en algunos casos de forma total y en otros de forma parcial de acuerdo a la densidad de los argumentos de interés que contenían, con el objetivo de elaborar registros individuales que contengan las declaraciones centrales para el presente trabajo. Se realizó una pormenorizada transcripción de las observaciones participantes, para generar fichas a partir de las transcripciones nodales recolectadas. Resultado de estos también se elaboraron cuadros comparativos para ahondar en el análisis de temas de interés respecto a la informalidad en la producción tambera masera, así como lo referidos a la visión del estado sobre estas producciones y sus situaciones, para complejizar el análisis y las comparaciones entre estas dos miradas. 
Vale recordar que al estar en contacto continuo con los casos y actores estudiados así como con informantes calificados, las instancias de intercambio y de ámbitos para la observación participante fueron recurrentes a medida que se avanzaba en la escritura de la tesis.

El análisis de la entrevistas permitió obtener información tanto sobre la producción y comercialización del producto elaborado así como también sobre las distintas percepciones de los productores en cuanto al estado, sus cuestiones burocráticas, y sus exigencias.

A continuación se presentan los cuadros de las técnicas abordadas, correspondiendo la primera letra "E-entrevista", la segunda al actor entrevistado "P- productor", "I-industrial" y "Ffuncionario"; y la última letra para identificar funcionarios de nivel "N-Nacional", "PProvincial" y "M-Municipal", a la vez en este mismo grupo se ubican los "D.U.-Docentes Universitarios". En el caso de las Observaciones Participantes las dividimos en dos grandes grupos “O.p.a." para citar aquellas en donde se contaba con presencia de funcionarios ligados a las problemáticas tratadas y "O.p.b." para aquellas en las que éstos no se encontraban lo cual creaba un ambiente, para la toma de información, de confianza y distención.

Tabla 3: productores y familias productoras entrevistadas.

\begin{tabular}{|l|l|}
\hline \multirow{4}{*}{ Entrevistas } & \multicolumn{1}{|c|}{ Productores/Flias. Productoras } \\
\cline { 2 - 3 } & E.P.1. San Vicente \\
\cline { 2 - 3 } & E.P.3. Punta Indio \\
\cline { 2 - 3 } & E.P.4. Brandsen \\
\cline { 2 - 3 } & E.P.5. Cañuelas \\
\cline { 2 - 3 } & E.P.6. Magdalena. \\
\cline { 2 - 2 } & E.P.7. Punta Indio \\
\hline NOTA: E (entrevista) & P (Productora/r) 1-7(identificacion). \\
\hline
\end{tabular}


Tabla 4: agroindustrias lecheras entrevistadas.

\begin{tabular}{|c|l|}
\hline \multirow{2}{*}{ Entrevistas } & \multicolumn{1}{c|}{ Fabricas de Muzzarella } \\
\hline \multirow{2}{*}{} & E.I.1. Industria San Vicente. \\
\cline { 2 - 2 } & E.I.2. Industria Magdalena. \\
\hline
\end{tabular}

NOTA: E (entrevista) I (industria) 1-2(identificacion).

Figura 5: registros fotográficos instancias de trabajo en terreno, entrevistas en profundidad, establecimientos.

Productoras/es, tambos, instalaciones
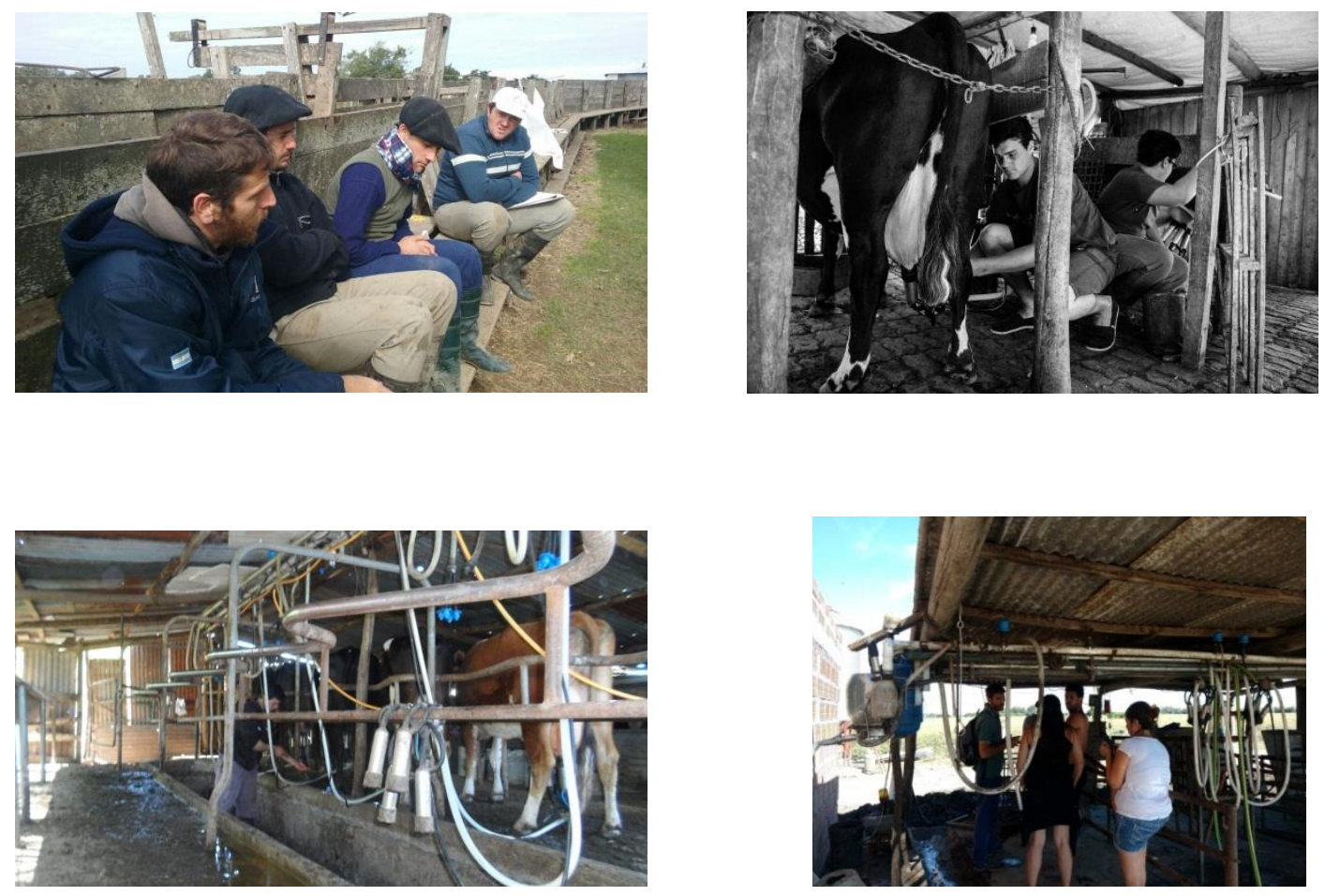

Nota: imagen propia, recolección de datos.

Tabla 6: funcionarios públicos Nacionales, Provinciales y Municipales, y docentes universitarios entrevistados.

\begin{tabular}{|l|l|l|l|l|}
\hline Funcionarios & Nacionales & Provinciales & Municipales & Universitarios \\
\hline
\end{tabular}




\begin{tabular}{|l|l|l|l|l|}
\hline \multirow{4}{*}{ Entrevistas } & E.F.N.1. Nación & E.F.P.1. Provincia & E.F.M.1. Municipal & E.D.U.1 \\
\cline { 2 - 5 } & & & & \\
\cline { 2 - 5 } & E.F.N.2. Nación & E.F.P.2. Provincia & E.F.M.2. Municipal & E.D.U.2 \\
\cline { 2 - 5 } & E.F.N.3. Nación & E.F.P.3.Provincia. & E.F.M.3. Municipal & E.D.U.3 \\
\cline { 2 - 5 } & E.F.N.4 Nación. & E.F.P.4. Provincia. & & \\
\cline { 2 - 5 } & & E.F.P.5. Provincia. & & \\
\hline
\end{tabular}

Tabla 7: Observaciones participantes realizadas.

\begin{tabular}{|c|c|c|}
\hline \multirow{5}{*}{$\begin{array}{l}\text { Observación } \\
\text { Participante }\end{array}$} & $\begin{array}{c}\text { Espacios con } \\
\text { Productores/Técnicos/Funcionarios }\end{array}$ & $\begin{array}{c}\text { Espacios con } \\
\text { Productores/Técnicos }\end{array}$ \\
\hline & $\begin{array}{l}\text { O.P.a.1. Asamblea Productores-Funcionarios } \\
\text { Municipales y Nacionales. Por interdicción de } \\
\text { maza para mozzarella. } 2017 \text {. }\end{array}$ & $\begin{array}{l}\text { O.P.b.1. Charla-Taller } \\
\text { innovaciones para tambos- } \\
\text { fabrica. San Vicente. } 2018 .\end{array}$ \\
\hline & $\begin{array}{l}\text { O.p.a.2. Jornada de Presentación de posibles } \\
\text { procesos de formalización. Brandsen. } 2017\end{array}$ & $\begin{array}{l}\text { O.P.b.2. Mesa de trabajo } \\
\text { realidad y experiencias de } \\
\text { tambos-fabrica. La Plata. } \\
\text { 8vas Jornada de Agricultura } \\
\text { Familiar. La Plata-UNLP. } \\
\text { 2018. }\end{array}$ \\
\hline & $\begin{array}{l}\text { O.p.a.3. Jornada de Presentación de posibles } \\
\text { procesos de formalización. San Vicente. } 2017\end{array}$ & $\begin{array}{l}\text { O.P.b.3. Foro por un Campo } \\
\text { Nacional y Popular. Estadio } \\
\text { Ferro. } 2019 .\end{array}$ \\
\hline & $\begin{array}{l}\text { O.p.a.4. Jornada de Presentación de posibles } \\
\text { procesos de formalización. Magdalena. } 2016 \text {. }\end{array}$ & $\begin{array}{l}\text { O.P.b.4. Reunión Grupo de } \\
\text { Productores Magdalena y } \\
\text { Punta Indio } 2015 .\end{array}$ \\
\hline
\end{tabular}

NOTA: O (observación) p (participante) a (espacio/ámbito) 1-4 (identificación).

Figura 8: registros fotográficos instancias de trabajo en terreno, observación participante. Asambleas, reuniones, jornadas. 

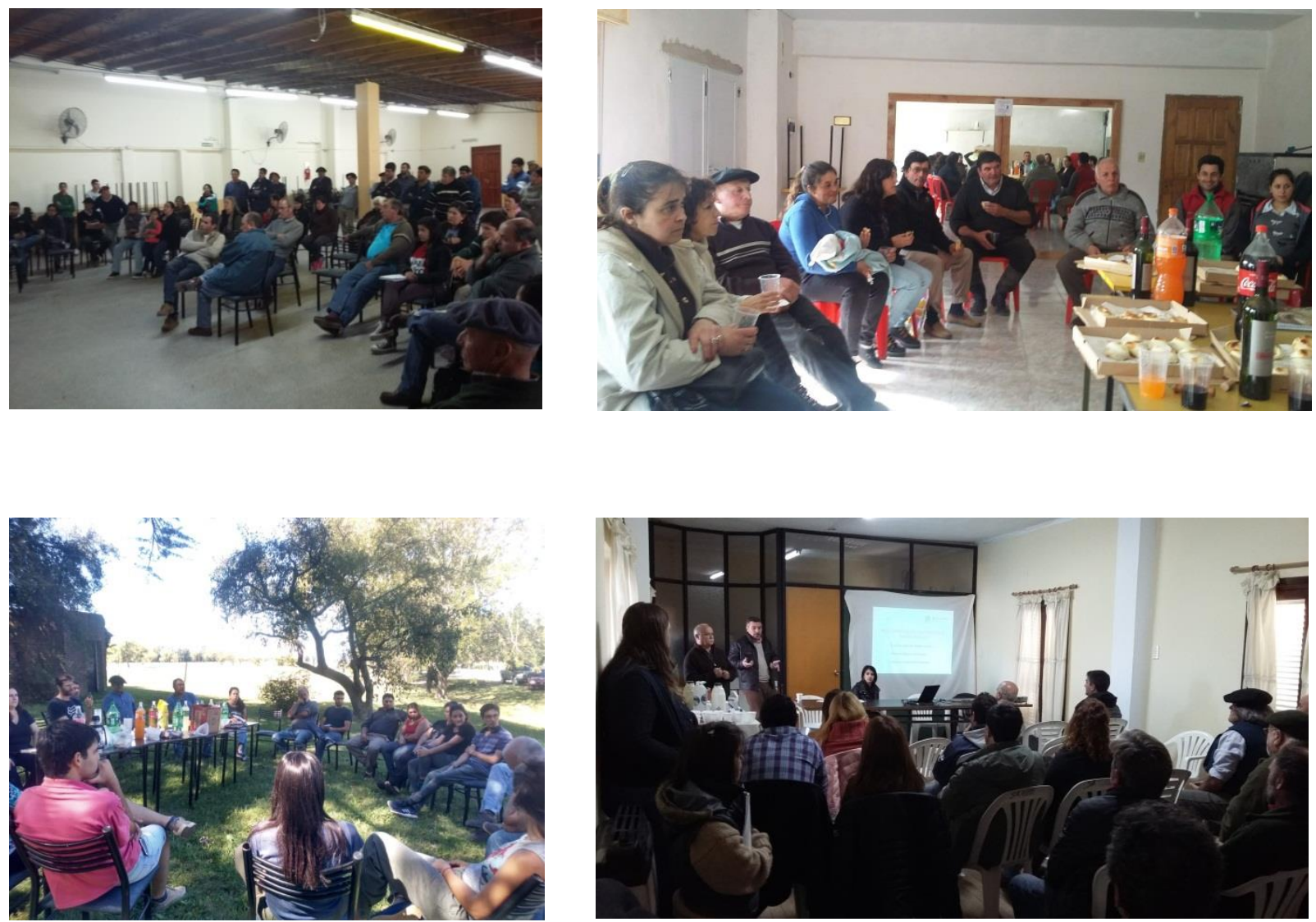

Nota: imagen propia, recoleccion de datos.

\section{Resultados}

\section{Territorio analizado}

Figura 9: Ubicación geográfica del territorio analizado. 


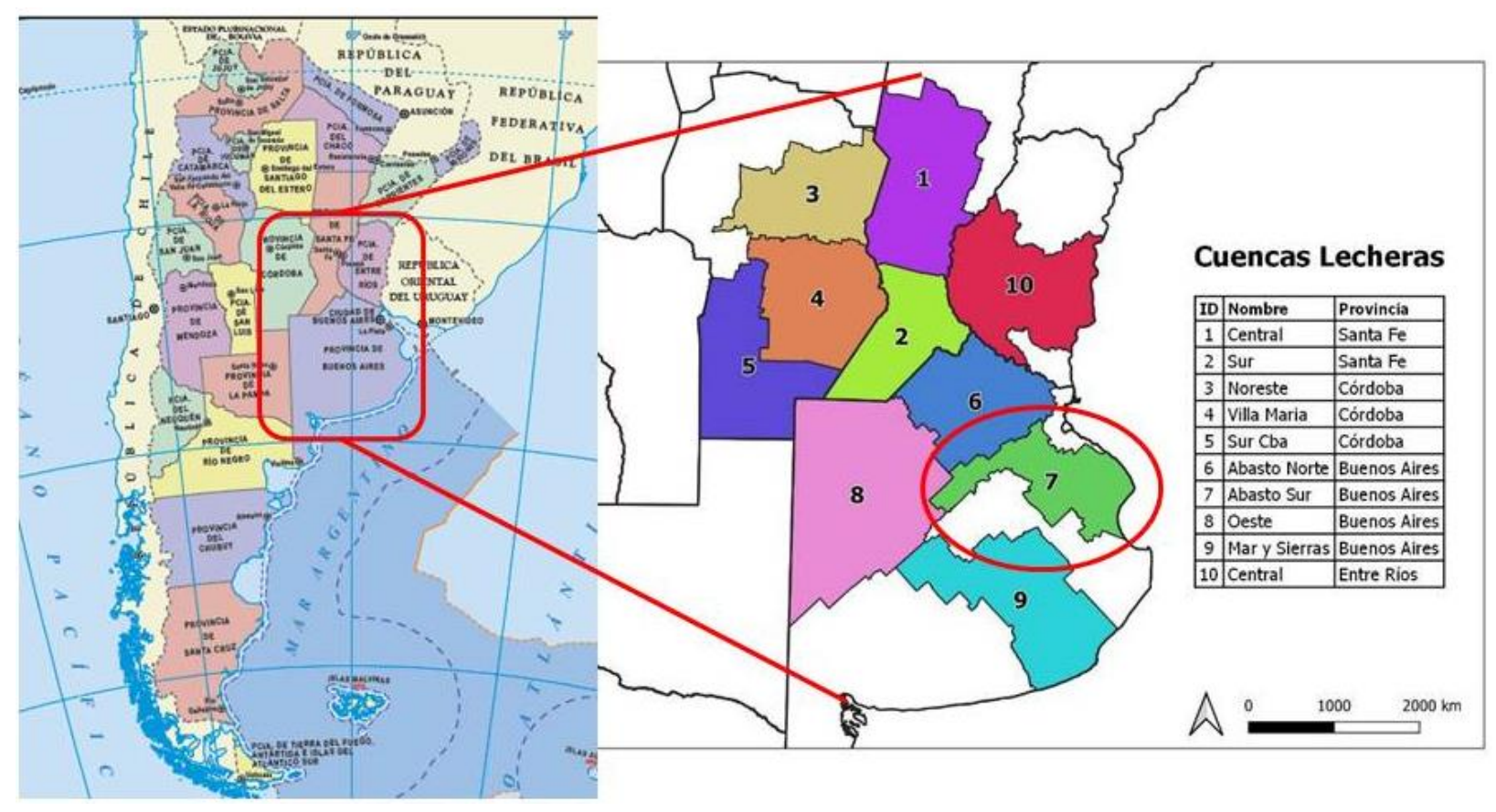

Fuente: elaboración propia a partir de datos y mapas de INTA (2020), IGN (Instituto Geografía Nacional).

Analizaremos a la Cuenca del Abasto Sur en relación con el Área Metropolitana de Buenos Aires (AMBA) y la Capital Federal, por contener no solo la mayor aglomeración poblacional del país con una gran heterogeneidad social, sino que también goza del principal polo industrial, financiero y comercial, y las sedes de los gobiernos de la Nación, de la Ciudad Autónoma de Buenos Aires y de la Provincia de Buenos Aires. Esto hace que por un lado, la masa premadurada para mozzarella, producto obtenido en la unidad tambo fábrica analizada, goce de una demanda firme y constante, con una comercialización dinámica, responsable de un activo circulante que permite el inmediato e indispensable retorno de dinero en efectivo, posibilitando el consumo, los gastos y los costos de la familia y de la producción, al respecto un productor decía "toda la masa que elaboro la vendo, hay veces que vienen de otros partidos a buscar masa, se la llevan toda, y todas las semanas me entra algo de plata" (E.P.4). Este efectivo operado en la instancia de comercialización primaria, le otorga al productor un cierto grado de libertad para 
maniobrar en los canales informales y fundamentalmente le da la posibilidad de transitar por fuera del sistema tributario e impositivo, así lo expresaba un productor "toda la plata que nos entra cuando vendemos se nos va en los gastos de la familia y comida para los animales, si tuviéramos que pagar los impuestos, no sé si llegaríamos" (E.P.4).

La relación con la Región Metropolitana de Buenos Aires es tan íntima que su tercera corona históricamente formó parte de la región del abasto, donde las producciones adquieren características propias, encontrando casos donde los animales pastorean en espacios públicos, en los márgenes de rutas y caminos vecinales, visibilizando uno de los principales problemas de la producción en este territorio, las limitaciones al acceso de la tierra (INTA, 2012). Esta corona comparte con la Cuenca los partidos de Brandsen, Cañuelas, General Rodríguez, Marcos Paz y San Vicente. A la vez, si contemplamos una cuarta corona ubicada entre la R.P. $N^{0} 6$ y la R.P. No 41, también comparten los partidos de General Las Heras, y Magdalena. Asi lo epresaba una productora, “...cuando era chica y mi papa hacia tambo todo esto era campo, ahora esta todo poblado"(E.P.1).

Figura 10: Ubicación de A.M.B.A. en Provincia de Buenos Aires, sus coronas urbanas y red vial 


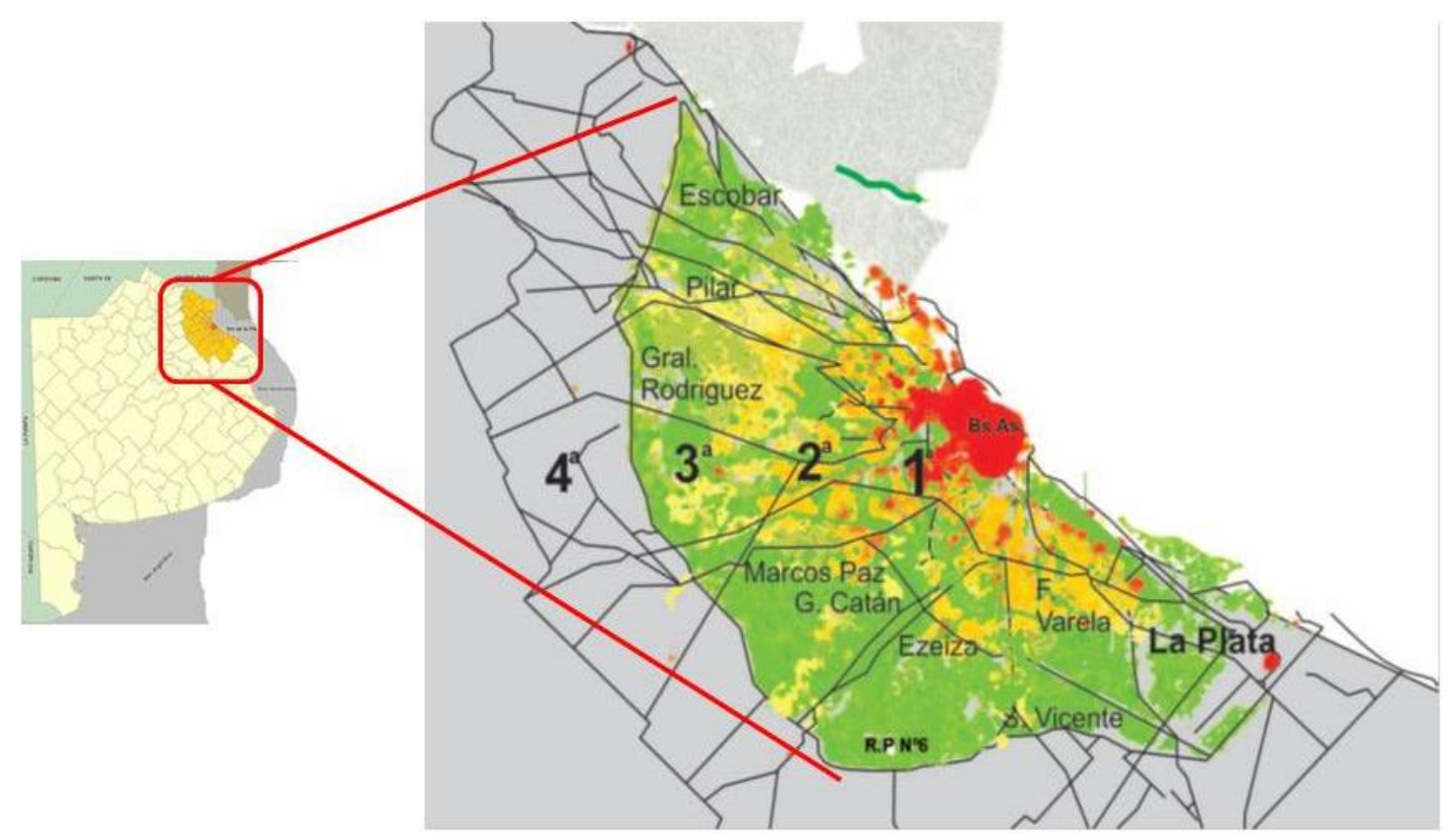

Fuente: Subsecretaría de Urbanismo de la Provincia. de Buenos Aires (2007).

\section{Transformaciones de la actividad lechera en la cuenca del Abasto Sur}

Al igual que en la trama láctea nacional, los productores lecheros de la Cuenca del Abasto Sur vivieron en los últimos 30 años un avance continuo de la tecnología tanto a nivel productivo como manufacturero, imprimiéndole una complejidad creciente y la necesidad de un aprendizaje continuo para la aplicación de procesos (Castignani, 2011). Esta nueva relación, impulsada desde la industria, le exigió a las unidades productivas tamberas un aumento de productividad, a través de la incorporación de paquetes tecnológicos que se transformaron en vehículos necesarios para transitar la sustentabilidad de la unidad productiva; generando que la adopción o no de tecnologías diera origen a dos tipos de tambos, los integrados y los no integrados al circuito mayor. En el caso de aquellos que no lograron ingresar al circuito mayor, pueden tomar dos caminos posibles, la integración a circuitos menores de escala local o la desaparición (Barros, 1999). A la vez, y sobre la misma línea de análisis, se puede citar el trabajo de Posada (1995) en 
donde plantea que el circuito de innovación tecnológica originó un proceso de diferenciación social del sector, consolidado en primer orden por la selección de tambos potenciales para el ofrecimiento y la adopción de las tecnologías propuestas y en segundo orden por un conjunto de tambos que no contaban con la capacidad para responder a este estímulo. Esto lo podemos ver plasmado en una entrevista en donde un productor mencionaba que:

Antes venían a llevar la leche, teníamos una empresa que nos compraba toda la leche, después cerró y ya no le pudimos volver a vender a la Serenísima ni a ninguno....nos pedían cosas que nunca pudimos llegar comprar y poner y también porque producíamos poco. (E.P.2).

Es aquí donde comienza un proceso de marginalización, que Pucciarelli (1993) lo describe como el reconocimiento por parte de los productores, desde un espectro económico y cultural, de la imposibilidad de adecuarse a las nuevas exigencias técnicas y económicas de los emergentes esquemas de producción.

Estos cambios tecnológicos, en los sistemas productivos, modificó las relaciones de producción, perdiendo el tambero el control del sistema productivo, lo que generó por un lado la desaparición de unidades productivas, por la particularidad de la práctica tambera que implica saberes específicos y acumulables en el tiempo y que nos orientan sobre la magnitud y la profundidad de los cambios (Fábregas y Perez Frattini, 2009), y por el otro, la aparición de los que lograban sostenerse a partir de la generación de estrategias que posibilitaran la permanencia y sostenibilidad de sus explotaciones familiares, elaborando productos con escaso valor agregado como a través de la manufacturación de la leche para transformarla en "masa" destinada a la elaboración de mozzarella en la industria quesera. También reorientaron su estrategia de comercialización a través de la inserción a circuitos alternativos (Barros et al., 2005), 
sobreviviendo por comercializar su producción en circuitos marginales, operando mayoritariamente fuera del control estatal, de alcance local o regional. Esta reorientación se vio en varios casos; viéndolo expresado en el relato del productor al cual se le había imposibilitado la comercialización de leche fluida “...desde el año 1999-2000 que empezamos a hacer masa para mozzarella, y desde ahí no dejamos más..." (EP: 2).

Figura 11: Evolución de los sistemas de producción láctea en Argentina.

\begin{tabular}{rcccccc}
\hline \multicolumn{1}{c}{ Año } & Tambos & Vacas & Mill Lts & VT/Tambo & Lts/VT/año & Lts/Tbo/d \\
\hline 1985 & 32.459 & 2.011 .140 & 5.962 & 62 & 2.964 & 503 \\
1990 & 27.489 & 2.009 .286 & 6.093 & 73 & 3.032 & 607 \\
1995 & 21.270 & 2.007 .501 & 8.507 & 94 & 4.238 & 1.096 \\
2000 & 16.458 & 2.005 .716 & 9.817 & 122 & 4.894 & 1.634 \\
2005 & 12.611 & 1.843 .847 & 9.493 & 146 & 5.148 & 2.062 \\
2010 & 11.576 & 1.749 .010 & 10.308 & 151 & 5.894 & 2.440 \\
2015 & 11.666 & 1.770 .056 & 12.061 & 152 & 6.814 & 2.832 \\
$2020^{\mathrm{e}}$ & 9.409 & 1.579 .841 & 10.734 & 168 & 6.795 & 3.126 \\
$2025^{\circ}$ & 9.084 & 1.619 .734 & 11.852 & 178 & 7.317 & 3.575 \\
\hline
\end{tabular}

Fuente: Ministerio de Agricultura ganadería y pesca (2017). www.dayrilando.com

De esto se desprende lo que Bisang (2008) caracteriza como aumento de la producción de leche en un contexto de concentración de la propiedad, con una sustantiva mejora tecnológica, la reducción del número de tambos y el incremento de la escala media de producción. Pudiéndose ver reflejado en un trabajo de Alvarez y Láuria (2013), donde afirman que de los 30.141 tambos existentes en el país en la década del '80, en el año 2003 sólo quedaban 13.000, en el año 2012 sumaba poco más de 11.000 y el trabajo realizado por el Ministerio de Agricultura Ganadería y Pesca (2019) arroja que el numero descendió a 8.368 tambos. Estos números finales fueron el resultado de la estrategia para permanecer en el sector, basada en un aumento de escala de los 
tambos remanentes, lo que explica que en dicho lapso el tambo medio pasó de 66 vacas totales y 544 litros por día, a 163 vacas totales y 2.827 litros por día.

En este contexto Nacional, la Cuenca del Abasto, sufre una transformación y pasa de caracterizarse por el afincamiento de numerosos tambos que abastecían a la gran urbe, a ser parte de un contexto dinámico y hostil para el productor agropecuario, que actúa y pone en juego su competitividad (Castignani, 2009) en un mundo de negocios con un entorno altamente competitivo, innovativo y cambiante.

Es aquí donde se expresa el poder ejercido por los intereses de las empresas transnacionales o del capital concentrado en la construcción de los marcos normativos implementados por el Estado en detrimento de las acotadas economías de los pequeños productores:

Hubo un cambio de paradigma del sistema de producción y los que están quedando, son los potenciales, los agroexportadores están trabajando bien, y lo que está quedando es un grupo, un 30-40 \% de tambos que están por fuera del sistema, que no pueden sostener la producción, la parte financiera, la parte precios, la parte comercial, que están afuera, que están en el mercado negro o gris de la comercialización de la leche. (E.F.N.1).

\section{Aspectos Institucionales, el Estado y su papel normativo en la elaboración de masa para mozzarella.}

\section{Higiénico Sanitario Nacional:}

La actividad láctea cuenta con una gran cantidad de instituciones privadas así como dependencias del Estado encargadas de regularla desde el punto de vista sanitario, comercial y

fiscal, y desde el punto de vista de desarrollo innovativo y la vinculación con la representatividad de los diversos intereses sectoriales. 
Durante la época de realización del presente estudio las acciones y políticas lecheras estuvieron regidas bajo la órbita de la SAGPyA (Secretaria de Agricultura Ganadería y Pesca de la Nación), que posteriormente al conflicto en el 2008 por la Resolución $\mathrm{N}^{\circ}$ 125, que imponía retenciones a las exportaciones de granos, pasa a constituirse como Ministerio de Agricultura, Ganadería y Pesca. Dentro de estas variantes de una misma estructura pública agropecuaria, se nuclearon las diferentes instituciones y organismos relacionados con el control y desarrollo agropecuario, encargados del cumplimiento de las normas relacionadas con la sanidad animal y con las de higiene en la producción primaria, salubridad y seguridad en las producciones industriales, de jurisdicción de corte nacional, delegando las funciones de poder de policía en los Ministerios o Secretarías que entienden de los temas a nivel provincial.

En particular el caso de la provincia de Buenos Aires, acorde con su desarrollo de producciones primarias y de industrias lácteas, posee un organigrama específico para las áreas de Lechería, encargadas de diseñar y ejecutar políticas a nivel provincial, por medio del diseño de mecanismos institucionales de coordinación (mesas sectoriales). Al existir estas áreas provinciales suelen encontrarse superposiciones en cuanto a lo normativo Nacional en determinadas actividades de control, lo que quita claridad, eficacia y eficiencia al sistema, así lo expresaba un funcionario provincial “...las provincias reservan para si las facultades que no delegan a la nación, es el principio básico del federalismo. Que después sea respetado o no es fruto de una mala política, pero es eso..." (EFP: 3). Esta superposición de incumbencias por parte de las instituciones públicas ronda en torno al dictado de legislaciones, controles y evaluaciones que afectan la eficiencia de las intervenciones económicas, normativas sanitarias, higiénicas y de inocuidad de los productos lácteos, haciendo referencia un entrevistado a que 
“...sobre una norma que el estado nacional dicte o determine, generar otra norma igual o más exigente que la que el estado nacional te sacó" (EFP.2).

No es intención del presente trabajo abordar con exhaustivo detalle las regulaciones, normativas y presiones fiscales que deben cumplir los productores, pero si hacer un recorrido por los compromisos a los que tiene que responder cualquier persona física o jurídica que quiera embarcarse en la producción de masa para mozzarella en la provincia de Buenos Aires.

Comenzando con el recorrido para el proceso de formalización de un tambo-fábrica encontramos obligaciones Nacionales a las que el productor se tiene que atener. Esto comienza en la unidad tambo (sala de ordeñe), producción primaria, en la cual se obtiene la materia prima, cuyas reglamentaciones igualan a las de un tambo convencional, ya que el tambo - fabrica está bajo la denominación de producción primaria.

La primera reglamentación que surge es la resolución $N^{\circ}$ 302/2012 que mediante disposición del Ministerio Nacional se crea el Registro Único de Operadores de la Cadena Agroalimentaria (R.U.C.A) alcanzando a personas físicas y/o jurídicas que intervengan en el comercio y/o industrialización de las cadenas agroalimentarias de los mercados lácteos, sus productos, subproductos y/o derivados. Teniendo el objetivo de "coordinar y controlar la operatoria referida a la matriculación y fiscalización de las personas físicas y jurídicas que intervengan en el comercio y la industrialización de las distintas cadenas agroalimentarias...”. (Boletín oficial).

A su vez, buscando transparencia y ordenamiento, en palabras de un funcionario Provincial, se crea por medio de Resolución Ministerial N²29/2016 el Sistema Integrado de Gestión de la 
Lechería Argentina $^{24}$ (SIGLeA), poniendo en marcha una plataforma de intercambio de información entre todos los eslabones de la cadena. Con el objetivo de simplificar la transmisión de datos dentro del sector para lograr una base de datos única, creando una plataforma donde confluya toda la información de la cadena; vinculando las bases de datos de AFIP y el SENASA, logrando así simplificar el intercambio de información entre los productores y las industrias con el Estado exponía sobre el tema el entonces Director Nacional de Producción Lechera del Ministerio de Agroindustria Sebastián Alconada (Revista Infortambo, Agosto 2017). En el mismo sentido, en cuanto al control productivo y comercial, el Estado cuenta con tres bases principales de datos: AFIP, SENASA y MINAGRO que, mediante los sistemas integrados, anteriormente mencionados, se fiscalizan la compra de leche, productos y derivados a través de la Liquidación Única Mensual Electrónica (LUME), entre industrias, tambos propios y masa para mozzarella. Este sistema deriva de la simplificación electrónica del Sistema de Liquidación Única, Mensual, Obligatoria y Universal que busca transparentar la cadena láctea. Cabe mencionar la obligatoriedad por parte de los privados del cumplimiento de las diferentes instancias de control y seguimiento, peligrando en caso de no cumplimiento la sanción de multas monetarias y/o clausuras.

En cuanto al control y fiscalización higiénico sanitario federal, su encargado, el Servicio Nacional de Sanidad y Calidad Agroalimentaria (SENASA) genera la información y la sistematiza como resultado de sus diferentes funciones e injerencias en los establecimientos lecheros. Dicho organismo es de los primeros eslabones burocráticos para poder iniciar una formalización en una producción lechera, ya que lo primero que se le exige al productor de manera obligatoria y gratuita por Resolución 423/2014 es generar un Registro Nacional

\footnotetext{
${ }^{24}$ https://www.agroindustria.gob.ar/sitio/areas/siglea/index.php
} 
Sanitario de Productores Agropecuarios (RENSPA). Este registro cuenta de un código constituido por 12 caracteres codificados, estableciendo la asociación de cada productor agropecuario con el campo donde realiza su actividad. Contiene datos del establecimiento, del productor, de la actividad que allí se realiza y de los animales que posee. El objetivo del RENSPA es fortalecer el control sanitario, a través de la obtención de información imprescindible para el planeamiento epidemiológico y rastreabilidad de hacienda partiendo del conocimiento y la identificación del productor como responsable sanitario de una explotación ganadera o de los animales que posea, el conocimiento de los tipos y características de la explotación y del lugar donde se encuentra. A su vez y acompañando la registración sanitaria, el SENASA genera una Clave Única de Identificación Ganadera (CUIG), a través de la resolución SENASA 754/2006, que consiste en un número abreviado del RENSPA (cinco dígitos) asociando al productor y al establecimiento con el animal (página oficial SENASA ${ }^{25}$ ). Como última función en torno a la producción lechera el servicio controla y monitorea el movimiento de animales entre los diferentes establecimientos. Lo hace a través del Documento de Traslado Electrónico (DTe), mediante resolución del SENASA №356/2008, con el objetivo de facilitar la rastreabilidad para el control epidemiológico de enfermedades (Carletti, 2015) consideradas un peligro para el status sanitario federal y que forman parte de Programas de Control y Erradicación, que a partir de las Resoluciones 128/2012 (TBC) y la 150/2002 (Brucelosis), actualmente derogada pero con el mismo fin por la Res. SENASA N 67/2019, se exige a los establecimientos lecheros realizar acciones sanitarias para obtener rodeos libres de dichas enfermedades.

\footnotetext{
${ }^{25}$ https://www.argentina.gob.ar/senasa
} 
Asimismo a nivel Nacional se cuenta con el Instituto Nacional de Alimentos (INAL) que se encarga del Control y Fiscalización Higiénico, Sanitario y de Inocuidad de todos los productos alimenticios elaborados en el país. Este Instituto se rige a partir del CODEX, el Código Alimentario Argentino ${ }^{26}$ (CAA) aprobado por Decreto 141/1953, el cual contiene las disposiciones higiénico-sanitarias, bromatológicas y de identificación de toda persona física, firma comercial o establecimiento elaborador de alimentos. Este CODEX se encuentra en permanente actualización, y es en el año 2006 que dispone incorporar en su Artículo 618 bis (Resolución Conjunta SPRyRS y SAGPyA N ${ }^{\circ} 33 / 2006$ y $\left.N^{\circ} 563 / 2006\right)^{27}$ que nombra las especificaciones y características de la masa para mozzarella a la vez que plasma las buenas prácticas de manufactura para la elaboración de ésta. Dicha incorporación es de suma importancia ya que cualquier producto final o intermedio que no figure en el código no podrá ser producido y por consiguiente comercializado por ser tratado como un producto ilícito, al respecto un funcionario expresa:

El código lo que vendría a hacer es englobar bajo un mismo estatus a todos los establecimientos y productos, vendría a unificar. Digamos la adhesión al código...las provincias le dan la potestad a la nación, es un control de la estructura nacional, te estoy hablando del pacto federal, cada provincia, como federalismo, tenía la potestad de su control, cuando se genera el estado nacional, todas las provincias delega al estado nacional, y después el estado nacional les vuelve a delegar a las provincias. (EFP: 3).

\footnotetext{
${ }^{26}$ https://www.argentina.gob.ar/anmat/codigoalimentario

27 Resolución del ex Ministerio de Salud y Acción Social № 435/97 se incorporaron al Código Alimentario Argentino las Resoluciones GMC N ${ }^{\circ}$ 29/96, 30/96, 31/96, 32/96, 34/96 y $42 / 96$ referidas a Reglamentos Técnicos de Identidad y Calidad en relación con Queso Pategrás Sándwich, Queso Tandil, Queso Tilsit, Queso Tybo y Masa para elaborar Queso Mozzarella.
} 
Resulta necesario aclarar que adicionalmente a las regulaciones nacionales, existe un conjunto de Resoluciones Mercosur que engloban los aspectos sanitarios y de calidad de la leche, y que son resultado de los procesos de armonización de las normativas de los países miembros, en donde a partir de la Resolución No 34/96 MERCOSUR/GMC/RES, lo ubica por encima de cualquier norma Nacional ${ }^{28}$, puntualizado por un funcionario provincial:

En la reforma de la constitución de los 90' se establece que los pactos internacionales tienen jerarquía superior a las leyes. Con lo cual si vos en temas sanitarios o de alimentos firmaste, dentro del tratado del Mercosur, adheriste expresamente a un pacto, lo internalizaste por los mecanismos legales de la Argentina, una ley dictada en el congreso, no puede violentar ese tratado. $\mathrm{Y}$ hay normas Mercosur que nos obligan en tema alimentos y muchas otras cosas. (EFP: 1).

Como vemos, un conjunto de normativas reglamentan la actividad láctea en lo relativo a las condiciones generales y particulares para los productores primarios e industriales; en torno a las condiciones, exigencias y características de los productos, relacionados con los aspectos de inocuidad y de calidad nutritiva. Estos parámetros están contemplados en diversos capítulos del Código Alimentario Argentino, y su control ha sido asignado al SENASA y al INAL, dependiendo del tipo de producto y de su orientación de mercado (local, nacional, de exportación).

Existen superposiciones e indefiniciones en cuanto a las atribuciones y responsabilidades de las diversas instituciones públicas a cargo de estas tareas, y entre las instancias nacionales,

28 Art. 75 inciso 22. Declaraciones, Convenciones, y Pactos complementarios de derechos y garantías. LOS TRATADOS tienen MAYOR valor que las leyes comunes de nuestro Estado Nación pero por DEBAJO de la Constitución. (Constitución Nacional Argentina) 
provinciales y municipales, producto de la potestad de cada Provincia de tener un ordenamiento jurídico propio. Esto hace que el Código Alimentario Argentino con toda su complejidad, no tenga un proceso que dictamine y se adopte tal decisión automáticamente en cada una de las Provincias, sino que estas poseen la opción de adherirse, no adherirse o plantear una modificación para su conveniencia.

\section{Fiscal - Tributario Nacional}

Así como el estado Nacional ejerce el control higiénico-sanitario sobre la trama a través de sus organismos de incumbencia, también ejerce un control y fiscalización tributaria a través de su Agencia Federal de Ingresos Públicos (AFIP) ${ }^{\mathbf{2 9}}$; estos tributos ejercidos por el Estado hacia las diferentes actividades productivas y comerciales se denomina carga o presión tributaria. La recaudación monetaria irá para uso de los tres diferentes estamentos de control de carácter Nacional, Provincial y Municipal. La AFIP es responsable de la aplicación, la percepción y la fiscalización de los tributos de todas las producciones originadas y/o desarrolladas dentro del territorio, esto lo hace sin tener una diferenciación clara entre la heterogeneidad de las explotaciones existentes en cuanto a tipo y modo de producción o niveles de facturación. Todos los sujetos tributarios de este sector son impositivamente tratados por igual ante los diversos tributos (no hay diferenciación de alícuotas), ya sean nacionales, provinciales o municipales (Monge y Portillo, 2016).

\footnotetext{
${ }^{29}$ La AFIP, por medio de la Resolución General 10/1997 y sus modificatorias, dispone el procedimiento que deberán observar las personas de existencia visible, las sociedades -incluidas las no constituidas regularmente y las de hecho-, asociaciones y demás responsables mencionados en el artículo $5^{\circ}$ de la Ley $\mathrm{N}^{\circ} 11.68310$, con la finalidad de solicitar la inscripción y/o altas, o informar sobre modificación de datos, como contribuyentes y/o responsables de impuestos, regímenes de retención, percepción y/o información, y Recursos de la Seguridad Social.
} 
Este universo tributario se encuentra avalado en la Constitución Nacional por medio de los principios de tributación, encontrando relevancia para este trabajo en el principio de legalidad referenciando la facultad que posee el Congreso como único ente capaz de crear tributos; en este contexto es que Pena de Ladaga y Berger (como se citó en Monge y Potillo, 2016) plantean el principio de igualdad que refiere al trato indistinto por parte de los entes recaudadores ante los contribuyentes y el principio de no confiscatoriedad o de propiedad privada, estableciendo que la carga tributaria no puede ser confiscatoria para los sujetos que la sufren.

Ante esto resulta clave dar un marco para asegurar el cumplimiento de las disposiciones previsionales e impositivas que permitan funcionar sin riesgos dentro de los canales formales. Para esto es necesario que el Estado, en sus tres niveles, realice una revisión, modificación o adecuación de la estructura impositiva que actualmente rige para la pequeña lechería, por ser la disposición tributaria vigente, un factor que afecta y pone en considerable riesgo la producción, atentando a la vez a la permanencia de los productores en la actividad, en todos los casos entrevistados de producciones formales, hicieron notar la falencia en este nivel, quedando demostrado en la expresión de una productora al decir:

Los productores que se van a meter en ese brete.... Aparte que hoy en día está todo encadenado. Porque nosotros tenemos factura, tenemos remito oficial, tenemos todo. O sea vos pasas a ser para el estado, para el afip hoy...por ahí un productor de 20-30 vacas es un criminal ante la afip, entonces vos decís...para qué? Entendes, no hay escala, es lo mismo un tipo que se chorea (roba) millones y millones, que un tipo que no vende la masa en blanco, y que la está peleando, entonces es como que no se justifica. (E.P.1). 
Las tributaciones se pueden diferenciar entre impuestos, tasas o contribuciones, estas últimas tienen como contrapartida la prestación de un servicio.

Actualmente la AFIP dispone de más de cuarenta instrumentos para cumplir su función. Los impuestos más importantes y/o relevantes que atraviesan la actividad en estudio son:

- Impuesto a las ganancias ${ }^{30}$ : aplica sobre toda ganancia obtenida por la persona, es un impuesto clasificado como directo y progresivo, es decir, el tributo es pagado por el sujeto que determina la ley y a una tasa creciente.

- Régimen Simplificado para Pequeños Contribuyentes (Monotributo) ${ }^{31}$ : El Régimen simplificado persigue por un lado una disminución de la presión fiscal indirecta de los contribuyentes, facilitando el cumplimiento de las obligaciones tributarias, y por el otro, mejoran la asignación de recursos de la Administración Tributaria, permitiendo la implementación de procesos sistemáticos de control masivo.

- Impuesto a la ganancia mínima presunta ${ }^{32}$ : El objeto principal de este tributo es el de gravar los inmuebles rurales - ubicados tanto en el país como en el exterior - de personas físicas o sucesiones indivisas domiciliadas o radicadas en el país.

- Impuesto a los bienes personales ${ }^{33}$ : El objeto del impuesto está dado por la posesión de bienes - cualquiera fuese el momento de su ingreso al patrimonio- de las personas físicas al 31 de diciembre de cada año. La propiedad de un patrimonio representa una reserva de poder adquisitivo para su propietario, capaz de ser empleada en cualquier momento en

\footnotetext{
${ }^{30}$ Ley $\mathrm{N}^{\circ} 20.628$ y sus modificatorias.

${ }^{31}$ Ley No 24.977 y sus modificatorias.

${ }^{32}$ Ley $\mathrm{N}^{\mathrm{o}} 25.063$.

${ }^{33}$ Ley $\mathrm{N}^{\mathrm{o}} 23.966$ y sus modificatorias.
} 
adición o sustitución del rédito; por esta razón se afirma que constituye un verdadero índice de capacidad contributiva.

- Impuesto al valor agregado (IVA) ${ }^{34}$ : El Impuesto al Valor Agregado grava el valor que cada etapa del proceso productivo comercial agrega a los productos o servicios. Es una imposición que incide en una manifestación de la capacidad contributiva del contribuyente, que es el consumo.

- Impuesto a los débitos y créditos bancarios ${ }^{35}$ : La bancarización obligatoria de todas las operaciones para el cómputo de créditos y deducciones impositivas, que surge en función de lo establecido por la ley anti evasión 25.345 , desemboca directamente en el impuesto. (www.afip.gob.ar)

Analizando la carga tributaria y fiscal que tienen que afrontar los productores es pertinente adoptar medidas en cuanto al otorgamiento de incentivos fiscales y crediticios para el apoyo a la participación de los diversos programas implementados. Esto se torna necesario a nivel nacional al quedar expresado en un trabajo publicado por Monge y Portillo (2016) en donde el marco impositivo nacional se adjudica el $84 \%$ de la presión tributaria, demostrando el peso de dicha tributación en los resultados económicos de los establecimientos.

\section{El Estado Provincial y su papel en la regulación de la actividad tambera-masera.}

\section{Higiénico Sanitario Provincial:}

\footnotetext{
${ }^{34}$ Ley $\mathrm{N}^{\circ} 23.349$ y sus modificatorias.

${ }^{35}$ Ley 25.41354. Decreto Reglamentario N’380/2001 y modificatorias. RG AFIP 2.111/2006.
} 
Es importante comenzar señalando que el Estado Provincial es el generador de gran parte de las reglamentaciones que conciernen al tambo - fabrica, también lo hacen sobre las unidades productivas de leche fluida y cualquier otra producción que concierne a la ganadería Provincial. Realizada esta aclaración se puede comenzar mencionando la obligatoriedad, para todo propietario de hacienda, de establecer propiedad sobre la misma, requiriendo para ello, registrar a su nombre las marcas o señales ${ }^{36}$ de su uso exclusivo. Exigencia ésta, tanto para ganado mayor como menor, requiriéndose como obligación esencial y previa a todo trámite, acreditar el carácter de propietario u ocupante legal de un inmueble rural en la Provincia de Buenos Aires y siendo uso exclusivo de quien la registre. El encargado de otorgarlo es el Departamento de Registro Ganadero, a la vez que se responsabiliza de las reglamentaciones.

Dentro de las competencias del Ministerio provincial también encontramos la primera acción específica para la formalización de la producción lechera, ésta es la inscripción de tambos. Vale destacar que un tambo en la provincia de Buenos Aires no se habilita, sino que se inscribe (registra $)^{37}$. Este requisito es obligatorio para todos los tamberos radicados en el territorio provincial y determina que toda explotación tambera deberá contar con el $\mathrm{N}^{\circ}$ de registro Provincial de tambos para entregar su producción. Esta inscripción no significa costo alguno y los datos obtenidos serán procesados como información estadística para el sector, amparados bajo secreto estadístico (https://www.maa.gba.gov.ar/sistemas/index2.php). Una vez realizadas

\footnotetext{
${ }^{36}$ En la provincia de Buenos Aires, sancionado por ley provincial n ${ }^{\circ} 469$ del año 1865 . Provincia de Buenos Aires Ley 10.081, sobre marcas y señales. La Marca es un dibujo, diseño o signo impreso a hierro candente o por procedimientos que produzcan análogos efectos, siempre que estén autorizados por dicho organismo competente. El ganado mayor debe ser marcado antes de cumplir el año (quedando prohibido contramarcar) y el ganado menor señalado antes de cumplir los seis meses de edad. Los únicos sitios en que se señalará serán ambas orejas.

${ }^{37}$ Ley 6703/61. Decreto Reglamentario 66/63 (art. 135, 136, 137, 138), Ley 7265 (art 7)

Datos amparados por secreto estadístico ley 17.622
} 
las tramitaciones mencionadas anteriormente, el productor tambero - masero tiene la obligación de cumplir con la Ley $\mathrm{N}^{\circ} 11.089$, la cual se detallará en el próximo punto.

Por último, los gobiernos locales poseen funciones para la radicación y habilitación de los establecimientos productivos lecheros maseros en su territorio. Esta acción es decisiva por la utilización de sus recursos, y su ordenamiento territorial. Es así que el Municipio otorga el:

Certificado de Zonificación: En todos los casos para la registración o habilitación de establecimientos, el organismo competente, suele solicitar primero la certificación de permiso de uso de suelo (recibe distintos nombres) otorgada por el MUNICIPIO: es aquel que según planeamiento urbano municipal, permite la instalación y funcionamiento del establecimiento (unidad de producción de materia prima o elaboración) en el espacio elegido.

Esto varía con cada jurisdicción local por lo que se debe consultar en dicho ámbito, los requisitos y pasos a seguir, según se trate de establecimientos de producción de materia prima o de productos elaborados. Esta constancia/certificado/habilitación, es la que será luego requerida por los demás organismos para continuar con los trámites.

Asentamiento y Permiso de Marca: Una vez realizado el trámite provincial de obtención del Boleto de Marca, este debe ser asentado en el registro del municipio correspondiente. Los requisitos de este trámite varían según el Municipio.

\section{Fiscal - Tributario Provincial}

Dejando por un momento los aspectos normativos técnicos productivos para la elaboración de masa, nos abocaremos a enumerar desde el punto de vista impositivo las cargas tributarias bonaerense para dicha producción, que al igual que para toda actividad productiva o comercial de la provincia los tributos son recolectados y posteriormente administrados por la Agencia de Recaudación, siendo el productor, tributario de: 
- $\underline{\text { Impuesto a los Ingresos Brutos }}{ }^{38}$ : Es el impuesto que corresponde a las actividades autónomas, actos u operaciones que consiste en la aplicación de un porcentaje sobre la facturación de un negocio independientemente de su ganancia, teniendo a la Agencia de Recaudación de la Provincia de Buenos Aires (ARBA) como autoridad de aplicación.

- Impuesto inmobiliario $^{39}:$ Los titulares de dominio, los usufructuarios y los poseedores a título de dueño pagarán anualmente por los inmuebles situados en la Provincia. Esta se constituye por la valuación fiscal de cada inmueble, multiplicada por los coeficientes anuales para cada Partido.

- Impuesto a los sellos ${ }^{40}$ : Se encuentran gravados en el presente tributo todos los actos, contratos y operaciones de carácter oneroso, formalizados en el territorio de la Provincia de Buenos Aires, en instrumentos públicos o privados suscriptos que exterioricen la voluntad de las partes.

- $\underline{\text { Impuestos a los automotores }}{ }^{41}$ : Los propietarios de vehículos automotores radicados en la Provincia pagaran anualmente este impuesto según el modelo año, modelo de fabricación, tipos, categorías y/o valuaciones.

Finalmente, a nivel municipal, también existe la tasa vial (tributo a la prestación de los servicios de conservación, reparación y mejorado de calles y caminos municipales) y la tasa de servicios generales a los que el productor se encuentra obligado a pagar.

\footnotetext{
${ }^{38}$ Ley 10.397 y modificatorias.

${ }^{39}$ Ley $\mathrm{N}^{\mathrm{o}} 10.397$ y sus modificatorias.

${ }^{40}$ Ley $\mathrm{N}^{\circ} 10.39783$ y sus modificatorias.

${ }^{41}$ Ley $\mathrm{N}^{\mathrm{o}} 10.397$ y sus modificatorias.
} 
A continuación se presenta una hoja de ruta con los requisitos y trámites Nacionales,

Provinciales y Municipales antes mencionados para registrarse como un Establecimiento Tambo/Fábrica elaborador de masa para Mozzarella de producción tipo Familiar.

Tabla 12: Requisitos higiénico/sanitarios Nacionales-Provinciales-Municipales.

\begin{tabular}{|c|c|c|c|c|}
\hline & Registro & $\begin{array}{c}\text { Institución que lo } \\
\text { otorga: }\end{array}$ & Oficina de gestiona: & requisitos \\
\hline 1 & RENAF & SsAF-MINAGRO & $\begin{array}{c}\text { Técnicos de territorio } \\
\text { de la SsAF }\end{array}$ & $-\mathrm{DNI}$ \\
\hline 2 & $\begin{array}{l}\text { Certificado } \\
\text { de } \\
\text { Zonificació } \\
\text { nó } \\
\text { permiso de } \\
\text { uso }\end{array}$ & MUNICIPIO & $\begin{array}{l}\text { Generalmente área } \\
\text { de PLANEAMIENTO }\end{array}$ & $\begin{array}{l}\text { Consultar en la oficina } \\
\text { correspondiente }\end{array}$ \\
\hline 3 & RENSPA & SENASA & Oficina Local & $\begin{array}{c}\text {-Fotocopia de DNI } \\
\text {-Constancia de } \\
\text { CUIL/CUIT }\end{array}$ \\
\hline & $\begin{array}{c}\text { Registro } \\
\text { actividad } \\
\text { productiva: } \\
\text { Tambo } \\
\text { Familiar }\end{array}$ & SENASA & Oficina Local & $\begin{array}{l}\text { Certificado de } \\
\text { Zonificación. } \\
\text { Carpeta Sanitaria } \\
\text { (Análisis Brucelosis - } \\
\text { Tuberculosis). }\end{array}$ \\
\hline 4 & Marca & $\begin{array}{l}\text { MINISTERIO DE } \\
\text { AGROINDUSTRIA DE } \\
\text { LA PROVINCIA DE } \\
\text { BUENOS AIRES }\end{array}$ & $\begin{array}{c}\text { Registro de Marcas y } \\
\text { Señales }\end{array}$ & $\begin{array}{l}\text {-Formulario único (ser } \\
\text { propietario, u } \\
\text { ocupante legal de un } \\
\text { inmueble rural en la } \\
\text { provincia de Buenos } \\
\text { Aires se acredita a } \\
\text { través de la } \\
\text { declaración jurada } \\
\text {-pago de tasa vigente } \\
\text {-Fotocopia de DNI. } \\
\text {-Fotocopia de la } \\
\text { CUIT/CUIL. } \\
\text {-Fotocopia de } \\
\text { Impuesto } \\
\text { (Inmobiliario Rural) }\end{array}$ \\
\hline
\end{tabular}




\begin{tabular}{c|c|c|c|c|c|c|c|}
\hline 5 & $\begin{array}{c}\text { Asentar la } \\
\text { Marca }\end{array}$ & MUNICIPIO & $\begin{array}{c}\text { Generalmente área } \\
\text { de Hacienda. }\end{array}$ & $\begin{array}{c}\text { Consultar en la oficina } \\
\text { correspondiente }\end{array}$ \\
\hline \hline 6 & $\begin{array}{c}\text { Permiso de } \\
\text { Marca }\end{array}$ & MUNICIPIO & $\begin{array}{c}\text { Generalmente área } \\
\text { de Hacienda. }\end{array}$ & $\begin{array}{c}\text { Consultar en la oficina } \\
\text { correspondiente }\end{array}$ \\
\hline
\end{tabular}
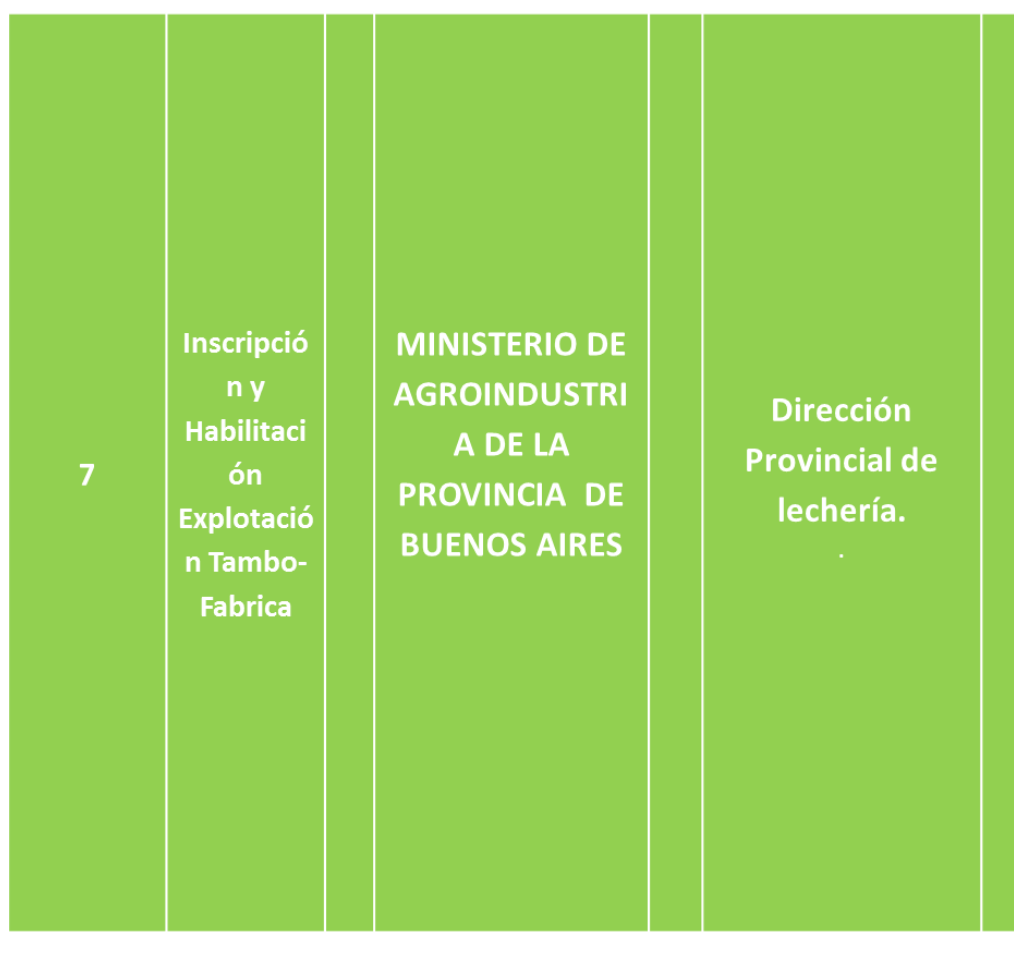
A. Declaración jurada documental habilitación establecimientos lácteos.
B. Certificado de radicación municipal (zonificación).
C. Solicitud de habilitación - declaración jurada técnica.
D. Plano de obra del establecimiento.
E. Memoria Descriptiva y Edilicia.
F. Certificado de habilitación de tambo.
G. Certificado de libre de Brucelosis y Tuberculosis.
H. Análisis físico-químico y bacteriológico.
I. Timbrado
Tasas según Ley Fiscal Anual Provincial, Inscripción / Habilitación / Rehabilitación de Explotación Tambo Fabrica.

Fuente: Butler, L. Elaboración propia en base a la información recabada. Nacional

Tabla 13: Requisitos en los diferentes sistemas Nacionales.

\section{Sistema Registral (electrónico)}

\begin{tabular}{|l|c|c|}
\hline LUME & $\begin{array}{c}\text { (Liquidación Única } \\
\text { Mensual) }\end{array}$ & MAGyP \\
\hline
\end{tabular}

\begin{tabular}{|l|c|c|}
\hline RUCA & $\begin{array}{c}\text { Registro Único de } \\
\text { Operadores de la } \\
\text { Cadena }\end{array}$ & MAGyP \\
Agroalimentaria & Mand
\end{tabular}




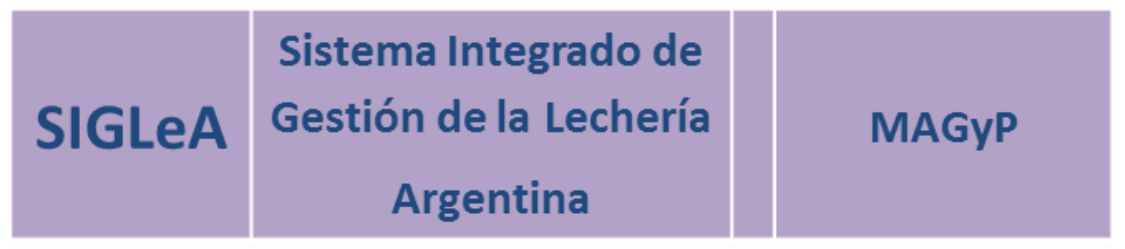

Fuente: Butler, L.

Elaboración propia en base a la información recabada en https://www.agroindustria.gob.ar/sitio/areas/ruca/actividades https://www.agroindustria.gob.ar/sitio/areas/siglea/index.php.

Tabla 14: Esquema de obligaciones a cumplir en lo tributario y fiscal Nacional y Provincial.

Esquema obligaciones a cumplir en lo tributario y fiscal Nacional como Provincial:

\section{CARGA TRIBUTARIA NACIONAL}

\section{MONOTRIBUTO}

\section{IMPUESTO A LAS} GANANCIAS

IMPUESTOA LA GANANCIA MÍNIMA PRESUNTA

IMPUESTOS A LOS BIENES PERSONALES

IMPUESTO A LOS DÉBITOS Y CRÉDITOS BANCARIOS

\section{CARGA TRIBUARIA E IMPUESTOS}

PROVINCIALES

\section{INGRESOS BRUTOS}

IMPUESTO A LOS SELLOS

\section{IMPUESTO AUTOMOTOR}

IMMPUESTO

INMOBILIARIO

Fuente: Butler, L. Elaboración propia en base a la información recabada en https://www.arba.gov.ar

Relacionado con lo que se ha desplegado anteriormente, Bisang et al. (2003) nombran de manera clara dos medidas alcanzables y con capacidad estatal para realizarlas, la primera es en torno a la 
coordinación de acciones de fiscalización entre AFIP, SENASA, e INAL, a fin de evitar superposiciones y reducir las asimetrías impositivas de acuerdo a los diversos circuitos lácteos que operan en la actualidad dentro de la trama. Esto se observa al momento de analizar los datos de entrevistas a funcionarios públicos donde algunas de las expresiones fueron: "debería haber una categorización de tambos de menos de 50 vacas, buscarle la vuelta, categorizarlos desde el punto de vista como una economía regional de sustentabilidad para que esos tambos tengan un gravamen impositivo diferente" (E.F.N.1) o en otro de los casos "no los pueden tratar como a los grandes tambos o tambos capitalizados porque no tiene la espalda para responder, y no solo eso, si no tienen una política impositiva diferencial nunca van a poder capitalizarse para avanzar, para crecer" (E.F.P.4).

Podemos aventurarnos a expresar por lo desarrollado precedentemente que los productores deben soportar una alta carga impositiva y una amplia cantidad de gestiones burocráticas para poder llevar adelante su unidad productiva, estando presente en todos los casos el Estado Nacional, el Provincial y el Municipal. Estos tres niveles gubernamentales poseen un papel fundamental, por considerar que a través de sus capacidades se podría reducir o compensar las asimetrías existentes, con políticas públicas que generen la inclusión de los sectores desfavorecidos, buscando de manera institucional la asimilación social de la informalidad, pasando del hostigamiento y estigmatización, asociado a lo ilegal, a la construcción de nexos para contener y acercar las producciones informales a las instituciones formales, como a las estructuras de gobierno (Campos Rios, 2006). Esto posibilitaría dar una continuidad que permita promover un proceso ininterrumpido de capitalización y formalización de los pequeños productores, con una estrategia de fuerte apoyo estatal para no atentar en su sostenibilidad (Narodowski, 2013), garantizando precio justo y retributivo, en condiciones de comercialización igualitarias entre los 
diferentes agentes económicos (con mayor o menor poder de negociación), minimizando las transferencias de rentas y excedentes hacia los sectores hegemónicos de las cadenas, que dañan y deprimen el desempeño de los más vulnerables (Rossi y Leon, 2005). A esta vulnerabilidad trabajada desde la óptica temporal de los actores tomados y analizados en su etapa de población económicamente activa, en donde las coberturas sociales muchas veces ausentes, se expresan en una baja calidad de vida, también se la puede dimensionar, a partir de integrar al análisis las complicaciones y las problemáticas de este mismo productor en su etapa pasiva, que no contará con los aportes previsionales realizados, siendo expresado por un/a productor/a "mi papá y mi mamá ya no pueden trabajar, no tienen jubilación, trabajaron toda la vida pero nunca ninguno de los dos hizo aportes ni les hicieron aportes, por lo que comen también del tambo" (E.P.6). Esta situación se ve en casi la totalidad de los casos entrevistados de la producción informal, los productores muchas veces se encuentran sin cobertura social alguna y sin aportes previsionales, expresión directa de una baja calidad de vida y una imposibilidad de contar con una actividad próspera en el mediano y largo plazo (Monge y Portillo, 2016).

El Estado tiene como contrapartida al sector Privado, tensionando para la construcción de políticas sectoriales, intervenciones y regulaciones. A partir de una representatividad concebida por instituciones de diversos intereses de los diferentes actores que conforman la trama láctea. Los intereses de los productores primarios están representados por organizaciones gremiales del sector agropecuario en general, especialmente las que representaban a pequeños y medianos productores, pues la producción láctea estuvo muy ligada a estos sujetos sociales en sus orígenes (Nogueira, 2010) formando parte de organizaciones como Sociedad Rural Argentina (SRA), Confederación Intercooperativa Agropecuaria (CONINAGRO), Confederación de Asociaciones Rurales de Buenos Aires y La Pampa (CARBAP) y la Federación Agraria Argentina (FAA) 
como algunas de las principales, teniendo en su estructura interna áreas específicas para la lechería. Más allá de las instituciones anteriormente nombradas, existen espacios específicos de la actividad primaria como la Unión General de Tamberos (UGT), surgida en 1920 cuando el modelo agroexportador comenzaba a tener resultados negativos por los precios muy bajos de la materia prima, teniendo dentro de sus objetivos tratar asuntos que se refieran a la producción de leche, como órgano de vigilancia y labor constante en salvaguardia de los intereses, estudiando las leyes, decretos, impuestos, actos y medidas perjudiciales a la producción para pedir modificación o abolición según se crea justo y razonable. Además, se proponen realizar toda clase de gestiones ante los poderes públicos o privados para generar un sistema en el que el mercado contemple las necesidades del productor, estimule y fomente la producción y el consumo, asegurando la calidad de la leche y su precio ${ }^{42}$ (Nogueira, 2010). Se encuentra también la Asociación de Productores Lácteos (APL), una estructura de segundo grado conformada por productores de leche, que focaliza su quehacer en la promoción de la actividad y de la calidad de la leche, la defensa de los intereses sectoriales, y la representación del sector frente a las instituciones públicas y privadas (Bisang et al., 2003).

Durante la década del noventa, con el contexto político neoliberal e instaurada la convertibilidad, la trama asociativa de representatividad láctea se modificó drásticamente, observándose una gran dispersión de las asociaciones tanto específicas de la trama láctea como de las generales del sector agropecuario, asumiendo roles definidamente ligados a las demandas específicas del sector, y reencausando los objetivos institucionales a formas de acción directa sobre situaciones particulares, durante coyunturas no favorables como la pérdida de rentabilidad de la actividad y

\footnotetext{
42 http://www.tamberos.org.ar/inst_estatuto.htm
} 
los bajos precios que se pagaban en usina al productor y en un segundo plano, la elaboración de una política pública sectorial con participación, en este eslabón de la cadena, de los productores (Nogueira, 2010).

En palabras de Nogueira (2010) podemos decir que la participación de las instituciones que representan al sector no han podido construir una participación plena en los procesos de elaboración o formulación de políticas públicas sectoriales, teniendo una baja intervención en el proceso de toma de decisiones. Esto se debe en buena medida al accionar de las entidades sectoriales tradicionales que instalan problemas como bajos precios, sequías, aumento de costos, desequilibrios en la vinculación intersectorial, etc., en la agenda pública y las instituciones sectoriales sostienen demandas muy concretas y acotadas, planteadas fuertemente en momentos de crisis. Se puede corroborar además, que no logran una participación plena en la generación de un plan estratégico, de políticas públicas sostenidas y de la generación y adecuación de marcos para la inclusión de todo el espectro productivo.

\section{Ley $N^{\circ} 11.089$, origen, implementación e inconvenientes para su cumplimiento.}

Se entiende oportuno iniciar el tratamiento de este apartado señalando, para luego abordar las características de la ley, que la mozzarella es un queso de origen Italiano, y que en el país, al igual que en la Provincia de Buenos Aires, históricamente se hizo de la manera tradicional ${ }^{43}$, cuya fabricación está permitida solamente en las industrias lácteas queseras, donde la elaboración se realiza a partir de leche fluida demandada a los tambos, ocurriendo el proceso de

\footnotetext{
${ }^{43}$ Elaborado a partir de la coagulación de la leche en tina, acidificación (generalmente bajo suero) acidificaciones rápidas y una vez alcanzado los valores de $\mathrm{PH}$, hilado en agua caliente, salado con sal en cristales y en masa, formado de la pieza, y enfriado en salmuera fría o simplemente en una pileta con agua natural o preferentemente fría (portal lechero).
} 
producción enteramente dentro de la industria, obteniendo el producto final listo para su comercialización y consumo.

Los cambios acontecidos en la trama láctea Argentina, con su consecuente impacto en la Provincia de Buenos Aires, sumado a las grandes inundaciones en esta Provincia de 1986-1987, con mayor incidencia en los partidos de Carlos Tejedor y Pehuajó, introdujo la urgente necesidad por parte del Gobierno Provincial de encontrar una respuesta inmediata para los establecimientos lecheros que se encontraban imposibilitados por el anegamiento, de poder sacar su producción (leche), así lo recordaba un funcionario de larga trayectoria en la lechería Argentina:

Cuando la problemática de los tambos se desborda por el tema de la inundación que la leche no podía llegar a la fábrica sale la ley de tambo fábrica. Las inundaciones grandes, esas fueron en el 86, 87, en la época de Armendáriz. Las inundaciones fueron tremendas, rutas y rutas cortadas en el oeste, que fue el disparador de todo esto. La 33 estuvo cortada 5 - 6 meses, la gente hacía masa para retirar la leche. (E.F.P.5).

Al tratarse de un producto sumamente perecedero, las decisiones políticas no podían esperar y, consecuentemente, la Dirección de Ganadería (hoy Dirección de lechería) autorizó temporalmente la fabricación de masa para mozzarella en los establecimientos primarios. A partir de este hecho el estado provincial comienza a moldear el surgimiento de esta nueva categoría de producción primaria para la elaboración de masa para mozzarella. De este proceso, en 1989 resulta una figura legal, el decreto $\mathrm{N}^{\circ} 1527 / 89^{44}$, que dota al Ministerio de Asuntos Agrarios y Pesca de la Provincia de Buenos Aires (hoy Desarrollo Agrario) de una reglamentación que le permita cubrir la producción y comercialización de la llamada "masa" o

\footnotetext{
${ }^{44}$ http://www.gob.gba.gov.ar/legislacion/legislacion/89-1527.html
} 
"cuaja-da" para la fabricación de Queso Mozzarella Argentino, no contemplada hasta ese momento por la legislación en vigencia. Permitiendo de esta manera, la elaboración, transporte y comercialización de "masa para la elaboración del queso mozzarella" en todo el territorio de la Provincia de Buenos Aires, bajo las condiciones fijadas por el Ministerio de Asuntos Agrarios y Pesca.

Teniendo en cuenta, que esta resolución data de 1989 y, que la autorización del Estado Provincial para su elaboración data de 1986, nos encontramos con tres años de una expansión de unidades productivas tamberas que optaron por esta manufactura intermedia, que se plasma en una fundamentación encontrada en la base de datos del Ministerio Provincial ${ }^{45}$, explicando la necesidad de regular legislativamente la actividad, por lo dificultoso del control de establecimientos autorizados y no autorizados para su elaboración. El documento no contiene fecha de redacción, pero las lecturas realizadas nos orientan y ubican temporalmente entre el decreto $\mathrm{N}^{\circ} 1527 / 89$ y la sanción de la Ley. Fundamento que comienza arrojando una serie de consideraciones para abordar el tratamiento legislativo, destacando la necesidad de dar respuesta a la imposibilidad de sacar la leche en los partidos bonaerenses afectados por las inundaciones, a la falta de caminos y a la sencillez de su fabricación, catalogando su obtención casi como una prolongación de la actividad de tambo y que admite su evacuación una o dos veces por semana, beneficiando al Municipio por un menor deterioro de la red vial. Asimismo considera a la masa para mozzarella como un producto intermedio elaborado diariamente en los tambos inmediatamente después del ordeñe, para luego depositarlo y comercializarlo una vez o dos a la semana y, que por añadidura, provee al productor del beneficio del suero restante para la crianza

\footnotetext{
${ }^{45}$ http://www.gob.gba.gov.ar/legislacion/legislacion/f-11089.html
} 
de animales. Este momento de emergencia está presente en los funcionarios provinciales, afirmando uno de estos que:

Aparece una figura, una legislación que permite que tambos dentro de unas condiciones determinadas tanto sea edilicia como higiénico sanitaria, procesen la leche y la transforme en un producto intermedio que es la masa para mozzarella. (EFP: 2).

Además, se indica que los productores comenzaron a producir masa encuadrando la actividad como ilegal, libre de impuestos y controles sanitarios, despertando quejas y presiones de la industria lechera a los organismos oficiales, demandando un marco regulatorio para dicha actividad, a lo que unos de los entrevistados afirma:

Los tambos masa empezaron a funcionar sin una legislación clara, no había al momento de su creación una normativa que guie los marcos de funcionamiento, esto trajo que al momento de las registraciones y habilitaciones empecemos con desventaja porque todo el universo ya se encontraba produciendo con mayor o menor grado de informalidad, pero todos informales. (E.F.P.3).

A estos acontecimientos se le suma con fuerza, el aumento del consumo interno de queso mozzarella, incrementando la demanda de este subproducto, llevando a la urgente necesidad de un encuadramiento legal y el correspondiente control sanitario de las instalaciones y del producto realizado. Esto marco para el proceso de formalización se ve complejizado por no estar comprendido dentro de los Decretos 1527/89 y 2687/77, que establecen las condiciones mínimas a que deben ajustarse las usinas lácteas, y la ley 7.229 y su Decreto Reglamentario 7488/72 de 
funcionamiento de industrias, no cubriendo el caso especial de la explotación tambera-masera como proveedor de este subproducto a la industria ${ }^{46}$.

En este contexto la necesidad de garantizar la inocuidad y calidad del producto y la consecuente percepción de los impuestos promueve la sanción de la presente ley. Se realiza entonces, una proclama final: Este proyecto de ley tiende solamente a solucionar los puntos descriptivos diciéndole al productor ¡Señor si lo desea hágalo, pero, hágalo bien! Pague además sus impuestos y la Constitución Nacional y las leyes de este país lo protegerán (proyecto de Ley $\mathrm{S} / \mathrm{f})^{47}$.

El proyecto de Ley se hace realidad, cuando el 6 de Junio 1991 la Legislatura Provincial sanciona la Ley $11.089^{48}$, visibilizando y reconociendo la necesidad del abordaje de este nuevo eslabón en la cadena láctea. Estableciendo en su Capítulo I a través de sus Artículos 1, 2 y 3, un régimen especial para aquellas explotaciones tamberas que deseen realizar una semi-elaboración de su leche, bajo la forma de masa para Mozzarella, para comercializarla a las fábricas que elaboran el producto denominado queso mozzarella Argentino, $\mathrm{u}$ otras formas como queso Caciocavallo (de mozzarella), o trenzas, lenguas o bolitas. Que el cumplimiento y la fiscalización de la presente ley, estarán a cargo del Ministerio de Desarrollo Agrario el cual también estará facultado para resolver los aspectos técnicos derivados del cumplimiento de la presente ley.

\footnotetext{
${ }^{46}$ http://www.saij.gob.ar/11089-local-buenos-aires-explotaciones-tamberas-semi-elaboracion-mozzarella-provinciabuenos-aires-lpb0011089-1991-06-06/123456789-0abc-defg-980-1100bvorpyel?

$47 \mathrm{https}: / /$ normas.gba.gob.ar/documentos/xa9wLuLx.html

48 http://www.gob.gba.gov.ar/legislacion/legislacion/l-11089.html
} 
El 16 de Diciembre del mismo año llega la reglamentación de la ley a partir del Decreto $\mathrm{N}^{\circ}$ $83 / 1991^{49}$, aprobando las normas sobre los establecimientos agropecuarios tamberos para la semi elaboración de su leche, considerando que a través de su aplicación buscará la normalización impositiva y asumiendo que en ese marco, se habrá de encuadrar esta producción que hasta la fecha se desenvolvía marginalmente. Se entiende además, que a su vez, promoverá una mejor calidad del producto final, dando por comprobado que la capacidad filante de la mozzarella elaborada a partir de masas es superior a la de cualquier otro origen. Expresándolo un funcionario provincial de la siguiente manera:

A través de la resolución $\mathrm{N}^{\circ} 11089$ (especifica tambo-fabrica) se crea la posibilidad de que vos hagas masa, vos salís con un número de la fábrica diferente a lo que son los números de fábrica de quesos y le podes vender a otra fábrica masa como materia prima. (EFP: 4).

La ley contiene siete (7) capítulos que recorren desde la fiscalización a través de su organismo de aplicación provincial, pasando por las buenas prácticas de manufactura para su elaboración, así como los requisitos en cuanto a infraestructura de la unidad tambo - fabrica, la higiene de ésta, la sanidad del rodeo y el registro por parte del órgano de aplicación con sus respectivos aranceles expresados en kilogramos de masa producida. Pasando a ser la Provincia de Buenos Aires la única jurisdicción en el país en contemplar dentro de su legislación la figura de tambo - fabrica. Tomando en cuenta el año del decreto y la sanción de la Ley nos encontramos que son coincidentes o contemporáneos con el inicio del gran proceso de transformación de la lechería en el país. Esto es significativo ya que al momento de darle forma a la ley, varios factores de este proceso influirían en su redacción, tal lo planteado por Gutman y Gatto (2009) quienes refuerzan

${ }^{49}$ http://www.gob.gba.gov.ar/legislacion/legislacion/91-83.html 
esta idea afirmando que la etapa de reestructuración productiva comienza en la década del ochenta y se manifiesta a través de un cambio cualitativo de la actividad, que empieza a incorporar paulatinamente elementos internacionales al sistema. Si tomamos el sector de la agricultura familiar con su perfil tecnológico adoptado y su funcionalidad estructural, se puede aseverar que su adopción tecnológica depende directamente de la escala productiva de la unidad, siendo que a mayor escala, mayor adopción tanto en lo exclusivamente productivo (cantidad de litros producidos) como en la mejora edilicia y de instalaciones, repercutiendo de manera exponencial sobre la productividad y calidad de trabajo (Castignani et al., 2009). A la vez, Comeron et al. (2000) afirma que la escala productiva es fundamental para el mantenimiento de la unidad productiva, en donde la eficiencia de la producción y de la mano de obra juega un rol importante en su resultado económico. Castignani et al. (2009) refuerza esta postura tomando a las particularidades de la producción láctea como nodales en este proceso de cambio tecnológico ya que la complejidad es creciente, dado que las tecnologías de procesos requieren de un aprendizaje continuo, y que la adopción de tecnologías de insumos requiere un alto costo de inversión del que no cuentan las pequeñas producciones. Por lo tanto, estos impedimentos, nos dan una idea de los diferentes inconvenientes para la aplicación de la legislación, y nos arroja, en relación a los mercados internos de productos lácteos, a la necesidad de una revisión de las estrategias de las unidades productivas y de los marcos regulatorios. Bisang et al. (2003) consideran importante remarcar que la estructura productiva se encuentra conformada por mercados formales e informales, este último asentado en base a dos grandes aspectos: el primero por las elusiones impositivas, y el segundo por tener un marco sanitario lábil. Ambos, con una íntima relación con la inequidad y los aspectos sanitarios, cristalizando las estructuras de mercado y generando tensiones permanentes al interior de la trama. Es claro que este esquema 
genera una ruptura con los procesos de coordinación, de transferencias de tecnologías y esfuerzos innovativos, generando que los actores perciban que el incumplimiento de las normas sanitarias e impositivas sean dos ejes de los cuales depende su sostenibilidad, teniendo en la informalidad, primero una rentabilidad mayor que les permita su subsistencia y segundo por la imposibilidad de encuadrarse dentro del marco normativo higiénico - sanitario debido a la falta de capital para la inversión. Esta situación de informal se ve expresada no solo desde el punto de vista productivo-comercial sino que genera marginalidad social debido a la ausencia de derechos individuales y laborales que tienen el resto de los habitantes del país, debido a la imposibilidad por parte de los productores a transitar los canales que se la aseguren, predominando la ausencia de registros y de contribuciones al régimen de seguridad social y al sistema tributario.

Figura 15: Unidad productiva familiar habilitada y sus consecuentes impactos.

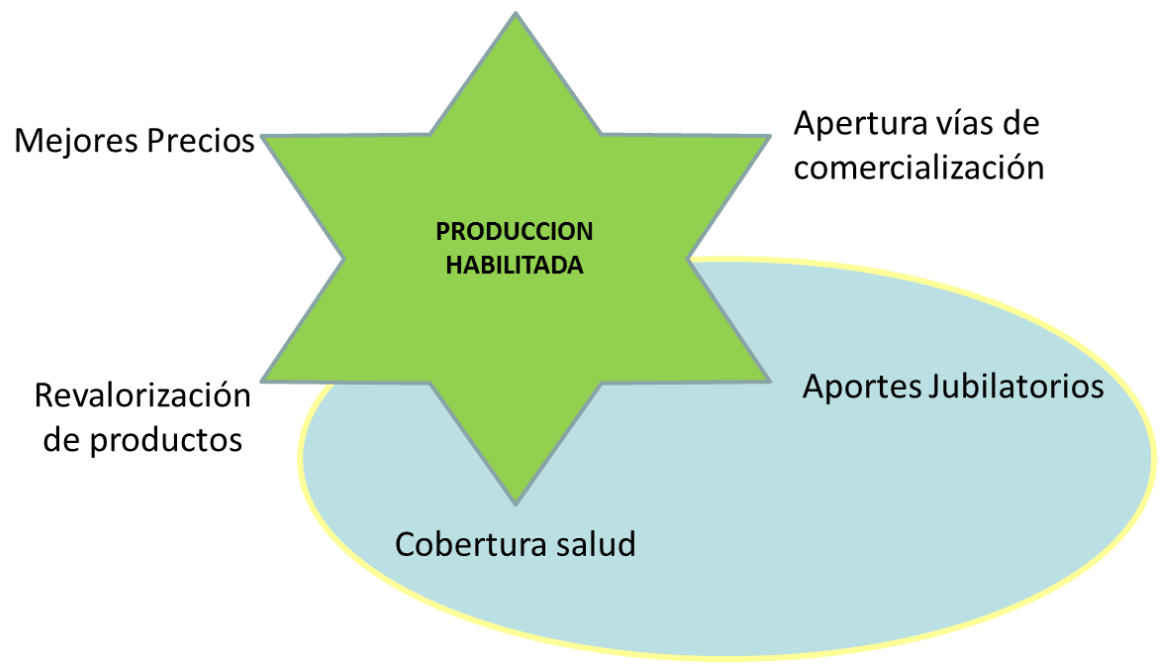

Fuente: Butler, L. Elaboración propia.

Sobre este punto es en donde emerge nuevamente la necesidad de actualizar, adecuar y modificar los marcos legislativos e institucionales normativos referido a lo higiénico sanitarios que rigen a 
la pequeña producción lechera (Barragan Lopez, 2016), expresado claramente en una entrevista "las registraciones tienen una serie de requisitos que muchas veces no contemplan la realidad del sector" (E.F.N.2) y que su presencia podría estar asegurada en marcos regulatorios sectoriales y diferenciados, reconociendo e interviniendo el Estado como autoridad de aplicación de una nueva base normativa, asegurando la participación en condiciones de igualdad de todo el sector de la pequeña producción (Rossi y Leon, 2005) en términos de equidad y sostenibilidad.

\section{Caracterización de la cadena láctea del queso mozzarella en los estratos de la pequeña producción.}

\section{Caracterización del tambo - fábrica en la Cuenca del Abasto Sur}

\section{Dimensión productiva.}

En este apartado nos abocaremos a aquellos tambos que fueron marginalizados por no cubrir con los requisitos tecnológicos industriales para transformarse y permanecer como oferentes de las grandes usinas, colocándolos en una situación de riesgo y vulnerabilidad, obligándolos a iniciar una puesta en marcha de estrategias productivas que puedan garantizar su permanencia en el campo, entre ellas la venta de masa, en la mayoría de los casos bajo condiciones de informalidad, pudiendo englobar las expresiones de los productores en una frase enunciada por uno de ellos, "si nosotros no hubiésemos empezado con la masa teníamos que cerrar el tambo porque no le podíamos vender a nadie..." (E.P.4).

Barros (2005) aporta elementos que fomentaron la inserción de los productores a los circuitos informales de producción y comercialización, sumando, a la ya nombrada incapacidad de adaptar los sistemas productivos a las exigencias tecnológicas de las grandes usinas, el contexto 
económico sectorial desfavorable de los precios y del valor de los insumos y el alto endeudamiento.

Dentro de este eslabón primario, nos encontramos con una diversidad de situaciones socioproductivas, con ordeñe mecánico pero con serias deficiencias de infraestructura respecto a la reglamentación vigente, con un bajo nivel de adopción tecnológica, como lo es la implementación de inseminación artificial, el enfriado de la leche y la suplementación alimenticia de las vacas generando una alta dependencia de insumos externos, entre otras. No obstante, podemos enumerar entre las principales dificultades comunes, el desconocimiento del estado sanitario de los rodeos, precarias condiciones en la rutina de ordeñe y en las condiciones de elaboración y/o conservación de la masa producida. Esto, reflejado en el trabajo de campo, arrojó una misma visión tanto en productores como en funcionarios en donde algunas de las expresiones más contundentes fueron las de un productor al decir que:

Cuando empezamos no teníamos nada, ordeñábamos a mano y teníamos 15 vacas, hoy pudimos comprar la máquina de ordeñe pero no nos alcanza para poder comprar o mejorar en otras cosas...es muy difícil poder juntar plata para hacer alguna mejora, porque lo que ganamos con la venta gran parte se va en alimento y en gastos del campo. (E.P.2).

A la vez que un funcionario declara que "yo veo tambos, veo fábricas que no cumplen con los estándares y con las obligaciones, no hacen análisis de enfermedades como brucelosis y tuberculosis" (E.F.N.1).

La fuerza de trabajo en estos sistemas es mayormente familiar, existiendo en algunos establecimientos tercerización de labores y/o trabajo ocasional de algún empleado. Predominando la presencia de productores familiares jóvenes que habitan el medio rural. 
Basándonos en un informe del Instituto Nacional de Educación Tecnológica -INET- (2010) podemos decir que las explotaciones familiares presentan una baja escala de producción, raramente producen más de 1.000 litros de leche diarios $\mathrm{y}$, por lo general, lo hacen con una alta estacionalidad. En muchas ocasiones se trata de tambos que realizan un único ordeñe diario y la estrategia productiva combina la producción de leche y la de terneros, aportando cada una de éstas ingresos similares. La baja especialización lechera se refleja en el nivel tecnológico, siendo común la cría al pie de la madre asociada a un sólo ordeñe, la utilización de toro a campo o a corral, la mala calidad del forraje o el uso de pastos naturales, sin suplementación o suplementando en forma reducida en momentos específicos como el ordeñe; este es mecánico a tarro y en algunos casos con línea de leche. Estas características sobre la baja adopción de tecnología, la baja productividad física y los déficits en cuanto a calidad de la leche producida, hacen que el productor sea marginal o se posicione con debilidad frente al sector industrial. Bajo tal escenario y al no desarrollar capacidades asociativas no pueden superar las condiciones que limitan el desarrollo de su producción (Alvarez y Láuria, 2013).

Por último, estas particularidades las podemos vincular con lo que Tokman llama (como se citó en Campos Ríos, 2006), la consolidación de la informalidad, evocando una serie de procesos que empiezan a suceder en la década de 1980, y que los relaciona con el comienzo de la fase de expansión de la globalización, ubicando la limitación de la acción del Estado Nacional, la reestructuración productiva y la constitución de macro mercados como los promotores de ésta.

\section{Informalidad/formalidad higiénico sanitaria.}

Los contextos abordados a lo largo de este trabajo, sumado a las limitantes de producción que caracterizan al sector de pequeños tamberos de la Cuenca del Abasto Sur, colocaron al productor 
en una situación de riesgo y vulnerabilidad, determinando la puesta en marcha de estrategias productivas que permitan garantizar su permanencia en el campo a través de la producción y venta de masa para mozzarella, en donde el sistema productivo tiene que operar bajo condiciones de informalidad, debido a que seguramente encuentre algún inconveniente para lograr enmarcarse en las numerosas obligaciones comprendidas en las leyes y normativas Nacionales, Provinciales, y Municipales. Larga lista de deberes y cumplimientos de carácter obligatorios requeridos para operar en condiciones formales, y que contradictoriamente, limitan o enmarañan el proceso de formalización; esto quedó registrado en las diferentes instancias de la observación participante en donde quedaban planteados los diversos inconvenientes para lograrlo, expresados en frases como “...hace rato que estoy intentando habilitar, pero siempre me falta algo" (O.p.a 2); o con respecto a la inversión inicial, “...pero ustedes lo que nos están pidiendo que construyamos vale mucha plata", "yo estoy alquilando, entonces toda la plata que me va a llevar construir para habilitar no la recupero más y se la queda el dueño del campo...” (O.p.a 4).

Esta proliferación de reglamentos y trámites según Campos Ríos (2006) se transforman en un número abundante de leyes, haciendo que el proceso de formalización vaya acompañado de un encarecimiento de la actividad productiva, por el hecho que para realizar y avanzar en los actos burocráticos se destinan recursos como tiempo, dinero y esfuerzo, a la vez que expone la relación directa entre el aumento del costo y el incentivo para evadirlos. En este sentido es interesante encontrar una posición común entre Campos Ríos (2006) y Hernando De Soto (1987) al afirmar ambos que el aparato gubernamental aparece como uno de los principales promotores de la economía informal.

En este proceso de formalización los productores al no poder cumplir con las condiciones que exigen las instituciones en su descontextualizado afán de convertirlos a toda costa en 
empresarios, y en nombre de la modernización someterlos a la economía formal, se limitan los apoyos oficiales, aumenta la informalidad y se llega a la aberración de volver clandestinos sus procesos y productos, considerándolos como infractores o incluso incorporar a la categoría de delincuentes (Barragán López, 2016). Esta fuerte consideración se pudo corroborar en la realidad a través de una entrevista a un productor que expresaba "pero encima...me tratan como a un delincuente y yo lo único que hago es trabajar todos los días, no es que yo no quiera estar en regla es que no puedo" (E.P. 6).

Nos es útil para diferenciar las informalidades, abordar la economía no registrada, estudiado por Porters y Haller (2004), permitiéndonos reforzar la diferenciación entre lo estrictamente normativo higiénico/sanitario y lo fiscal/tributario, comprendiendo las actividades que incumplen con los requisitos de los organismos del Estado, sea cual fuere su nivel, en materia de inscripción o registro de la producción, siempre dentro de actividades informales relacionadas con bienes lícitos (leche), produciendo por fuera del ámbito de la regulación del Estado, pero teniendo como objetivo la supervivencia de una persona o de un hogar a través de la producción directa con fines de subsistencia (economías informales de supervivencia). Narodowski (2013) sobre estos puntos, reflexiona en torno a la optimización de los recursos de la esfera pública sobre dos ejes fundamentales, la mejora de las unidades productivas por medio de la intervención estatal, para acompañar el progreso de estas y minimizar los riesgos y la precariedad de este sector vulnerable, a la vez de buscar una menor complejización de la formalización, debido a que el aumento de las regulaciones pueden ser determinantes para la definición de la estructura económica - productiva y del rol de los actores, por el hecho de que a la hora de agregar valor, los organismos requieren una serie de exigencias difíciles de cumplir en la práctica. Este punto es lo que nos lleva a proyectar que las producciones de masa para mozzarella que se encuentran 
funcionando en condiciones de marginalidad y precariedad, hacen que el encuadramiento dentro de los canales formales de producción, le originen una complejidad que los volvería insoportablemente dependientes de procedimientos administrativos, tecnocráticos y burocráticos, que atentarían contra la tipicidad, calidad e incluso permanencia en la producción de la misma (Barragán López, 2016). En este sentido un funcionario admitía que:

El productor tiene que estar inscripto en el sistema L.U.M.E. (liquidación única mensual electrónica) para también tener que inscribirse como operador de lácteos a través del R.U.C.A (registro único de comercialización de alimentos) y a la vez que deben inscribirse en el SiGLEA (sistema integrado de gestión de la lechería argentina), trabajando estos sistemas interrelacionados con los datos de AFIP y SENASA para cruzar, corroborar y estudiar incompatibilidades para accionar. (E:F:N: 2).

En torno a esto es sumamente interesante lo que plantea la CEPAL (1980) al afirmar que la economía informal puede cumplir el papel de un entorno protector que evita la carga de regulaciones caras y complejas que pueden hacerlos fracasar prematuramente o poner en riesgo su crecimiento, floreciendo la conjetura que a medida que las unidades productivas maduran, ingresan a la economía formal contribuyendo a su crecimiento (Portes y Haller, 2004), y esto lleva a relacionar directamente la posibilidad de entrar en la esfera formal a partir del aumento de su escala productiva.

Por último nos podemos basar en una conceptualización trabajada por Campos Ríos (2006) en donde define el fenómeno de la informalidad en la economía contemporánea, como una respuesta a las incapacidades de la economía tradicional para construir un proyecto de desarrollo que acobije a amplios sectores de la sociedad. $\mathrm{O}$ a partir de lo expresado por la CEPAL con otra 
mirada sobre la construcción de las políticas de regulación, se busca favorecer a ciertos sectores a costa de los intereses y de las raquíticas economías de los pequeños productores. Si la intención oficial que predomina -inducida por los intereses de empresas transnacionales - fuera congruente con sus discursos, se apoyaría con inversión pública para las pequeñas unidades de producción agropecuaria, se simplificarían y adecuarían los trámites y robustecerían el apoyo a sanear los hatos de los pequeños productores como la mejora de la infraestructura básica y productiva, facilitando el intercambio de conocimientos entre productores y de éstos con la academia sobre las buenas prácticas de manufactura que cada uno de esos actores conoce; y finalmente habría que invertir también en facilitar o al menos en no obstaculizar con normas inaplicables para el acceso a los mercados (Barragán López, 2016) en forma justa, ya que la comercialización al igual que la producción se realiza por canales informales, generando incertidumbre, inestabilidad en los precios de venta y una posición desventajosa ante los intermediarios y la industria. Lo mencionado anteriormente, se ha podido confirmar durante las observaciones participantes en las que solo se encontraban productoras/es y técnicos/as, ya que hay una diferencia que va a hasta un $30 \%$ más de precio final a la masa comercializada por los canales formales (O.P.b.2 y O.P.b.4).

\section{Informalidad/formalidad fiscal/tributaria.}

Los Pequeños Productores Familiares poseen explotaciones que por sus dimensiones, disponibilidad de medios de producción y, cantidad y calidad de bienes producidos, no alcanzan a generar excedentes para la acumulación de capital, o bien, visto desde otra perspectiva, no alcanzan a generar ingresos mayores a los necesarios para sostener la reproducción simple de una unidad. Este deterioro en los procesos productivos sumado a la baja rentabilidad hace que, insertos en las cadenas agropecuarias en condiciones de muy baja productividad (Rossi y Leon, 
2005), actúen por fuera del sistema registral tributario. Por esto se observa necesario un consecuente inicio de un proceso de acumulación que los contenga e involucre en condiciones sostenibles en la esfera económica donde actúa (Rofman, 2005) con acuerdos sectoriales y promoviendo los incentivos económicos, crediticios y fiscales a partir de un estímulo asociativista. Según Álvarez (2013), ello dará el marco que generará capacidades para el inicio de un proceso de formalización que minimice los obstáculos, dificultades y consecuentemente los riesgos de éste, desnaturalizando, como lo indica Barragán López (2016), la tendencia estatal de contribuir a la clandestinidad mediante normas improcedentes.

Podemos aquí utilizar dos términos genéricos de la economía utilizadas por Feige (como se citó en Portes y Haller, 2004), en primer lugar, la "economía informal", que abarca las actividades económicas que omiten el costo que supone el cumplimiento de las leyes y las normas administrativas que rigen las relaciones de propiedad, el otorgamiento de licencias comerciales, los contratos de trabajo, los daños, el crédito financiero y los sistemas de seguridad social de las que se encuentran excluidos. Y en segundo lugar utilizaremos "la economía no declarada", que consiste en la realización de acciones que soslayan o evaden las normas impositivas establecidas en los códigos tributarios, esto es que el monto de los ingresos que deberían declararse a las autoridades impositivas, no se declaran (Portes y Haller. 2004), representando en un productor un ejemplo posible de las producciones estudiadas en este trabajo al entrar en los circuitos formales:

Yo estoy habilitado, hago remito, tengo bolsa y todo, pero no puedo facturar todo, todo lo que vendo, porque si no, me paso de lo que me pide el contador, y si me paso, me cobran una cantidad de plata que sería imposible de que pueda pagar. (E.P: 7). 
Una característica no menor que nos ayuda a dimensionar y contextualizar la descripción de estas situaciones económicas, en donde las personas transitan su actividad dentro de la informalidad, es que los individuos comprendidos dentro de este universo pertenecen a la Población Económicamente Activa (PEA) y que no son desempleados (Campos Ríos, 2006), por el contrario son responsables de las unidades productivas, con capacidad de gerenciamiento y decisores de las estrategias productivas.

El escenario planteado se desarrolla en un marco donde los sistemas de administración tributaria no cuentan con categorías de contribuyentes específicas para pequeños productores, que se encuentran incluidos como productor primario debido a la denominación por parte de la ley $\mathrm{N}^{\circ}$ 11.089. De tal manera, se comprueba que el sistema registral no contempla la situación del pequeño productor, lo que implica las mismas obligaciones que dicho sistema les impone a los medianos y grandes productores. Al preguntar sobre este escenario a un funcionario nos advierte que:

Si se quiere apuntalar a las pequeñas producciones tendrían que existir contemplaciones para ellos, para mi debería ser así, ojo si queremos estimular la lechería, sino se estimula a los grandes productores y se deja de lado a los pequeños para que se fundan, que puede ser una política no...que se queden los grandes y que los chicos se fundan y desaparezcan. (EFN: 1).

Esto demuestra que, tratados como cualquiera de los grandes tambos empresariales, para el pequeño productor implicaría involucrarse en un nuevo universo administrativo de facturación y contabilidad electrónica, nómina, carga fiscal, cuenta de cheques, clave bancaria para las declaraciones por sistemas (Internet), inscripción a sistemas de seguimiento y declaración, etc.; 
sumado a que lo deben poder llevar a cabo en un medio con serias deficiencias de infraestructura y servicios públicos que aqueja a las zonas rurales y claves para el acceso fluido y practicable de la información (Barragán López, 2016) con la que no se cuenta. Al momento de analizar los datos recabados en las entrevistas, la totalidad de los productores entrevistados y un alto porcentaje de los técnicos, manifestó no conocer con claridad la hoja de ruta para la habilitación de los establecimientos, diciendo "no sabemos lo que tenemos que hacer para habilitar" (E.P.3) declaraba un productor, a lo que un funcionario abonaba "nos han dicho en más de una ocasión que la verdadera dificultad esta puesta ahí, en no saber qué es lo que uno tiene que hacer...” (E.F.N.4). Resultado de la complejidad que atañe a la comprensión de esta información que involucra los tres niveles gubernamentales con varias de sus reparticiones, el acceso a la información de calidad, claridad y funcional ${ }^{50}$. Cuestiones estas, que tuvieron una altísima mención en las entrevistas e intercambios, en las instancias de observación participante y en todo ámbito relacionado o destinado a los procesos de formalización de la actividad, destacándose posiblemente como una de las principales causales de los riesgos para lograr y sostener la formalización. Clarificando la situación a través de la visión de un funcionario Nacional al decir:

La exigencia que se le debe requerir a un productor chico es distinta a la que se le tiene que requerir a uno que tiene contador, acceso al sistema informático, y con su oficina en Buenos Aires, es distinto, entonces, hay que manejar la cosa de forma diferente, pero bueno se maneja todo igual. (EFN: 1).

Estas problemáticas estructurales sumadas a cuestiones vinculadas con las condiciones/calidad de vida (vivienda, acceso a educación, etc.) no solo son causas centrales para el incumplimiento

\footnotetext{
50 2. adj. Dicho de una cosa: Diseñada u organizada atendiendo, sobre todo, a la facilidad, utilidad y comodidad de su empleo. Real Academia Española (C) Todos los derechos reservados. https://dle.rae.es .
} 
de las normas impositivo/previsionales, sino que a su vez desalientan la permanencia de las nuevas generaciones dentro de las zonas rurales y en los sistemas de producción de los pequeños productores (Rofman, 2005).

Es sobre estas dimensiones que Álvarez (2013) expresa que para promover la permanencia de los tambos es necesario conocer, entender y atender las principales causas que afectan su sustentabilidad, incluyendo de forma indisociable aspectos productivos, sociales, económicos y ambientales. Son estos obstáculos los que encuentran los pequeños productores al momento de iniciar un proceso de formalización, todas perfectamente enmarcadas en políticas macroeconómicas y sectoriales necesarias para adecuar las realidades y confeccionar una estrategia para el manejo sustentable de los recursos regionales (Barkin, 2002).

Estas Políticas macroeconómicas y sectoriales con necesidad de adecuación y reformulación, las toma en cierta manera Rofman (2005) al plantear que la capacidad de hacer frente al desafío de integrar, contener y fortalecer las pequeñas producciones, implica una verdadera revolución productiva y técnica en las actividades agroindustriales nacionales, dado que no es lo mismo la capacidad de afrontar estas realidades por parte de un productor mediano y/o de un gran productor capitalizado con relaciones formales dentro y fuera del sistema económico y estrechos vínculos con las instituciones financieras del país y/o del exterior que por un pequeño productor con ingresos subsistenciales o, incluso, menores a su sobrevivencia digna, con una inserción informal y sin canales de obtención de crédito institucionalizado; expresado con claridad en una entrevista:

Para mí la informalidad es un tema económico. Una complicación económica, es tan complejo que al tipo le resulta lamentablemente más fácil, estar en la informalidad que estar en la formalidad. Es sencillo, lo complica tanto, pierde plata, tiempo, se siente....en 
vez de apuntalado por el estado se siente presionado, entonces el tipo sigue así, toda la vida sigue así, me la compran, sobrevivo. (E.F.N: 4).

Este singular contraste impone una evaluación correcta de las capacidades diferenciales de acceso que tienen los productores agropecuarios argentinos según su tamaño, recursos financieros, acceso a la información y posibilidades de obtener financiamiento y asistencia técnica en abundancia y a bajo costo. Pero aún, si todo lo expuesto estuviera al alcance del pequeño productor, su posibilidad de entrar en el circuito de los ganadores queda fuertemente opacada cuando se reconoce que actualmente los ingresos que obtienen lejos están de alcanzar una magnitud tal como para sostener a su familia en la satisfacción de sus necesidades básicas, y lograr un excedente suficientemente significativo como para financiar todos los compromisos que la citada inserción supone. Más aún, si se sitúa en una estructura tributaria regresiva que convive con espacios de renta libre de imposiciones, y que revela una debilidad en la alianza política de este sector marginal, atentando con la posibilidad de romper con estructuras oligopólicas y oligárquicas y generar un sistema estatal fuerte, incluso haciendo inestable el modelo macro. Es claro que se trata de la construcción política del mercado, y al mismo tiempo del Estado, es decir, es un producto de la lucha política por imponer un determinado modelo de economía, de sociedad y de Estado (Narodowski, 2013). 
Figura 16: Dimensiones a abordar en un proceso de formalización.

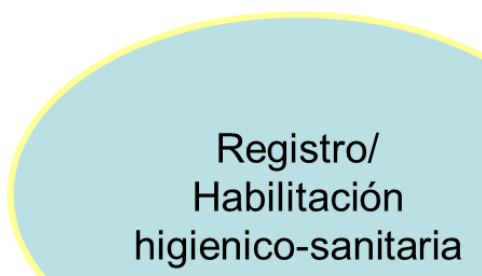

Registro/ Inscripción

Tributario-Fiscal.

Fuente: Butler, L. Elaboración propia.

\section{Estructura de los mercados, eslabón comercial, agroindustria.}

Los organismos encargados del registro, habilitación y contralor de las unidades tamberasmaseras son la Dirección de Lechería y la Dirección de Productos Lácteos de la provincia de Buenos Aires. Estas direcciones tienen la misión de registrar y habilitar todo establecimiento elaborador de productos lácteos instalados en el territorio provincial. En sus registros cuentan con 303 plantas industriales, de las cuales 22 no se encuentran en funcionamiento (MAGyP, 2019).

Según estimaciones realizadas en la provincia de Buenos Aires se procesaron un total de 10.265.358 millones de litros de leche (MAGyP, 2019). El sector industrial involucrado dista 
mucho de ser homogéneo, así lo refiere Craviotti destacando la gran heterogeneidad del sector industrial y productivo. Motivo por el cual se dificulta englobar toda la agroindustria bajo la denominación de agronegocios (Craviotti, 2017), se observan además, diversas escalas de procesamiento y de formas empresariales, y una clara asociación entre el tamaño de las explotaciones tamberas y el tamaño de la planta receptora Pucciarelli (1993). Esto se ve reflejado en que solamente en tres partidos de la Provincia de Buenos Aires se procesa el $60 \%$ de la materia prima (MAGyP, 2019).

La masa para mozzarella es comercializada por los productores a distintos intermediarios o directamente a fábricas de mozzarella, teniendo estos dos canales un común denominador, el alto porcentaje de informalidad, estimándose que la mozzarella elaborada y consumida proveniente de circuitos informales de producción y comercialización se encuentra por encima del $50 \%$ (Revista Infortambo, 2017). Es interesante como Bisang et al. (2003) ubica esta informalidad como rasgo central en la estructura empresarial agroindustrial, observándola variable según los años y creciente durante períodos de crisis. Se trata de firmas que en su gran mayoría son productoras de quesos blandos, operando gran parte al margen de controles sanitarios y de calidad, y de las normativas legales sociales e impositivas. En períodos de fuerte crisis, este estrato engloba también a empresas medianas que se "deslizan" desde el circuito formal. La dinámica de entrada y salida de las dimensiones de lo formal y lo informal no tiene grandes impactos en cuanto a la demanda de la materia prima ya que la existencia de un entramado de relaciones entre los productores que pertenecen a una misma comunidad facilita la construcción de reputación a los compradores; así, a partir de su vínculo inicial con algún productor que se constituye en referente en la zona éste logra acceder a otros, construyendo vínculos de confianza, con una gran asimetría de poder entre productor y acopiador que posibilita a este último fijar las 
condiciones de la transacción (Craviotti, 2017). Es interesante poder corroborar mediante el trabajo en terreno estas afirmaciones, ya que se observó una relación de confianza entre los productores y la industria, construida a través de la realización de pagos a término, de la compra de la materia prima de manera continua aun en condición informales y del mantenimiento de precio a lo largo del año (por más que este sea bajo), al respecto los productores expresaban:

A X le voy a vender siempre, por más que aparezca uno que me pague más que $\mathrm{X}$ no me importa porque hace años que le vendo, nunca tuvo una queja, siempre me pago a tiempo, le vendo masa desde que empecé y si alguna vez necesité algo, él estuvo para ayudarme. (E.P.7).

A lo que otro productor sostenía “...a X le vendí siempre y le voy a seguir vendiendo porque siempre se portó muy bien con nosotros..." (E.P.6).

Dimensionando la multiplicidad de combinaciones existentes entre empresas y productores, e incluso al interior de cada empresa, deriva en que no exista un precio único y fiable como buen predictor de negocio o precio justo. Esta conformación estructural, lejos de generar equilibrio, equidad y certeza de transacciones justas a largo plazo (deseable en proporciones distintas tanto por la producción como por la industria) tiene algunos aditamentos que cobran mayor o menor relevancia de acuerdo con la relación de escasez y/o abundancia de materia prima frente a requerimientos de la demanda (Bisang et al., 2008).

Es en este contexto que se presenta un importante desafío sectorial para sostener la competitividad de las pequeñas y medianas explotaciones tamberas y de las pequeñas y medianas Pymes de la industria lechera. Estos últimos establecimientos, a pesar de su baja relevancia en el total de la producción, tienen un significativo impacto socio-productivo por su inserción 
territorial en espacios y localidades rurales (INET, 2010), otorgándoles una gran importancia en las dinámicas económicas locales, o como las denomina Rofman (2005) en los circuitos productivos, que comprenden a un conjunto de unidades de producción, distribución y consumo que actúan vinculadas entre sí a partir de una actividad común a todas ellas, comenzado desde el inicio del proceso y que se van encadenando, en forma consecutiva, acciones de transformación e intercambio hasta obtener el producto final que va al mercado de consumo. Dentro de estos circuitos hay una dominancia de una o varias actividades claves, las cuales van a ejercer el control del reparto del excedente económico global producido en el circuito e imponiendo a los demás agentes económicos que operan en el mismo, su poder dominante de negociación, apropiándose de parte del valor agregado que otros han producido por desplegar al interior del circuito productivo las relaciones de poder asimétricas. Esta situación se ve expresada en la disminución de la rentabilidad por los precios relativamente bajos que reciben las pequeñas unidades tamberas, en virtud de la circulación de la producción y de la incidencia de las distintas funciones comerciales que, lejos de conformarse de acuerdo a condiciones de transparencia y de costos reales de intermediación, se basan en la existencia de altos costos de transacción, baja calidad de la producción y problemas de gestión y acceso a la información (Rossi y Leon, 2005). A su vez hay que tener en cuenta para el análisis, que los bienes y servicios suministrados por los productores informales a la agroindustria, reducen los costos de consumo de los trabajadores de la economía formal y los costos de producción y distribución de las empresas formales, contribuyendo de este modo a su viabilidad económica (Portes y Haller, 2004). 
Figura 17: Variables y condicionamientos de la informalidad.

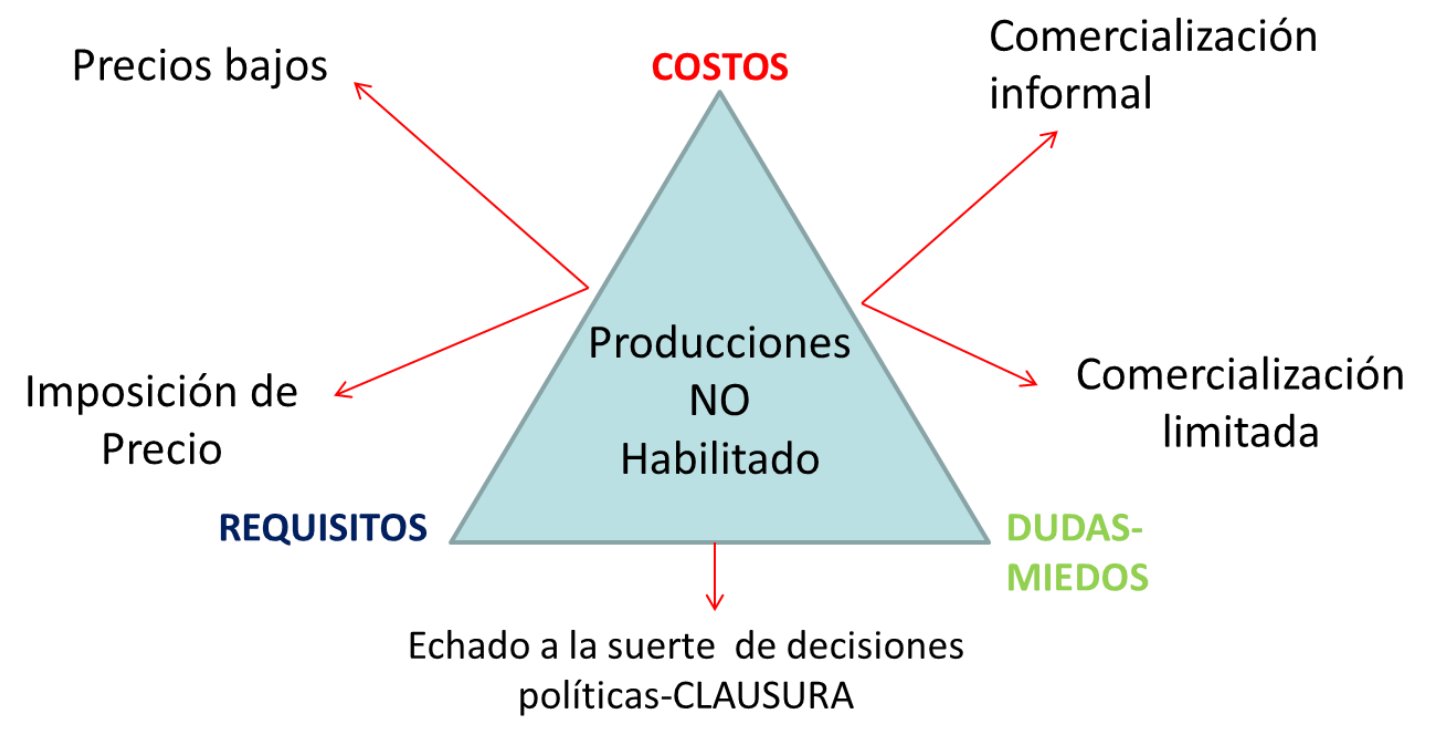

Fuente: Butler, L. Elaboración propia.

El estado, las Instituciones no gubernamentales inherentes y sus concepciones sobre la formalidad/informalidad.

En el desarrollo de este punto se habrá de contextualizar y describir la lógica propia y la convivencia entre los sectores públicos y privados en relación a la trama productiva tambera masera de la Cuenca del Abasto Sur. Pretendemos enfocarnos en el proceso de formalización, desde la perspectiva de construcción de las regulaciones del estado que hacen a la formalización de las unidades productivas. Estas medidas políticas, merecen e implican un debate sobre el rol del Estado para con este sector (Min. Economía de la Prov. de Bs. As, 2001).

En la Argentina, históricamente la representación institucional a nivel del sector primario lechero estuvo fragmentada, conviviendo simultáneamente Cámaras de productores y Mesas de Lechería, 
tanto a nivel nacional, interprovincial, provincial, y por cuenca productora, imprimiéndole una gran cuota de dificultad a la hora de concretar las negociaciones, acuerdos y avances para la cadena, sin lograr consolidar un espacio de negociación común entre todos los actores involucrados (Castellano, 2014). Esta dispersión puede ser la causa de la baja representatividad y poder de lobby estatal (Nogueira, 2010).

Según FUNPEL ${ }^{51}$, fundación que nuclea a entidades gremiales de producción primaria, pymes y entidades gubernamentales con injerencia en la trama láctea, consideran que la construcción colectiva es de suma importancia, expresando ser el único camino para la planificación estratégica sectorial o por cadena (Mozeris et al., s/f), a partir de la coordinación de la sociedad civil y las alianzas público - privadas (IICA, 2010).

Esta planificación estratégica sectorial planteada por FUNPEL requiere de acuerdos entre agentes económicos de un sistema agroindustrial, y al mismo tiempo, la definición de un marco organizacional e institucional para su ejecución. Este planteo en los términos del presente trabajo se puede ver reflejado en dos ejemplos concretos y reales, en un primer caso si el marco institucional permite o recompensa la evasión fiscal, los agentes económicos optaran por la evasión impositiva y la informalidad. En su defecto, si el Estado a través de sus marcos legales e institucionales, con sus normativas y burocracias, sumado a los requerimientos de los mercados y a las exigencias de las grandes empresas, pretende imponer un modelo de desarrollo unilineal, uniformador de lógicas y prácticas económicas, resultara inadecuado frente a la situación y condiciones económicas y/o culturales de los productores primarios a pequeña escala, perjudicando la sostenibilidad y poniendo en peligro la viabilidad económica de estos (Barragan

\footnotetext{
${ }^{51}$ Fundación para la Promoción y el Desarrollo de la Cadena Láctea Argentina.
} 
Lopez, 2016), dando como resultado el aumento, como el caso anterior, de la evasión y la informalidad higiénico sanitaria. En el mismo sentido Portes y Haller (2004) analizan sobre la misma óptica que cuanto mayor es la amplitud y el alcance de las medidas de regulación que intenta aplicar el Estado, tanto más variadas serán las posibilidades de evitarlas (Portes y Haller, 2004).

Situándonos desde la esfera de los pequeños productores se puede percibir que las medidas tienden a la intensión de su conversión en "empresarios", no solo desde lo estrictamente gubernamental (por sus marcos legales, burocracias y normativas), sino que también por parte de instituciones académicas, técnicas y científicas (con sus propuestas de cambio técnico aparentemente neutro), y de los mercados, tomando como única salida para la sostenibilidad de las pequeñas producciones familiares la estandarización productiva, la maximización de la producción y en consecuencia la transformación a empresa agropecuaria. En definitiva esta conversión al tipo de producción empresarial, acarreará una entrada a la economía formal de los productores, haciéndolos transitar en un terreno desconocido y por demás requisitorio y complejo, tornándolo según Barragán López (2016) en un verdadero laberinto sin salida, basado en la proliferación de reglas y controles por parte del Estado para abordar las actividades no reguladas (siendo muchas veces, ellas mismas las que inducen la irregularidad). En el siguiente grafico elaborado por la CEPAL se observa que cuando los controles del Estado son limitados, la mayor parte de la actividad económica se autorregula y se realiza a través del sector formal, pues no contraviene ninguna norma oficial. A medida que aumenta el número de reglas, aumentan concomitantemente las posibilidades de soslayarlas hasta que, en la situación límite, se pueden violar las normas en toda la economía para obtener beneficios (Portes y Heller, 2004). 
Figura 18: Variabilidad de la informalidad en relación a la regulación estatal.

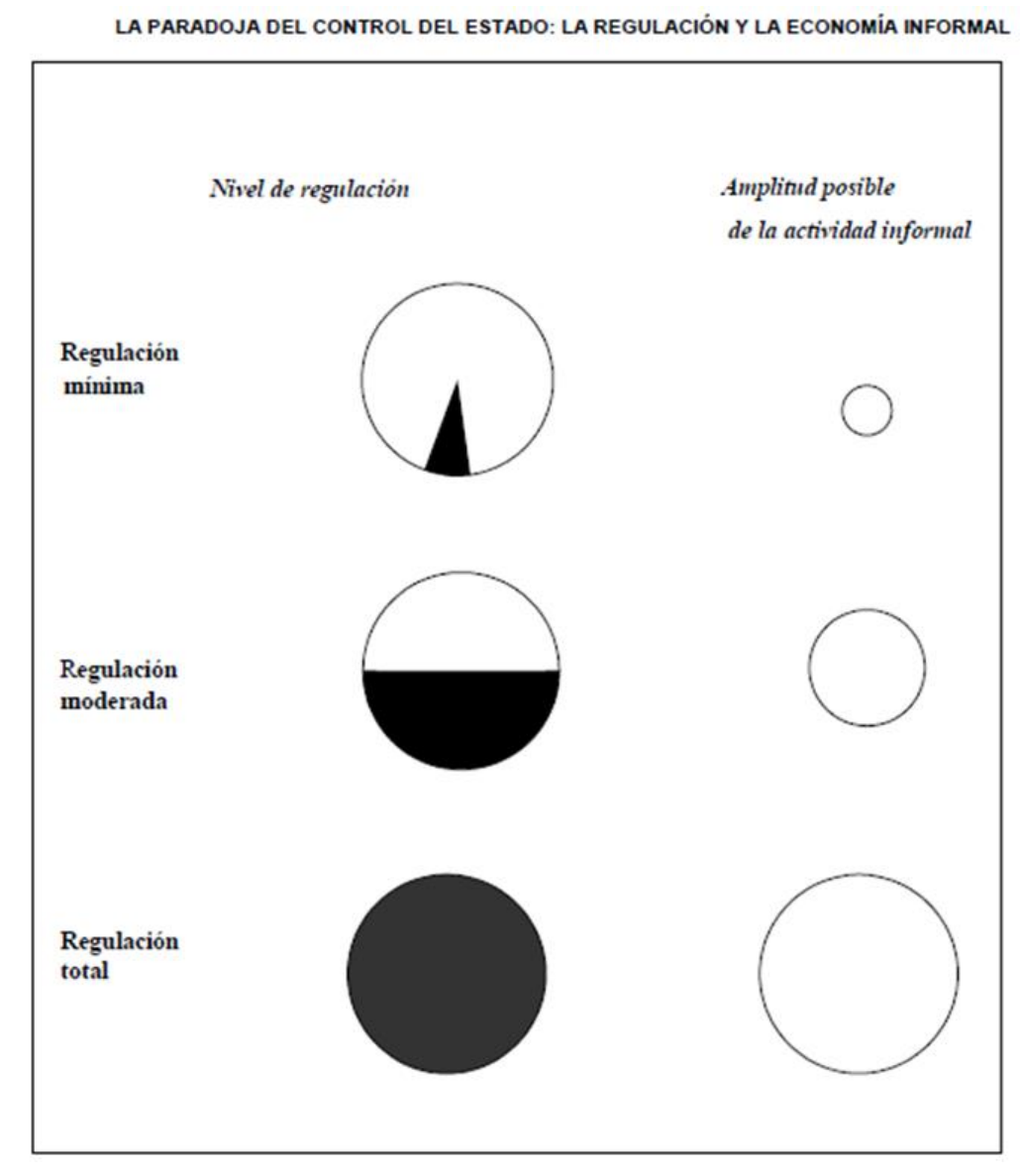

Fuente: extraído de Portes, Alejandro; Heller, William. 2004. (Pag. 23).

De ahí que la FUNPEL le otorga importancia a un buen diseño institucional, que tienda al retorno de facilidades y estímulos que recompensen el esfuerzo por la inclusión en los circuitos formales, desalentando los fenómenos contrarios. Es así, ya que se considera que la eficiencia y la equidad de una sociedad dependen en buena medida de su sistema institucional y de la calidad de sus organizaciones, capaces de hacer efectivos los acuerdos arribados en la cadena productiva y capaces de formalizar la concertación entre los actores, tanto como entre estos y los gobiernos 
nacionales y subnacionales, para que a partir de allí se coordinen las políticas públicas. Se corrobora entonces, que los actores involucrados acostumbrados a la ausencia del Estado, compensan a través de la autosuficiencia los medios para sobrevivir, desconfiando de cualquier intervención oficial, considerándose la organización de unidades prodcutivas informales como una cosa normal y la participación en la economía informal como una forma justificada de resistencia, a lo que un productor expresaba:

Toda la vida trabaje así, ahora vienen con todo eso de la habilitación, pero si yo habilito me van a hacer pagar de todo y no sé si me va a alcanzar y no sé qué me va a pedir SENASA, porque siempre vacuno pero cada vez que voy a la oficina un problema tengo. (E.P.1).

Barragán López (2016) hace un recorrido por diferentes experiencias en distintos países sobre la representatividad del sector y sobre los espacios de diálogo, coordinación y concertación entre los agentes económicos que conforman las cadenas lácteas. En su trabajo, manifiesta que en todos los casos las relaciones e interacciones tienden a planificar y ejecutar actividades orientadas a fortalecer y mejorar la competitividad del sistema, destacando la acción colectiva y las alianzas productivas, impulsando acuerdos, vínculos y/o compromisos entre dos o más eslabones de la cadena, coordinando recursos humanos y financieros, técnicas y metodologías, así como esfuerzos y habilidades, con el objetivo estratégico común de lograr beneficios mutuos, avanzar en acuerdos y, sobre todo, compromisos publico/privado para marcar un rumbo común de adecuación de los marcos legales e institucionales a las múltiples realidades de las pequeñas producciones, con acciones que tiendan a que las políticas sean expresadas en marcos normativos, programas, proyectos y voluntades, que atiendan las necesidades y realidades que enfrentan cotidianamente la mayoría de los pequeños productores. 
Estas instancias ayudarían a encontrar puntos en común entre todos los actores involucrados para abordar las diferentes problemáticas o puntos críticos que interfieren u obstaculizan un proceso de mejora de la cadena con equidad. Si dicha instancia no se logra, los esfuerzos del Estado para afrontar la actividad económica no regulada, pocas veces permitirá alcanzar su objetivo ya que sumado a la normalidad de los actores en la participación de esta, se activarán sistemáticamente las fuentes latentes de solidaridad de la población, produciendo resultados opuestos a los buscados (Portes y Haller, 2004), dado que los actores al no formar parte de las decisiones y acciones por parte del Estado, toman la economía informal como una respuesta a la interferencia inapropiada de este, demostrando una gran capacidad de resistencia, y que lejos de desaparecer, puede subsistir y florecer en forma subterránea, así es que Lomnitz (como se citó en Portes y Haller, 2004) señala "el orden crea el desorden y la economía formal crea su propia informalidad".

Ante las numerosas presiones que reciben los gobiernos para luchar contra la economía informal, lo cual, sumada a la incapacidad de comprensión, es común encontrar dos caminos del manejo del conflicto, una es emprender contra ella, en un marco de violencia gubernamental (Campos Ríos, 2006), o adoptando una actitud ambigua, tolerando su existencia al menos temporalmente, acarreando como riesgo, poner en entredicho la credibilidad y la disposición de los "formales" a seguir cumpliendo con sus obligaciones. Si tomáramos la primera, se contribuiría a eliminar el "colchón" que constituyen las actividades informales o, lo que es peor, puede impulsarlas a esconderse aún más, privando a las autoridades de todo tipo de control e información sobre ellas, ocultando sistemáticamente información a los agentes del gobierno, logrando eficazmente la resistencia. En este sentido Cross et al. (como se citó en Portes y Haller, 2004) nos ayuda a la comprensión de la importancia de esta situación al decir que la economía informal contribuye a 
la estabilidad política y la viabilidad económica de las naciones más pobres, ayudando a explicar por qué generalmente muchos gobiernos toleran las actividades informales en contradicción con sus obligaciones en materia de fiscalización.

\section{Evolución y estado actual de la producción masera en la cuenca de Abasto Sur.}

La Cuenca del Abasto Sur, cuyo nacimiento se produjo por su cercanía al mayor centro de consumo urbano del país, se vio diezmada por varios factores, pero dos centrales para su estructura y transformación: uno fue el cierre masivo de tambos y el otro el pasaje masivo de la formalidad a la informalidad. Como consecuencia del periodo de dominio, exigencia y condicionamiento por parte de las usinas lácteas en cuanto a condiciones de calidad y volumen de la leche remitida a sus instalaciones (Vertiz, 2017), condiciones que únicamente podían ser alcanzadas por los tambos a través de importantes inversiones en materia de infraestructura e instalaciones, maquinarias, siembra de pasturas, compra de animales, etc.

Estas adopciones tecnológicas tendrían que haber sido asumidas, por su importancia, por el Estado, a la hora de pensar los procesos de transformación, para consecuentemente promover y avanzar con éxito en el desarrollo de un nuevo modelo agropecuario (Álvarez, 2013) disminuyendo o anulando de ese modo las consecuentes marginalidades resultantes de su aplicación, para obtener una amplia adopción por parte de la gran mayoría de tambos, al respecto una productora describía:

Toda mi vida fui tambero, nos casamos y mi papá nos dio este pedazo de campo nos armamos el tambo, vendíamos leche, ordeñábamos unas 30 vacas a mano y con eso vivíamos, no nos sobraba la plata pero vivíamos, hasta que un día nos dijeron que no iban

a pasar más porque era muy poca leche, nos habían ofrecido prestarnos plata para 
comprar una máquina de ordeñe y algunas vacas mas pero yo nunca fui de pedir prestado, así que les dijimos que no pero nos dejaron de comprar. (E.P.2).

Por el contario, el Estado, se desentendió de la intervención y dejó los procesos de transferencia tecnológica en manos de las industrias privadas, sin asumir los cambios en las prácticas generadas por esta, abocándose solo a escoltarlo mediante la implementación de normas sanitarias con enfoque punitorio (castigos, clausuras) para su implementación, disociando la transmisión de conocimientos con el cambio en las conductas, aislándose del diálogo y la participación de los actores involucrados (Fernández et al., 2010), produciendo como consecuencia procesos de marginalidad y desaparición. Esta dinámica de desaparición de establecimientos queda plasmada en un productor que expresaba:

Acá estaba lleno de tambos, éramos un montón los que teníamos, pero de a poco fueron cerrando, quedamos casi solos, hay uno sobre la ruta y el otro cerca de acá derecho por esta misma calle, todos los demás cerraron porque les dejaron de comprar leche y no sabían que hacer. (E.P.5).

En el año 2011 en la provincia de Buenos Aires se identificaron 397 tambos pequeños, albergando la cuenca Abasto Sur el 32\% del total provincial, unos 140 tambos (Marino, 2011), que por su escala de producción y su baja adopción tecnológica se dedican a la venta de pequeñas cantidades de leche fluida en forma particular, a la elaboración de quesos y en su mayoría a la elaboración de masa para mozzarella. Situaciones y cambios productivos a los que se vieron obligados a afrontar por el modelo de desarrollo basado en la estandarización de procesos y productos, que fueron acompañados por un desplazamiento hacia la informalidad 
higiénico sanitaria y económica y que lejos de disminuir, es una tendencia que se ensancha y que cada día se torna más difícil de franquear. (Barragán López, 2016).

En la Argentina se calcula que más del $50 \%$ de la Mozzarella elaborada a través de masas premaduradas está por fuera de los canales formales de producción y comercialización. De este porcentaje gran parte se encuentra en la provincia de Buenos Aires, con 150 tambos-fábrica registrados, un número que no es representativo dada la cantidad de establecimientos que producen y comercializan de manera informal. Esto lo podemos observar en el trabajo de campo realizado por Castellanos et al. (2009) en base a un relevamiento realizado por el MAA (2007), en donde indica que en la Cuenca del Abasto Sur se encuentran 33 tambos fábrica, comparado con el trabajo de campo de la presente tesis, el número por lo menos duplica este dato. Esto se ve reflejado en una entrevista a la industria que nos señalaba:

Nosotros sabemos que compramos masa informal, pero no es que buscamos esa masa en particular, lo que pasa es que hay muy poca masa formal para comprar, si nosotros no compraríamos esa masa nos fundimos, porque la enorme mayoría de la masa que tenemos para comprar cerca, es informal. Cuando la Provincia nos interdicto ${ }^{52}$ muchísima masa por ser informal empezamos a comprar a tambos fabrica habilitados, pero venia de muy lejos con un gran costo de flete, y a un precio muy pero muy alto que no nos iba a permitir sacarle ganancia. (E.I.2).

Es muy importante por último, hacer mención al aumento exponencial de tambos elaboradores de masa que se logró identificar desde su autorización (allá por la década del 1980), hasta la actualidad, no solo como actividad principal, sino también como actividad complementaria.

\footnotetext{
52 2. m. Der. Juicio posesorio, sumario o sumarísimo. (Real Academia Española- https://www.rae.es/)
} 
Trabajando en torno a esto el resultado podemos esbozar tres momentos claros en la presencia y surgimiento de los tambos fábrica. Un primer momento que coincide con su autorización, que es el de "reconversión inicial", y no son más que los tambos que se encontraban entregando leche fluida y que se vieron incapacitados de seguir entregando por las inclemencias climáticas, una segunda etapa que la podemos encuadrar dentro de una "reconversión inducida" por la imposibilidad de cumplir con las exigencias tecnológicas requeridas por las usinas. $\mathrm{Y}$ un tercer momento que se lo puede denominar de "emergencia plena" que son los nuevos jóvenes tamberos que encuentran en esta producción una forma de vida. Un alto porcentaje de estos nuevos productores maseros lo hizo y lo hace por fuera de los canales formales, al hacer eso, se encuentra que realizando una muy baja inversión en infraestructura precaria y con un número reducido de animales, alcanza para producir, elaborar y mantener una familia, teniendo asegurada una alta demanda del producto y una fácil comercialización a partir de intermediarios, o directamente a fábricas con retiro en campo, al respecto una productora sentenciaba:

Cuando yo empecé ordeñaba en ese tinglado que tenía cuatro chapas, no tenía paredes y el piso era de barro, estuve muy poco tiempo ordeñando a mano, pero estuve, y al poco tiempo me compre una máquina de ordeñe de 2 bajadas, y ahí estuve mucho tiempo ordeñando 9-10 vacas, a ese tingladito le debo mucho. (E.P:3).

Esto nos da a entender que más allá de los precios bajos obtenidos, estos significan un capital circulante de rápido retorno, tornándose una alternativa para muchos jóvenes por generar un ingreso semanal, sencillo, de transacción directa, rápido y de bajo costo. 


\section{Conclusiones}

A lo largo de este trabajo se han abordado una serie de cuestiones relativas a los cambios producidos en la trama láctea en los últimos treinta años, a los requisitos para su formalización y a la informalidad como una situación estratégica y necesaria para la sostenibilidad de las unidades productivas tamberas-maseras, como consecuencia de la imposibilidad de alcanzar los requisitos y de sortear los inconvenientes surgidos en los procesos de formalización. Abordaje que tiene como fin contribuir al conocimiento de los modos y las características que asume el pasaje de la informalidad a la formalidad productiva para estas pequeñas producciones familiares, atendiendo especialmente a las consecuencias y riesgos que implicaría dicho pasaje.

De las primeras conclusiones a las que se puede arribar, y probablemente la más importante, es el debate sobre la visión del sujeto informal, planteándose dentro de los términos productivos del presente trabajo que ninguna persona es informal, sino que lo informal es su producción, o sus medios de producción, siendo la persona absolutamente legal y formal, con derecho e identidad, con necesidades y problemáticas a la que se le tiene que asegurar la seguridad laboral y social. Esta visión es indispensable a la hora de iniciar un debate serio sobre los cambios estructurales necesarios para con las lógicas productivas

Realizamos un recorrido en el que se fueron analizando los cambios tecnológicos impuestos por parte de la industria lechera y la ausencia del estado (como política pública) para evitar marginalidades y desapariciones de las unidades productivas como derivación de la misma. La intervención del Estado la vimos presente en el armado de las diferentes reglamentaciones,

normativas, programas y sistemas electrónicos a los que el productor se debe encuadrar 
necesariamente para adquirir la formalidad dentro de la actividad. Esta intervención, fue basada en una visión parcial y sesgada hacia las grandes empresas, lo que acarreó un escenario absolutamente hostil para todo pequeño emprendimiento.

Este trabajo nos muestra que, ante la decisión de generar una política pública para llevar a cabo estos cambios estructurales necesarios, el Estado Nacional, Provincial y Municipal a través de sus Organismos e Instituciones de Ciencia y Tecnología tienen la capacidad para asegurar los consensos y acompañar los procesos que posibiliten el fortalecimiento de las producciones del sector más vulnerable de la trama. Por ello, se torna necesario para poner en marcha esta maquinaria Estatal una alta asignación presupuestaria y una continua articulación territorial capaz de motorizar un proceso de empoderamiento de las familias productoras y un fortalecimiento de sus unidades productivas, integrando una estrategia de acompañamiento crediticio con un análisis pormenorizado de las obligaciones, con el objetivo de dilucidar los inconvenientes del proceso de formalización, para dar paso a las posibles readecuaciones de las regulaciones y procedimientos según las escalas y diversidades productivas. El trabajo en terreno, permitió confirmar que gran parte de la población objetivo posee en su historia alguna experiencia relacionada con la implementación de proyectos y programas estatales, que por no estar dentro de políticas públicas adecuadas no tuvieron mayores alcances y/o transformaciones en los territorios.

Se observa también, que el sistema punitivo no ha dado resultado a lo largo de los años, y que resulta necesario disminuir la brecha existente entre la tecnología disponible/requerida y la efectivamente utilizada y alcanzada. Para esto es necesaria la participación activa del productor, en los ámbitos institucionales locales, donde logren reconocer sus capacidades y saberes, y luego con plena articulación regional cumplan con la misión de combinar a los Estados Provinciales y 
Nacionales para que sean los garantes, junto con los actores privados, de la generación de innovaciones regulatorias basadas en las realidades económicas, tecnológicas y sociales. Se propone esto, desde una óptica en donde se renuncia a la idea de una discusión por una menor o más laxa regulación, seguimiento e inspección, sino que se plantea eliminar de raíz las causas que los han puesto en tal situación a través de una adecuación y sectorización de las reglamentaciones hasta el momento improcedentes. $\mathrm{Y}$ es mediante estas modificaciones y/o adecuaciones que se otorgará la posibilidad de incluir a un mayor número de unidades productivas dentro de la esfera estable de aseguramiento de inocuidad por parte del Estado, abandonando los voluntarismos políticos para avanzar hacia un proceso de fortalecimiento en base a reglas claras, concretas y establecidas por todos los actores.

La complejidad del Estado, en cuanto a los procesos de formalización abordados, nos lleva a poner en un lugar central la universalización y facilitación de la información, como medio para la minimización de los inconvenientes y riesgos que podrían surgir en éste, creyendo que parte de la generación de equidad, se alcanzará con una mayor y mejor accesibilidad a los organismos del Estado, a sus trámites por incumbencias, a sus tiempos y a sus dinámicas a través de un mejorado y creciente acceso a la misma, teniendo el interés continuo para generar la mayor interacción/acción posible, entre el Estado y el incumbido.

La bibliografía consultada, robustecida mediante el trabajo de terreno, nos arrojó la necesidad imperiosa de apuntalar la subsistencia y permanencia del sector, generando y fortaleciendo cierta evolución económica, contemplada bajo una visión de financiamiento integral, abarcativo y diferenciado, ejerciendo en forma creciente la efectividad de las acciones tendientes a elevar el ingreso y la calidad de vida del pequeño productor y su familia. Siendo crucial para su concreción, una fuerte inversión pública sobre las familias productoras y sus unidades 
productivas en materia de tenencia de tierra, infraestructura e instalaciones adecuadas a normas aplicables, potenciado por una extensión de elevado despliegue territorial para el acompañamiento, seguimiento y ejecución de los procesos, garantizando la generación de tecnologías co-construidas como medio de apuntalamiento para las necesitadas innovaciones tecnológicas, administrativas, legales y regulativas actuales. Se puede afirmar que el Estado es el único medio capaz de llevarlo a cabo, actuando como columna vertebral de las articulaciones necesarias e imprescindibles para el avance y la gestión del desarrollo del sector, por medio de sus instituciones fortalecidas capaces de hacer frente a los programas y proyectos implementados.

Se considera fundamental plantear la necesidad de abrir distintos y variados frentes de debates en cuanto a la obtención de la inocuidad y de la calidad de los productos finales de los establecimientos familiares. Sin poner en discusión lo absoluto de la "inocuidad", proponiendo rediscutir los caminos para obtenerla, siempre en el marco de la exigencia y la seriedad que la salud pública amerita.

Toca hacer mención a lo trabajado y abordado dentro del universo tributario y fiscal que más allá de que el presente trabajo no tuvo la intención de hacer un análisis profundo, nos permitió dilucidar puntos claves que se deben contemplar para la sostenibilidad de los productores y las familias productoras en sus unidades productivas. En este sentido es interesante nombrar la similitud encontrada entre la presión fiscal ejercida y las normativas higiénico-sanitarias requeridas encontrando para ambos una falta de discriminación según escala y tipo de producción, estratificación económica y sectorización productiva. La complejidad de las gestiones necesarias, sumado a la limitación de los medios necesarios para acceder a las mismas 
se refleja en un mayor riesgo de incumplir con algunas de sus obligaciones, dando como saldo una gran inestabilidad social y económica.

Por lo abordado a lo largo de este trabajo en relación a tecnologías de producción, políticas públicas, valor agregado, normativas, leyes, tributaciones y modos de producción familiar entre otras, pudimos comprobar la elevada complejidad de los procesos de formalización. Lo que hizo concebir una visión general e integral para aceptar nuestra hipótesis inicial de que las producciones familiares tamberas maseras ponen en riesgo su permanencia al intentar salir de la informalidad productiva sin un fuerte y sostenido acompañamiento por parte del estado, debido a los altos costos de inversión requeridos, a la dificultad de alcanzar y mantenerse en el sinnúmero de cumplimientos normativos higiénicos/sanitarios y fiscal/tributarios, a la escasa claridad en la obtención de información para su cumplimiento y renovación, así como la incapacidad de llevar las gestiones, poniendo en juego cotidianamente el encuadramiento en la formalidad en un contexto adverso por no contar con todas las herramientas para su desenvolvimiento en este ámbito, más allá de poder contar con una producción arraigada.

Por último, esta tesis y las reflexiones de ella obtenidas pueden ser contribuciones, aportes para futuros análisis e investigaciones, abriendo nuevos interrogantes y eventuales líneas de trabajo. Será entonces importante, analizar sobre las alternativas que se vislumbran, identificando las fortalezas y debilidades de los marcos normativos y de los procesos administrativos en los distintos niveles del Estado, que sirvan como insumo para el diseño e implementación de políticas públicas sostenidas y concertadas democráticamente que apunten a generar cambios estructurales para el desarrollo de los territorios, garantizando la permanencia y empoderamiento de las unidades productivas familiares. 


\section{Bibliografía}

Abramavoy, Ricardo. 2006. Para una teoría de los estudios territoriales. En Desarrollo Rural. Organizaciones, instituciones y territorios. G. Neiman, M. Lattuada \& M. Manzanal (compiladores). 1 ra Ed. Buenos Aires, Fund. Centro Integral Comunicación, Cultura y Sociedad - CICCUS. pp. 51-70.

Albadalejo, C. y Bustos Cara, R. (2004). "El desarrollo local: ni azar maravilloso, ni resultado programado de una política". En: Albadalejo, Ch.y Bustos Cara, R. (comps.) 2004,"Desarrollo local y nuevas ruralidades en Argentina." Coedición : Universidad Nacional del Sur, Université de Toulouse Le Mirail, Dynamiques Rurales; Institut de Recherche pour le Dévelopement, Institut National de la Recherche Agronomique. Bahía Blanca, Argentina.

Alburquerque, F. (2003). “Teoría y práctica del enfoque del desarrollo local”. Instituto de Economía y Geografía Consejo Superior de Investigaciones Científicas c/. Pinar 25 (28006) Madrid. 2003.

Álvarez, H. y Lauría, M. (2013). Ley de lechería: lineamientos para promover el crecimiento del sector lechero. Actas de las VIII Jornadas Interdisciplinarias de Estudios Agrarios y Agroindustriales, Facultad de Ciencias Económicas (FCE)- Universidad de Buenos Aires (UBA). Buenos Aires, Noviembre de 2013.

Arzubi, A y Schilder E. (2006). "Una observación de los sistemas de producción de leche realizada desde la eficiencia". Trabajo presentado en la reunión anual de la Asociación Argentina de Economía Agraria.

Arzubi, A. y Berbel, J. (2003). "Análisis de Eficiencia sobre Explotaciones Lecheras de la Argentina”. [Tesis de Doctorado de Ingeniería Agronómica, Universidad de Córdoba]. http://docplayer.es/38001917-Universidad-de-cordoba.html

Barkin, D. (2002). "El desarrollo autónomo: un camino a la sostenibilidad". En CLACSO "Ecología Política. Naturaleza, sociedad y utopía. El desarrollo autónomo: un camino a la sostenibilidad" (pp. 169-202) Buenos Aires. Editorial: CLACSO. http://bibliotecavirtual.clacso.org.ar/clacso/gt/20101002060759/9barkin.

Barragan Lopez, E. (2016). "Entre oportunidades y obstáculos. Lo que devela el proceso de inserción del queso Cotija artesanal en la economía formal". En "Entre Diversidades". Revista de Ciencias Sociales y Humanidades. Número 7, Articulo III, otoño-invierno 2016. ISSN 20077602. Instituto de Estudios Indígenas. Universidad Autónoma de Chiapas, San Cristóbal de Las Casas, Chiapas, México. https://biblat.unam.mx/es/revista/entrediversidades-revista-de-cienciassociales-y-humanidades/articulo/entre-oportunidades-y-obstaculos-lo-que-devela-el-proceso-deinsercion-del-queso-cotija-artesanal-en-la-economia-formal 
Barros, C. (1999). "De rural a rururbano: transformaciones territoriales y construcción de lugares al sudoeste del área metropolitana de Buenos Aires”. Scripta Nova, No 45 (51), pp. 1546-1560.

Barros, C.; González Maraschio, F. y Villareal, F. (2005). “Actividades rurales y neorrurales en un área de contacto rural-urbana", en IV Jornadas Interdisciplinarias de Estudios Agrarios y Agroindustriales, Facultad de Ciencias Económicas, Universidad de Buenos Aires.

Bertoni, L y Soverna, S. (2015). La transición en las Políticas públicas para la agricultura familiar argentina: de los Programas a la Ley. Secretaría de Agricultura Familiar /Ministerio de Agricultura Ganadería y Pesca, Argentina.

Biolatto, R., Bassi, A., Marini, P., Tobin, M. y Ottmann, G. (2003) "El trabajo familiar en explotaciones lecheras: una estrategia de permanencia en el sector productivo". Revista FAVE Ciencias Veterinarias Volumen 2 - Numero 2. https://doi.org/10.14409/favecv.v2i2

Bisang, R.; Gutman, G. y Cesa, V. (2003) "La Trama de Lácteos en Argentina", en Lineamientos para fortalecer las fuentes del desarrollo económico, Buenos Aires, CEPAL, Ministerio de Economía de la Nación, pp. 1 - 80.

Bisang, R., Anlló, G. y Campi, M. (2008). "Una revolución (no tan) silenciosa. Claves para repensar el agro en Argentina". CEPAL. Buenos Aires.

Bisang R., Porta F., Cesa, V. y Campi, M. (2008). "Evolución reciente de la actividad láctea: el desafío de la integración productiva". CEPAL. https://www.cepal.org/es/publicaciones/3612evolucion-reciente-la-industria-lactea-desafio-la-integracion-productiva

Burbano, A. (2009). "Desarrollo y postdesarrollo: Modelos y Alternativas", publicado por la Escuela de Trabajo Social y Desarrollo Humano de la Universidad del Valle, Cali. http://www.scielo.org.co/scielo.php?script=sci_arttext\&pid=S0120-48232011000100022

Bustos Cara, R. y Albaladejo, C. (2006). "Nuevas competencias y mediaciones para la gobernanza de los territorios rurales en Argentina". IX Seminario internacional de la red iberoamericana de investigación en globalización y territorio.

Bustos Cara, Roberto. 2002a. Cambios en los sistemas territoriales. Actores y sujetos entre la estructura y la acción. Propuesta teórico-metodológica. II Jornadas interdisciplinarias del Sudoeste Bonaerense. Bahía Blanca 2002. 13 pp.

Bustos Cara, Roberto. 2002b. Los sistemas territoriales. Etapas de Estructuración y Desestructuración en Argentina. En Anales de Geografía de la Universidad Complutense. Vol. 22. pp. 113-129.

Bustos Cara, Roberto. 2002c. Teoría de la acción territorial. Actores y sujetos entre la estructura y la acción. Respuestas teórico-metodológicas de la Geografía ante las recientes espacialidades. Bahía Blanca. Ediuns. 17 pp. 
Campos Ríos, G. (2006). “Área: economía social el autoempleo y la economía informal”. X Jornadas de economía crítica. http://www.sociedadeconomiacritica.org/

Carletti, M. (2015). Operaciones en Ganadería Bovina: Estructura Impositiva y Comercialización. Bolsa de Comercio de Rosario. http://www.capacitacion.bcr.com.ar/Documentos/EdicionesBCR/16/Comercio\%20Ganadero.pdf

Carpio, J. (2007). "Formalidad e informalidad en los mercados de trabajo en la región: Los programas de promoción de la microempresa". FOCO (Foro Ciudadano de Participación por la Justicia y los Derechos Humanos Serie: Documentos de Trabajo No 5. Buenos Aires, Argentina. https://es.scribd.com/document/378375914/Formalidad-e-Informalidad-doc-5

Castellano, A., Issaly, L., Iturrioz, G., Mateos, M. y Teran, J. (2009). “Estudios socioeconómicos de los sistemas". ISSN 1852-4605. Agroalimentarios y agroindustriales $\mathrm{N}^{\circ} 4$. Proyecto Específico 2742 (INTA).

Castellano, A. (2014). "Programa Nacional-Territorio, Economía y Sociología, y Prospectiva y Políticas Publicas”. INTA. https://inta.gob.ar/proyectos/territorios-economia-y-sociologia-yprospectiva-y-politicas-publicas c.pdf

Castellano, A. (2014). "Conducta, dinámica y patrones tecnológicos de la cadena de lácteos bovinos". - 1a ed. - Buenos Aires: Ministerio de Ciencia, Tecnología e Innovación Productiva,. E-Book. ISBN 978-987-1632-22-01. https://inta.gob.ar/sites/default/files/script-tmpinta_mincyt_conducta_dinamica_patrones tecnologicos_c.pdf

Castignani, M., Blangetti, E., Osan, O., Rossler, N. y Cursack, A. (2009). "Los recursos humanos en la empresa lechera: un análisis de su relación con el perfil tecnológico y estructural mediante estudios de casos". VII Jornadas interdisciplinarias de estudios agrarios y agroindustriales. $\begin{array}{llll}\text { Proyecto C.A.I.D. UNL } & \mathrm{N}^{\mathrm{o}} & 22-120 .\end{array}$ https://www.researchgate.net/publication/265110648_Los_recursos_humanos_en_la_empresa_le chera_un_analisis_de_su_relacion_con_el_perfil_tecnologico_y_estructural_mediante_estudios de_casos

Castro García, M., Comelli, M., Ciccolella, M., Negro, M., Godfrid, J. y Schvartz, A. (2009). “El campo en conflicto. Disputas y sentidos en torno a la Resolución $\mathrm{N}^{\circ} 125 \%$. V Jornadas de Jóvenes Investigadores. Instituto de Investigaciones Gino Germani, Facultad de Ciencias Sociales, Universidad de Buenos Aires, Buenos Aires.

https://www.aacademica.org/000-089/68

CEPAL. (1980). "América Latina en la nueva estrategia internacional de desarrollo". Director Raúl Prebisch, Secretario Técnico Adolfo Gurrieri, Editor Gregor Ioweinberg. Santiago de Chile, agosto de 1980. Revista de la CEPAL. Número 11.

https://repositorio.cepal.org/handle/11362/38094?locale-attribute $=\mathrm{es}$

Conferencia Internacional del Trabajo. (2002). "El trabajo decente y la economía informal". Sexto punto del orden del día. Oficina Internacional del Trabajo Ginebra. El trabajo decente y la 
economía informal. ISBN 92-2-312429-8. ISSN 0251-3226. Primera edición 2002. 90 Reunión. Informe VI. https://www.ilo.org/public/spanish/standards/relm/ilc/ilc90/pdf/rep-vi.pdf

Craviotti, C. (2013). "La agricultura familiar en Argentina: ¿Fortalecimiento institucional y debilitamiento estructural?". Situación actual y perspectivas de la agricultura familiar en el ámbito del Mercosur. XXIX Congreso de la Asociación Latinoamericana de Sociología. Argentina.

Craviotti, C. (2008). "Enfoques sobre vulnerabilidad social y conformación de agentes productivos agrarios: reflexiones a partir del caso argentino". p. 249-265. En "Pobreza, exclusión y desigualdad" por Jorge Granda Aguilar. FLACSO, Sede Ecuador/Ministerio de Cultura del Ecuador. $\quad$ https://www.flacso.edu.ec/portal/publicaciones/detalle/pobreza-exclusion-ydesigualdad.3775

Craviotti, C. (2017). "La problemática de la coexistencia entre la agricultura familiar y la agroindustria: una aproximación desde la producción de quesos". Revista Brasileira de Sociología Vol. 05, No. 10. 2017. http://dx.doi.org/10.20336/rbs.20910.20336/rbs.209

Comerón, E., Zehnder, K., Schneider, G., Granda, J., Fernández, G., Ferreiro, A. y Rocchiccioli, J. (2000). "Informe de situación de los tambos de la cuenca central argentina. XXXI". Reunión Anual de la Asociación Argentina de Economía Agraria.

Cuadrado Roura, J. (2006) "Política Económica, Elaboración, Objetivos e Instrumentos". Editorial: Mc Graw Hill, Tercera Edición.

De Soto, H. (1987). "El Otro Sendero”. Editorial: Sudamericana S. A. Segunda Edición. ISBN 950-07-0441-2. 1987.

Eschenhagen, M. (2001). "Argumentos para repensar el "desarrollo". INNOVAR, Revista de ciencias administrativas y sociales". $\mathrm{N}^{\circ} 17$, pp 109-122.

Escobal, J. y Ponce, C. (2002). El beneficio de los caminos rurales: ampliando oportunidades de ingreso para los pobres. (Documento de Trabajo, 40). Lima: GRADE Group for the Analysis of Development. https://nbn-resolving.org/urn:nbn:de:0168-ssoar-51268-4

Escobar, A. (2005). "El postdesarrollo como concepto y practica social". En Daniel Mato (coord.), Políticas de economía, ambiente y sociedad en tiempos de globalización. Caracas: Facultad de Ciencias Económicas y Sociales, Universidad Central de Venezuela, pp. 17-31.

Escobar, A. (2002). "Globalización, Desarrollo y Modernidad”. Corporación Región, ed. Planeación, Participación, y Desarrollo (Medellín: Corporación Región, 2002), pp.9-32.

Escobar, A. (2007). "La invención del Tercer Mundo. Construcción y deconstrucción del desarrollo". 1ra.Edición Fundación Editorial el perro y la rana Caracas, ISBN 978-980-396-7765. Venezuela. 
Feito, M. (2008). "Políticas públicas de desarrollo territorial: el caso del municipio del pilar, provincia de buenos aires, argentina". IV Congreso Internacional de la Red SIAL, Mesa J 14.

Fernandez Equiza, A. (2010). "La sustentabilidad de la agricultura familiar en la Argentina". En "Las agriculturas familiares del Mercosur: trayectorias, amenazas y desafíos" (pp. 297-318). Compiladores Manzanal, M. y Neiman, G. 1era Edición. Buenos Aires. Fundación Centro de Investigación, comunicación, cultura y sociedad. CICCUS. ISBN 978-987-1599-35-6.

Fernández, L., Abraham, A. y Velarde, I. (2010). "Implementación de buenas prácticas de manufactura en pequeñas queserías de Tandil: construyendo calidad desde el enfoque peligroriesgo". "1ras. Jornadas de Agricultura Familiar" Facultad de Ciencias Veterinarias, La Plata.

Fernandes, Bernardo Mançano. 2006. Cuestión Agraria: conflictualidad y desarrollo territorial. Disponible en $\quad$ http://webcache.googleusercontent.com/search?q=cache:Q1rP19mzvYJ:web.ua.es/en/giecryal/documentos/documentos839/docs/bmfunesp2.pdf $+\&$ cd=1\&hl=es419\&ct=clnk\&gl=ar. Último acceso: Mayo 2016. 39 pp.

Fletes Ocón, H., Ocampo Guzmán, G. y Valdiviezo Ocampo, G. (2016). "Reestructuración de la agricultura e inseguridad alimentaria. Las iniciativas y retos de los pequeños productores en Chiapas”. Entre Diversidades. Revista de Ciencias Sociales y Humanidades. Número 7. Instituto de Estudios Indígenas. Universidad Autónoma de Chiapas. México. ISSN 2007-7602. https://doi.org/10.31644/ED.7.2016.a04

Foro Nacional de la Agricultura Familiar. (2006). Lineamientos generales de políticas públicas orientadas a la elaboración de un plan estratégico para la agricultura familiar. Impresión: Federación Agraria Argentina. Documento, Buenos Aires. http://fediap.com.ar/administracion/pdfs/Lineamientos $\% 20$ para $\% 20 \mathrm{Pol} \% \mathrm{C} 3 \% \mathrm{ADticas} \% 20 \mathrm{P} \% \mathrm{C}$ 3\%BAblicas\%20orientada $\% 20 \mathrm{a} \% 201 \mathrm{a} \% 20$ Elaboraci\%C3\%B3n $\% 20 \mathrm{de} \% 20$ un $\% 20 \mathrm{Plan} \% 20$ Estrat \%C3\%A9gico\%20para\%201a\%20Agricultura\%20Familiar\%20-\%2006.pdf

García, I. L.; García, A.; Rofman, A. y Rodriguez, E. (2008) "Los dos 'campos' argentinos. Estudio de las relaciones asimétricas y diseño de estrategias para el desarrollo rural", II Jornadas de Investigadores en Economías Regionales, Centro de Estudios Urbanos y Regionales, CEURCONICET, Universidad Nacional del Centro, UNICEN, Tandil.

García Delgado, D. y Peirano, M. (2011), "El modelo de Desarrollo con inclusión social. La estrategia de mediano plazo". CICCUS, Buenos Aires.

García Delgado, D., y Casalis, A. (2013). "Modelo de desarrollo y universidad en Argentina. Análisis crítico y contribución de la extensión universitaria al desarrollo local y regional". Universidad Nacional del Litoral. Revista $+\mathrm{E} \mathrm{N}^{\circ}$ 3. ISSN N: 2346-9986 / Año. 2013 / $\mathrm{N}^{\circ}$ 3.Edición digital. https://ri.conicet.gov.ar/handle/11336/26108

Giarracca, N., Teubal, M., Palmisano, T. (2008). "Paro Agrario. Un conflicto alargado", (pp. 3354) en Revista Realidad. Económica, No 237, ISSN 0325-1926, IADE, Buenos Aires. http://www.iade.org.ar/system/files/ediciones/realidad_economica_237.pdf 
Gras, C. (2006). "Redefinición de la vida rural en el contexto de la modernización: Relatos de ganadores y perdedores en una comunidad rural en la región pampeana argentina". VII Congreso Latinoamericano de Sociología Rural. Quito.

Granda Aguilar, J. (2008). "Enfoques sobre vulnerabilidad social y conformación de agentes productivos agrarios: reflexiones a partir del caso argentino". En "Pobreza, exclusión y desigualdad" (pp. 11-32) por Granda Aguilar, J. FLACSO, Sede Ecuador/Ministerio de Cultura del Ecuador.

Gutman G. y Gatto, F. (1990). "Agroindustrias en la argentina cambios organizativos y productivos (1970 -1990)". En Gutman, G. y Gatto, F. (Compi.), (pp.17-45). Bibliotecas Universitarias. Centro Editor de América Latina. CEPAL-CEAL, Buenos Aires,.

Gutman, G. y Rebella, C. (1990). "Subsistema lácteo". En Gutman, G. y Gatto, F. (comp.), Agroindustrias en la Argentina. Cambios organizativos y productivos (1970-1990) (pp. 79-112). Buenos Aires, CEPAL.

Gutman, G. (2000). "La industria láctea en la Argentina en la década de los noventa”. En "El Desempeño Industrial Argentino, Más Allá de la Sustitución de Importaciones” (pp. 180-184). Editores: Kosacoff, B., Yoguel, G., Bonvecchi, C., Ramos, A. https://repositorio.cepal.org/handle/11362/31459

Gutman, G. (2006). “Obstáculos y Desafíos para la Integración Competitiva de Pequeños Productores Agropecuarios en Tramas Regionales. Reflexiones a partir de Estudios de Caso". IX Seminario Internacional de la Red Iberoamericana de Investigadores sobre Globalización Territorio (RII); Universidad Nacional del Sur, Bahía Blanca.

Heras Monner Sans, A., Burin, D., Foio, M. y Pérez Rubio, A. (2008). "Sobre el desarrollo: sujetos, discursos, acciones". En "Trabajo, desarrollo, diversidad: una investigación sobre políticas y metodologías de desarrollo local con acento en la generación de empleo, trabajo e ingresos" (pp. 21-44). Compilado por Heras, I, y Burin, D.-1era Edición- Buenos Aires: Fundación Centro de Integración, Comunicación, Cultura y Sociedad- CICCUS.

Hernandez Sampieri, R., Fernandez Collado, C. y Baptista Lucio, P. (2006). "Metodología de la investigación". Cuarta edición. Iztapalapa. México D. F. Editores: Mc Grawhilli Interamericma, ISBN 970-10-5753-8.

Instituto Interamericano de Cooperación para la Agricultura. (2010). "Plan estratégico 20102020 / IICA" - San José, C.R.: IICA, 2010. (Serie documentos oficiales / IICA, ISSN 10185712; NO. 86) 56 P.; 21 CM X 16 CM. ISBN13: 978-92-9248-320-3. Asistencia Técnica I. IICA II. Título III. Series Agris DEWEY.

Instituto Nacional de Educación Tecnológica. (2010). Sector Lechero “Informe Preliminar". https://docplayer.es/16072765-Sector-lechero-informe-final-preliminar.html 
Instituto Nacional de Tecnología Agropecuaria. (2004). "El INTA que queremos. Plan Estratégico Institucional 2005 - 2015". Buenos Aires. https://inta.gob.ar/documentos/planestrategico-institucional-2005-2015

Instituto Nacional de Tecnología Agropecuaria. (2012). "Agricultura Urbana y Periurbana en el Área Metropolitana de Buenos Aires: Creación de la Estación Experimental Agropecuaria AMBA. Comité de Edición: Maggio, A., Cieza, G., Gómez, C., Carrasco, M., Mas, D., Palacio, D. y Orueta, M. https://inta.gob.ar/sites/default/files/script-tmp-creacin eea amba.pdf

Lattuada, M. y Nogueira, M. (2011). “Capacidades estatales y políticas públicas. Una propuesta para el abordaje de las políticas agropecuarias en la Argentina contemporánea (1991-2011)". (Pág. 30-54). En Estudios Rurales. Publicación de Centro de Estudios de La Argentina Rural. Bernal, Vol. $1 \mathrm{~N}^{\circ}$ 1, 2011. ISNN: 2250.

Lattuada, M y Moyano Estrada, E. (2001). "Crecimiento económico y exclusión social en la agricultura familiar Argentina” (pp. 171-193). En Economía Agraria y Recursos Naturales, ISSN: 1578-0732, Vol.1, 2 (2001).

Lattuada, M., Nogueira, M. y Urcola, M. (2015). "Tres décadas de desarrollo rural en la Argentina: continuidades y rupturas de intervenciones públicas en contextos cambiantes 19842014". 1a ed. - Ciudad Autónoma de Buenos Aires. Universidad Abierta Interamericana. 456 p. ISBN 978-987-723-026-01.

Linck, Thierry. 2006. La economía y la política de la apropiación de los territorios. En Globalización, Desarrollo y Territorios Menos Favorecidos. Compilador: Alberto Riella. Departamento de Sociología, Facultad de Ciencias Sociales, Universidad de la República. Montevideo, Uruguay. pp. 107-143.

Luzuriaga, J. (2017). "Nota Al Filo de la Ley”. Revista Infortambo Agosto. Número 339. Página 24-31.

Fernandez, $\quad$ B. $(\mathrm{s} / \mathrm{f})$. Territorio, teoría $\quad \mathrm{y}$ política. https://horizontescomunitarios.files.wordpress.com/2016/10/mancano-fernandez-territoriosteoria-y-politica.pdf

Manzanal, M. (1990). "Polarización y pobreza en el agro argentino. Reflexiones y propuestas para el desarrollo rural” (pp. 51-61). En Revista EURE (Vol. XVI, No 49), Chile.

Manzanal, M., Neiman, G. y Lattuada, M. (2006). "Desarrollo rural. Organizaciones, instituciones y territorios". Compiladores. $1^{a}$ Edicion. Buenos Aires: Fund. Centro Integral Comunicación, Cultura y Sociedad - CICCUS, 2006. ISBN 987-9355-27-X.

Manzanal, M. y Schneider, S. (2011). "Agricultura Familiar y Políticas de Desarrollo Rural en Argentina y Brasil (Análisis comparativo, 1990-2010)", (p. 35-71). En Revista Interdisciplinaria de Estudios Agrarios N³4, CIEA, FCE, UBA, ISSN 15141535. 1er semestre, Buenos Aires. 
Manzanal, M. y Neiman G. (2010). "Las agriculturas familiares del Mercosur: trayectorias, amenazas y desafíos". 1a ed. - Buenos Aires. Fundación Centro de Integración, Comunicación, Cultura y Sociedad - CICCUS, 2010.

Marino, M., Castignani, H. y Arzubi, A. (2011). "Tambos Pequeños de las Cuencas Lecheras Pampeanas: Caracterización y Posibles Líneas de Acción”. Issue Publicación Técnica No 61. ISSN 0485-9057.

Marradi, A., Archenti, N. y Piovani, J. (2007). "Metodología de las Ciencias Sociales". Ed. Emecé. Buenos Aires. 328 p.

Martinez Nogueira, R. (1995). “Análisis de Políticas Públicas. Trabajo preparado para el Instituto Nacional de la Administración Publica" https://www.academia.edu/11915294/ANALISIS_DE POLITICAS_PUBLICAS Roberto_Mart \%C $3 \%$ ADnez_Nogueira

Mateos, M. (2006). "La industria láctea: heterogeneidad estructural y comportamiento tecnológico" en "Estrategia y dinámica de la innovación en la industria alimentaría argentina". Editora: Astralib COP. Buenos Aires.

Mendiaz, M. (2004). "El Estado y las Políticas Públicas. Visones desde el Neo institucionalismo". En Seminario de Doctorado "Lecturas para una Sociología del Estado: desde el pensamiento clásico al contemporáneo". Facultad de Ciencias Política y Relaciones Internacionales. Universidad Nacional de Rosario.

Ministerio de Agricultura, Ganadería y Pesca. (2019). "Estado de situación de la industria láctea argentina para la definición de políticas públicas 2016-2018”. Secretaría de Agricultura, Ganadería y Pesca, Dirección Nacional Láctea. http://www.ocla.org.ar/contents/news/details/14685677-estado-de-situacion-de-la-industrialactea-argentina-2016-2018

Ministerio de Asuntos Agrarios. (2010). "Resumen estadístico de la cadena láctea de la Provincia de Buenos Aires". Coordinación: Dirección de auditorías agroalimentarias: Taylor J. y la Dirección de producción Láctea: https://www.gba.gob.ar/static/agroindustria/docs/direccion_de_Leche_productos_lacteos_y_deri vados/ESTAD\%C3\%8DSTICAS/Informe_Relevamiento.pdf

Ministerio de Economía de la Provincia de Buenos Aires. (2001) "El dilema de la economía informal: evidencias y políticas". Cuadernos de Economía N59. La Plata. https://eco.mdp.edu.ar/cendocu/repositorio/00811.pdf

Ministerio de Ganadería, Agricultura y Pesca. (2009). "Proyecto Desarrollo Empresarial de los Queseros Artesanales y Mejora de su Potencial para la Exportación”. OEA / SEDI / AICD. Montevideo (Uruguay). 
Monge, E. y Portillo, J. (2016). "Presión tributaria sobre la actividad tambera en Argentina. Caso de estudio: tambo ubicado en Azul, Provincia de Buenos Aires". Universidad de Buenos Aires. Facultad de Agronomía. Licenciatura en Economía y Administración Agrarias. https://agro.uba.ar/apuntes/wpcontent/uploads/2020/01/22carga tributaria_en_la_actividad tambera_un_estudio_de_caso_en azul bsas argentina.pdf

Moreira, V; Bravo Ureta, B; Arzubi, A y Schilder, E. (2004). "Medidas alternativas de eficiencia técnica en tambos de la Argentina, utilizando una frontera de producción estocástica y datos de panel desbalanceado". En 1er. Congreso regional de economistas agrarios.

Mozeris, G., Palladino, A., Tellechea, M. (s/a). "Análisis comparativo de las organizaciones de apoyo a la Cadena Láctea en países seleccionados". Fundación para la Promoción y el Desarrollo de la Cadena Láctea Argentina (FUNPEL). http://www.fundacionpel.org/img/content/pdf/trabajo-organizaciones-cadena-lactea-en-elmundo-funpel.pdf

Murmis, M. (1991). “Tipología de Pequeños Productores Campesinos en América” (pp. 29-52) En Ruralia, FLACSO/ARG. Buenos Aires No 2.

Murmis, M. (1993). "Incluidos y excluidos en la reestructuración del Agro Latinoamericano". XIX Latinoamericano de Sociología.

Muñoz, D. y Viaña, J. (2012). ¿Cómo se posicionan los pequeños productores en América Latina respecto a los mercados? IIED /Hivos/Mainumby, London/The Hague/La Paz. https://pubs.iied.org/pdfs/16522IIED.pdf

Narodowski, P. (2013). "Una estrategia para sostener la actual alianza política y profundizar el cambio estructural” (pp. 100-131). En Revista Realidad Económica Nº 279.

Neiman, G. (2010). "Pobreza, políticas sociales y desarrollo rural. Algunas evidencias de su relación a partir de la experiencia Argentina" (pp.79-90). En "La agricultura familiar del MERCOSUR. Trayectorias, amenazas y desafíos". Compiladores: Manzanal, M y Neiman, G. Buenos Aires. 1era Edición. Buenos Aires. Fundación Centro de Investigación, comunicación, cultura y sociedad. CICCUS. ISBN 978-987-1599-35-6

Neiman, G. y Quaranta, G. (2006). "Los estudios de caso en la investigación sociológica” (pp. 213-238). En Estrategias de investigación cualitativa. Coord.: Vasilachis de Gialdino, I. Editorial: Gedisa. Buenos Aires.

Nogueira, M. (2008). "La producción familiar en lechería. Algunos comentarios sobre las características de tamberos en el departamento Iriondo durante la década del noventa". IX Congreso Argentino de Antropología Social. Facultad de Humanidades y Ciencias Sociales Universidad Nacional de Misiones, Posadas. 
Nogueira, M. (2010). "La problemática láctea desde una mirada política: actores y formas de representación sectorial en el último tiempo". Mundo Agrario, 11(21). Disponible en: http://www.fuentesmemoria.fahce.unlp.edu.ar/art_revistas/pr.4460/pr.4460.pdf.

Nogueira, M. (2013). "Agricultura familiar y políticas públicas en la Argentina de los últimos años. Algunas reflexiones en torno a una relación compleja". Editorial: Universidad Nacional de Santiago del Estero. Facultad de Humanidades y Ciencias Sociales. ISSN: 1514-6871. https://ri.conicet.gov.ar/handle/11336/22570

Organización Internacional de Trabajo (OIT). (2002). "El trabajo decente y la economía informal". Conferencia Internacional del Trabajo. 90.a reunión 2002. Informe VI. Oficina Internacional del Trabajo Ginebra. ISBN 92-2-312429-8. ISSN 0251-3226. Primera edición.

Organización Internacional de Trabajo (OIT). (2014). "La transición de la economía informal a la economía formal". Conferencia Internacional del Trabajo103. " Reunión 2014. ISBN 978-922-327755-0. Ginebra, Suiza. Primera edición.

Paz, R. y Gonzalez, V. (2010). "Hablemos sobre agricultura familiar: siete reflexiones para su debate en Argentina". Ponencia presentada al VIII Congreso Latinoamericano de Sociología Rural, Porto de Galinhas.

Paz, R. (1999). "Integración, Exclusión y vulnerabilidad del campesino ocupante en Argentina". Trabajo y Sociedad, Indagación sobre el empleo, la cultura y las prácticas políticas en sociedades segmentadas. $\mathrm{N}^{\circ} 2$ vol. II. Santiago del Estero, Argentina.

Pengue, W. (2014). "Cambios y escenarios en la agricultura argentina del siglo XXI". Dr. Ing. Agr. GEPAMA, FADU, UBA / Ecología UNGS / Panel de los Recursos UNEP.

Pérez Frattini, M. y Fabregas Lengard, M. (2009). “¿Soja vs. tambo?. Algunas reflexiones en torno al proceso de reconversión productiva en un área de la Cuenca Lechera de Abasto de la Provincia de Buenos Aires".

Pérez Frattini, M. L. y Fabregas Lengard, M (2009). “¿Soja vs. tambo? Algunas reflexiones en torno al proceso de reconversión productiva en un área de la Cuenca Lechera de Abasto de la Provincia de Buenos Aires (Argentina)" (pp. 41-48). En Espacios de crítica y producción. No 42, Noviembre,

Portes, A. y Haller, W. (2004). "La Economía Informal”. En CEPAL - SERIE Políticas sociales. Número 100. ISBN: 9213226101. División de Desarrollo Social. Santiago de Chile. https://www.cepal.org/es/publicaciones/6091-la-economia-informal

Posada, M. (1995). "La Agroindustria Láctea Pampeana y los cambios tecnológicos". (pp. 85113). En Debate Agrario. $N^{\circ} 21$, Lima.

Pucciarelli, A. (1993). "Cambios en la estructura agraria de la pampa bonaerense". Ciclos, Año III, Vol. III, $\mathrm{N}^{\circ} 5$, 2do semestre. 
Vial, Revista. (2018). "Los caminos rurales en Argentina un freno al desarrollo. Marzo. Disponible en: http://revistavial.com/los-caminos-rurales-en-argentina-un-freno-al-desarrollo/

Rofman, A., del Pilar Foti, M. y Garcia, I. (2005). "Acceso de los pequeños productores al crédito formal e informal: diagnóstico y propuestas". Edicion: Buenos Aires. Secretaría Agricultura, Ganadería, Pesca $\quad$ y $\quad$ Alimentación. http://www.ciap.org.ar/Sitio/Archivos/Acceso $\% 20 \mathrm{de} \% 2010 \mathrm{~s} \% 20$ pequenos $\% 20$ productores $\% 20 \mathrm{al}$ $\% 20$ credito $\% 20$ formal $\% 20 \mathrm{e} \% 20$ informal $\% 20$ Diagnostico $\% 20 \mathrm{y} \% 20$ propuestas.pdf

Rossi, A. y León, A. (2005). “Temas fundamentales en la Inserción de Pequeños Productores en Cadenas Comerciales para una Estrategia de Desarrollo Rural”, Proyecto Argentina Rural. http://bibliotecadigital.econ.uba.ar/download/riea/riea_v28_n1_01.pdf

Salomón, A. (2017). "Los caminos rurales desde una perspectiva histórica: Antecedentes y novedades del Plan de Caminos de Fomento Agrícola (Argentina, 1956)". História: Debates e Tendências - v. 18, n. 2, maio/ago. 2018, p. 260-275. http://dx.doi.org/10.5335/hdtv.18n.2.

Schneider, Sergio. 2004. A abordagem territorial do desenvolvimento rural e suas articulações externas. Sociologias, Porto Alegre, ano 6, n. 11, jan/jun 204. pp. 88-125.

Schejtman, A. y Berdegué J. (2004). "Desarrollo territorial rural”. Documento elaborado para la División América Latina y el Caribe del Fondo Internacional de Desarrollo Agrícola (FIDA) y el Departamento de Desarrollo Sustentable del Banco Interamericano de Desarrollo (BID).

Sevilla Guzman, E y Alonso Mielgo, A. (2004). "El Discurso Ecotecnocratico de la Sostenibilidad. Instituto de Sociología y Estudios Campesinos". Escuela Técnica Superior de Ingenieros Agrónomos y Montes de la Universidad de Córdoba. Córdoba.

Schneider, Sergio; Peyré, Iván. 2006. Territorio y enfoque territorial: de las referencias cognitivas a los aportes aplicados al análisis de los procesos sociales rurales. En Desarrollo Rural. Organizaciones, Instituciones y Territorio. M. Manzanal, G. Neiman, Guillermo \& M. Lattuada, Mario. (compiladores) Buenos Aires: Ed. Ciccus. pp. 71-102.

Sili, M. (2010). ¿Cómo revertir la crisis y la fragmentación de los Territorio rurales? Ediciones: INTA. ISBN 978-987-1623-77-8.

Sili, M y Soumoulou, L. (2011). "La problemática de la tierra en argentina, Conflictos y dinámicas de uso, tenencia y concentración". FIDA-Cooperazone Italiana alto Svilupo (Min. Degli Affari Esteri)-Ministerio Agricultura, Ganadería y Pesca. https://www.magyp.gob.ar/sitio/areas/prodear/biblioteca/_archivos//000001Desarrollo\%20Rural/100811La\%20Problem\%C3\%A1tica\%20de\%201a\%20Tierra\%20en\%20Argentina\%20\%20FIDA $\% 202011 . p d f$ 
Soler Roca, Miguel. 2008. Ponencia presentada en el Seminario Internacional sobre Formación de Formadores para el Desarrollo Rural. Tacuarembó, Montevideo - Tacuarembó - Uruguay Uruguay. pp. 17-40.

Soverna, S. (2004). "Políticas de desarrollo rural: situación actual y propuestas". PROINDER, Dirección de Desarrollo Agropecuario, Secretaría de Agricultura, Ganadería, Pesca y Alimentos de la Nación. II Congreso Nacional de Políticas Sociales (Mendoza).

Tassi, N. (2012). “La otra cara del mercado. Economías populares en la arena global”. La Paz. Editor: ISEAT.

Teubal, M. (2001). "Globalización y nueva ruralidad en América Latina”. En Colección Grupos de Trabajo de CLACSO. Grupo de Trabajo Desarrollo Rural. (p. 45). Coordinadora: Giarracca, N.

Teubal, M. y Rodríguez, J. (2001). “Globalización y sistemas agroalimentarios en la Argentina". Ciclos, Año XI, Vol. XI, N²2.

Tomassino, H. (2001). "Sustentabilidad rural: desacuerdos y controversias". En Pierri y Foladori (edit.), ¿Sustentabilidad? Desacuerdos sobre el desarrollo sustentable, Ed. Trabajo y Capital, Montevideo. 2001.

Tokman, V. (2001). Libro "De la Informalidad a la modernidad". Santiago, Oficina Internacional del Trabajo. ISBN 92-2-312682-7.

Tokman, V. (2011). "Informalidad en América Latina: balance y perspectivas de políticas". Realidad, datos y espacio revista internacional de estadística y geografía. Vol. 2 Núm. 3.

Vadell, Antonio; Ion, Lilian; Gonsalves, Guillermo. 2012. Las Mesas de Desarrollo Rural implementadas por el Proyecto Uruguay Rural, Ponencia presentada en el 1er. Congreso de Ciencias Sociales Agrarias, Departamento de Ciencias Sociales, Facultad de Agronomía, Universidad de la República, 16 y 17 de agosto 2012. 13 pp.

Vasilachis de Gialdino, I. (2006). "La investigación cualitativa. En: Estrategias de investigación cualitativa". Vasilachis de Gialdino, Irene. (coord.). Ed. Gedisa. Buenos Aires. pp. 23-64.

Vértiz, P. (2017). "El complejo lácteo argentino: integración subordinada de la producción primaria a la dinámica del capital agroindustrial (período 2002-2015)". Universidad nacional de la plata facultad de humanidades y ciencias de la educación. Doctorado en Ciencias Sociales.

Vorley, et al. (2013). "Agricultores de pequeña escala en el mercado globalizado: tomando decisiones en un mundo cambiante”. IIED/Hivos/Mainumby, London/The Hague/La Paz.

Yin, R. (2009). "Case Study Research: Design and Methods-fourth edition". Fourth Edition. SAGE Publications. CA. 
Zeller, N. (2007). "Marco conceptual Metodológico para el Estudio de las Políticas Públicas". Subsecretaria de Gestión Pública. Instituto Nacional de la Gestión Pública. Jefatura de Gabinete de Ministros. Dirección de investigación. N 44. ISSN 1851-0094

\section{Sitios web consultados}

- https://www.arba.gov.ar

- https://www.argentina.gob.ar/anmat/codigoalimentario

- $\quad$ http://www.saij.gob.ar/11089-local-buenos-aires-explotaciones-tamberas-semi-

elaboracion-mozzarella-provincia-buenos-aires-lpb0011089-1991-06-06/123456789-

0abc-defg-980-1100bvorpyel?

- https://www.agroindustria.gob.ar/sitio/areas/ruca/actividades/

- https://www.agroindustria.gob.ar/sitio/areas/siglea/index.php

- $\quad$ https://dairylando.com/lecheria-argentina/la-lecheria-argentina/

- http://www.fonaf.org.ar/

- $\quad$ http://www.reafmercosul.org/

- http://servicios.infoleg.gob.ar/infolegInternet/verNorma.do;jsessionid=E213D8AE1789A 9C460F94BD4D1B43269?id=302712

- https://www.agroindustria.gob.ar/sitio/areas/ss_control_comercial/

- https://www.agroindustria.gob.ar/sitio/areas/ss lecheria/?accion=noticia\&id info=18051 $\underline{7173131}$

- https://www.maa.gba.gov.ar/sistemas/index_sistemas.htm

- https://www.rae.es/

- https://www.argentina.gob.ar/senasa 
- $\quad$ http://www.tamberos.org.ar/inst_estatuto.htm

- http://www.gob.gba.gov.ar/legislacion/legislacion/89-1527.html

- http://www.gob.gba.gov.ar/legislacion/legislacion/f-11089.html

- http://www.gob.gba.gov.ar/legislacion/legislacion/91-83.html 
Anexos

Dispositivo usado en el campo, diseño de los ejes de las entrevistas para los diferentes actores, preguntas disparadoras.

\begin{tabular}{|c|c|}
\hline & Eje: Trayectoria de las Políticas Publicas Agropecuarias. \\
\hline \multirow{4}{*}{ Productores } & ¿Se sintió alguna vez parte de alguna medida lanzada por el gobierno? \\
\hline & ¿Recuerda alguna medida de algún gobierno que haya tenido impacto en su producción? \\
\hline & ¿Noto usted algún cambio de exigencia para con su productos por parte de la industria? \\
\hline & ¿Tuvo que reorientar su producción por estas exigencias? \\
\hline \multirow{3}{*}{$\begin{array}{l}\text { Ámbito } \\
\text { Privado }\end{array}$} & $\begin{array}{l}\text { ¿Nota algún cambio en el territorio con respecto a las pequeñas producciones tamberas en los } \\
\text { últimos } 25 \text { años? }\end{array}$ \\
\hline & ¿Noto un salto tecnológico en la producción lechera local? ¿Cuál? \\
\hline & ¿Tuvo cambios de demandas técnicas y de ventas de insumos? \\
\hline \multirow{4}{*}{$\begin{array}{c}\text { Funcionarios } \\
\text { Técnicos } \\
\text { Investigadores }\end{array}$} & $\begin{array}{l}\text { ¿Considera que hubo en los últimos } 25 \text { años un cambio en materia de Políticas sanitarias } \\
\text { (normativas), emergiendo nuevos estándares de calidad? }\end{array}$ \\
\hline & $\begin{array}{l}\text { Si la respuesta es afirmativa: ¿Qué se aspectos (productivo, económico) se contemplaron en la } \\
\text { creación de este nuevo escenario? ¿Qué se priorizo? }\end{array}$ \\
\hline & ¿Hubo un impacto a nivel productivo en las producciones menos tecnificadas? \\
\hline & $\begin{array}{l}\text { ¿Se guarda una relación directa de las normativas nacionales con las internacionales? ¿Por } \\
\text { qué? }\end{array}$ \\
\hline
\end{tabular}




\begin{tabular}{|c|c|}
\hline & Eje: Surgimiento de la nueva Política Publica Agropecuaria \\
\hline \multirow[b]{2}{*}{ Productores } & $\begin{array}{l}\text { ¿Noto en los últimos } 10 \text { años algún cambio en cuanto a la presencia de instituciones gubernamentales } \\
\text { en el territorio? }\end{array}$ \\
\hline & $\begin{array}{l}\text { ¿Usted cree que en la actualidad, el estado lo tiene en cuanto a la hora de decidir alguna política para el } \\
\text { campo? }\end{array}$ \\
\hline \multirow{2}{*}{\multicolumn{2}{|c|}{$\begin{array}{l}\text { Ámbito } \\
\text { Privado }\end{array}$}} \\
\hline & \\
\hline \multirow{4}{*}{$\begin{array}{l}\text { Funcionarios } \\
\text { Técnicos } \\
\text { Investigadores }\end{array}$} & $\begin{array}{l}\text { ¿Considera que hubo una mayor visibilización y posterior análisis del medio rural para la configuración } \\
\text { de nuevas políticas agropecuarias sectoriales? }\end{array}$ \\
\hline & $\begin{array}{l}\text { ¿Esta visibilización con las consecuentes políticas públicas, a que se debió? ¿A un marcado aumento } \\
\text { de la institucionalidad de la A.F. marcando una necesidad o, a un programa político gubernamental? }\end{array}$ \\
\hline & $\begin{array}{l}\text { ¿Cree necesaria la participación de los pequeños productores para la construcción de políticas públicas } \\
\text { hacia su sector? }\end{array}$ \\
\hline & ¿Estas nuevas políticas sectoriales ponen al estado en un nuevo rol? \\
\hline
\end{tabular}




\begin{tabular}{|c|c|}
\hline & Eje: Surgimiento de la nueva Política Publica Agropecuaria \\
\hline \multirow[b]{2}{*}{ Productores } & $\begin{array}{l}\text { ¿Noto en los últimos } 10 \text { años algún cambio en cuanto a la presencia de instituciones gubernamentales en } \\
\text { el territorio? }\end{array}$ \\
\hline & $\begin{array}{l}\text { ¿Usted cree que en la actualidad, el estado lo tiene en cuanto a la hora de decidir alguna política para el } \\
\text { campo? }\end{array}$ \\
\hline \multirow{2}{*}{\multicolumn{2}{|c|}{$\begin{array}{l}\text { Ámbito } \\
\text { Privado }\end{array}$}} \\
\hline & \\
\hline \multirow{4}{*}{$\begin{array}{l}\text { Funcionarios } \\
\text { Técnicos } \\
\text { Investigadores }\end{array}$} & $\begin{array}{l}\text { ¿Considera que hubo una mayor visibilización y posterior análisis del medio rural para la configuración de } \\
\text { nuevas políticas agropecuarias sectoriales? }\end{array}$ \\
\hline & $\begin{array}{l}\text { ¿Esta visibilización con las consecuentes políticas públicas, a que se debió? ¿A un marcado aumento de } \\
\text { la institucionalidad de la A.F. marcando una necesidad o, a un programa político gubernamental? }\end{array}$ \\
\hline & $\begin{array}{l}\text { ¿Cree necesaria la participación de los pequeños productores para la construcción de políticas públicas } \\
\text { hacia su sector? }\end{array}$ \\
\hline & ¿Estas nuevas políticas sectoriales ponen al estado en un nuevo rol? \\
\hline
\end{tabular}




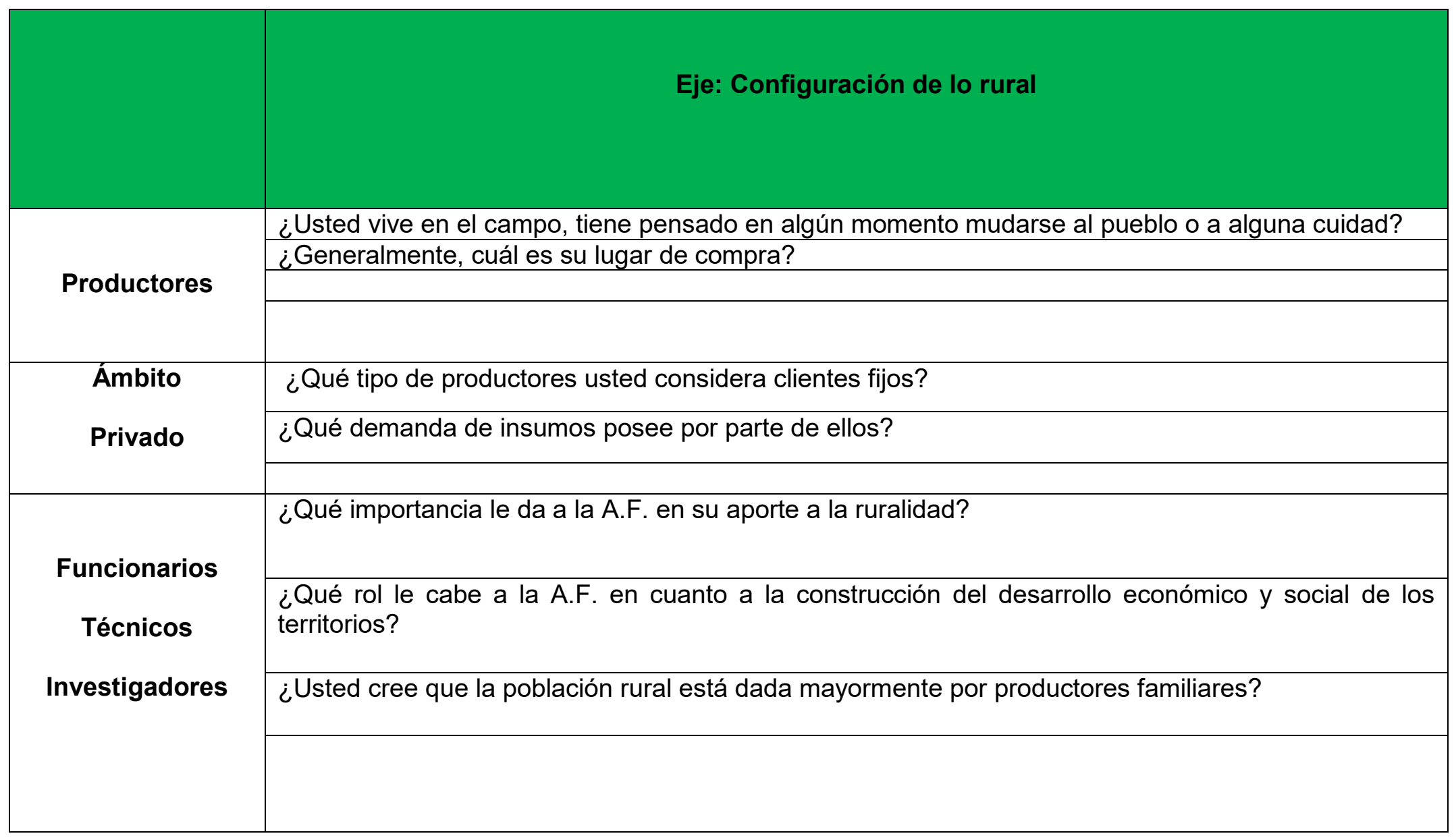




\section{Eje: Socio - Económico}

¿Usted, se considera una persona que aporta para que su pueblo se mantenga?

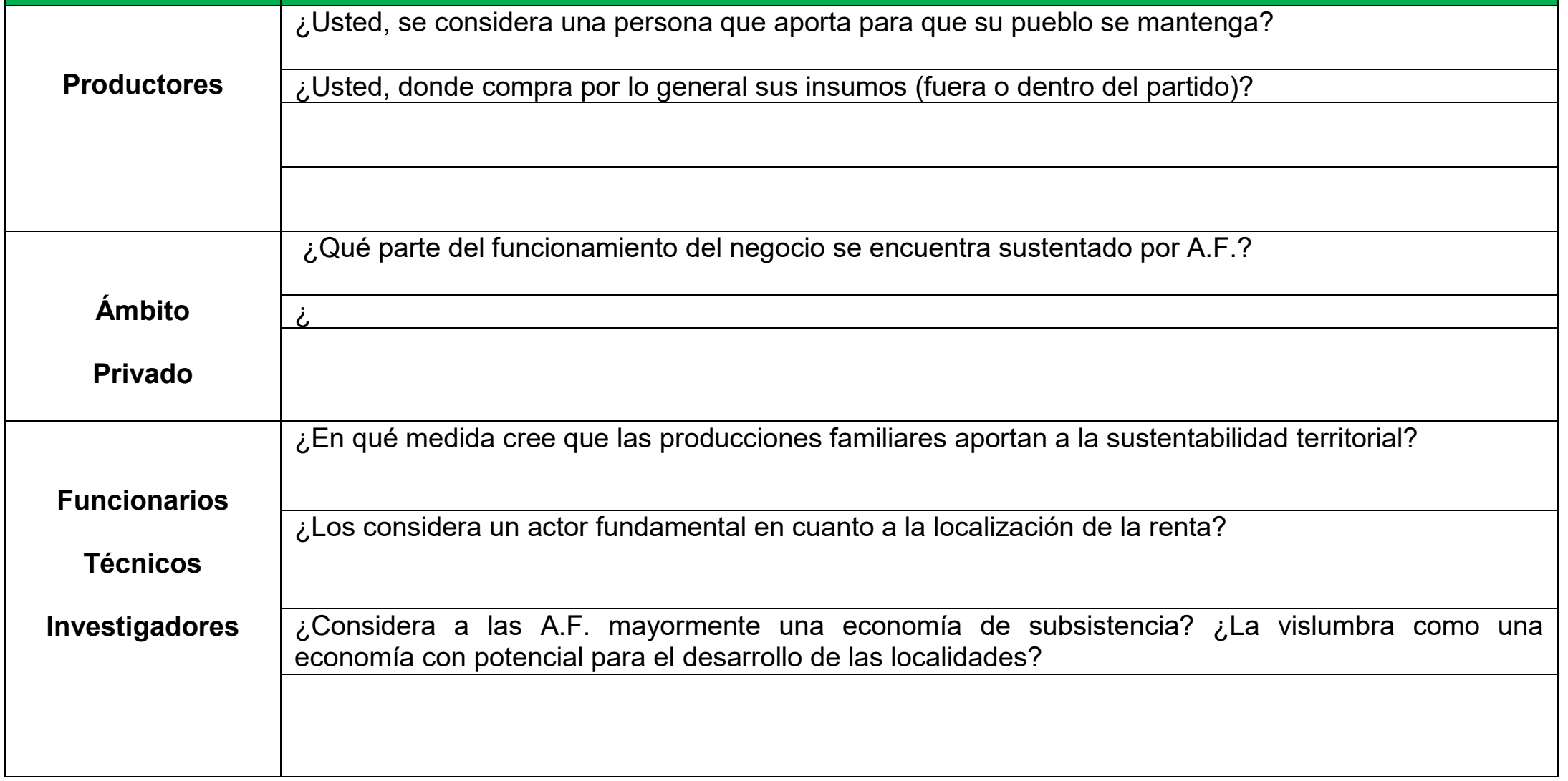




\begin{tabular}{|c|c|}
\hline & Eje: Socio Cultural \\
\hline \multirow{4}{*}{ Productores } & ¿Se encuentra formando parte de alguna organización formal o informal de productores? \\
\hline & ¿Formo parte alguna vez de alguna? \\
\hline & ¿Se siente identificado con alguna conmemoración local? \\
\hline & ¿Es de participar de los eventos locales? \\
\hline \multirow{2}{*}{$\begin{array}{l}\text { Ámbito } \\
\text { Privado }\end{array}$} & \\
\hline & \\
\hline \multirow{5}{*}{$\begin{array}{l}\text { Funcionarios } \\
\text { Técnicos } \\
\text { Investigadores }\end{array}$} & ¿Qué visión tiene del territorio? \\
\hline & ¿Qué importancia cree que tiene la agricultura familiar en cuanto a la consolidación cultural local? \\
\hline & $\begin{array}{l}\text { ¿Cree que la organización de productores bajo en cualquiera de sus formas, favorece el desarrollo de estos y, } \\
\text { por ende de su territorio? }\end{array}$ \\
\hline & ¿El agricultor familiar es en algún aspecto un factor (sujeto) que le otorga equilibrio al territorio? \\
\hline & \\
\hline
\end{tabular}




\section{Eje: Dotacion de Recursos}

¿Es sujeto de crédito bancario? ¿Tiene alguna línea de crédito para poder sobrellevar alguna inversión grande?

\begin{tabular}{l|l} 
Productores & ¿Si usted quisiera hacer todas las modificaciones en cuanto a infraestructura que exige la legislación
\end{tabular} para producir, lo podría hacer?

¿Tiene la posibilidad de generar excedentes para una planificación a largo plazo?

¿Si usted tuviera apoyo del gobierno, por medio de créditos accesibles para la inversión, lo haría?

Ámbito

Privado

-

Funcionarios

¿Qué cree que separa la actividad informal de la formal? La productividad, la escases de recursos,...

¿El gobierno nacional y/o provincial tiene programas de apoyo para la formalización?

Técnicos

¿De dónde cree que nace la informalidad, se debe a una falta de voluntad por parte del productor, o a una estrategia de este para poder sostenerse minimizando riesgos?

¿Cree que la informalidad le otorga al productor cierta flexibilidad para cambiar de estrategias productivas para asegurar la subsistencia? Vendo leche fluida o masa o quesos, según los precios y la demanda; Ordeño solamente 1 vez al día y le dedico más tiempo a los cerdos...

¿Cómo visualiza la producción de masa para mozzarella en cuanto a las recursos necesarios (altos, medios, bajos) para comenzar, mantenerse y dar sostenibilidad? 


\begin{tabular}{|c|c|}
\hline & Eje: Economica (Fiscal y tributaria) \\
\hline \multirow[b]{3}{*}{ Productores } & ¿Usted, conoce lo que se requiere para la inscripción (afip) de su tambo-fabrica? \\
\hline & ¿Su situación de informal (afip), le trae ventajas o desventajas en cuanto a la situación económica? \\
\hline & ¿Usted cree que si estuviera inscripto en la Afip, tendría algún beneficio? \\
\hline \multicolumn{2}{|l|}{ Ámbito } \\
\hline \multicolumn{2}{|l|}{ Privado } \\
\hline \multirow{4}{*}{$\begin{array}{c}\text { Funcionarios } \\
\text { Técnicos } \\
\text { Investigadores }\end{array}$} & ¿Cree que la A.F. es capaz de acumular excedentes tales como para costear los gastos impositivos? \\
\hline & $\begin{array}{l}\text { ¿El estado, posee alguna herramienta impositiva para acompañar el fortalecimiento de las unidades } \\
\text { productivas tamberas-maseras? }\end{array}$ \\
\hline & ¿Se encuentran líneas impositivas diferenciadas según tipo y escala de producción? \\
\hline & ¿Se contemplan planes en cuanto a beneficios impositivos para su iniciación y subsistencia? \\
\hline
\end{tabular}




\begin{tabular}{|c|c|}
\hline & Eje: Normativo Higiénico-Sanitario \\
\hline \multirow{4}{*}{ Productores } & ¿Usted conoce los requisitos para la habilitación de su tambo-fabrica? \\
\hline & ¿Qué ventajas y/o desventajas cree usted que le traería un posible formalización? \\
\hline & $\begin{array}{l}\text { ¿Conoce a los principales organismos estatales y sus respectivas funciones, vinculados al sector } \\
\text { agropecuario? }\end{array}$ \\
\hline & ¿Cuál cree que es su principal obstáculo para la formalización? \\
\hline \\
\hline \multicolumn{2}{|l|}{$\begin{array}{l}\text { Ámbito } \\
\text { Privado }\end{array}$} \\
\hline \multirow{4}{*}{$\begin{array}{l}\text { Funcionarios } \\
\text { Técnicos } \\
\text { Investigadores }\end{array}$} & $\begin{array}{l}\text { ¿El estado tiene cierta responsabilidad en cuanto a la informalidad de la A.F. por las exigencias } \\
\text { requeridas? }\end{array}$ \\
\hline & $\begin{array}{l}\text { ¿Se posee un análisis profundo (positivo, negativo, con correcciones) de las normativas vigentes en } \\
\text { cuanto a las exigencias H-S requeridas según escala y modo de producción?. }\end{array}$ \\
\hline & ¿Es posible una estructura normativa en donde se contemple una producción artesanal? \\
\hline & $\begin{array}{l}\text { ¿Cree usted que el productor posee la suficiente información en cuanto a los requisitos, tramites y } \\
\text { documentación para la formalización de su producción }\end{array}$ \\
\hline
\end{tabular}

